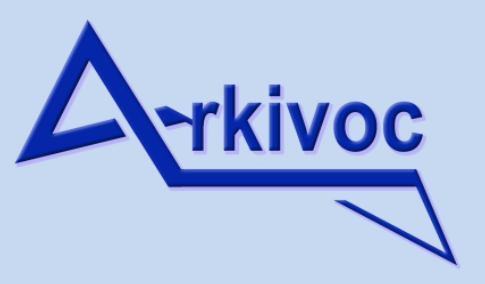

Free to Authors and Readers
A Platinum Open Access Journal for Organic Chemistry
Paper

Arkivoc 2021, part vi, 268-314

\title{
Star-shaped oligofluorene truxene macromolecules - synthesis and properties as a function of alkyl chain length
}

\author{
Clara Orofino, ${ }^{a}$ Alexander L. Kanibolotsky ${ }^{b, c *}$ and Peter J. Skabarab,* \\ ${ }^{a}$ WestCHEM, Department of Pure and Applied Chemistry, University of Strathclyde, Glasgow, G1 1XL, United \\ Kingdom \\ ${ }^{b}$ WestCHEM, School of Chemistry, University of Glasgow, Glasgow G12 8QQ, United Kingdom \\ 'Institute of Physical-Organic Chemistry and Coal Chemistry, 02160 Kyiv, Ukraine \\ Email: Oleksandr.Kanibolotskyy@glasgow.ac.uk, Peter.Skabara@glasgow.ac.uk
}

Dedicated to Professor Philip Hodge, recognizing his contributions to polymers in synthesis over 45 years

Received 08-04-2021

Accepted Manuscript 10-09-2021

Published on line 11-09-2021

\section{Abstract}

Star-shaped oligofluorene truxenes are very promising materials and have demonstrated excellent properties as the gain medium in organic semiconductor lasers (OSLs). ${ }^{1-10}$ Alkyl chains in oligofluorene truxenes act as solubilizing groups as well as spacers to prevent intermolecular $\pi-\pi$ stacking that leads to quenching of the light emission. A new series of star-shaped systems analogous to hexyl oligofluorene truxenes ${ }^{11}$ with alkyl chains of different lengths (butyl chains and octyl chains) was synthesized. The objective of this study was to investigate the effect of alkyl chain length on the film-forming properties of oligofluorene-truxene materials and, as a result, on their optoelectronic properties for applications as the gain medium in OSLs.

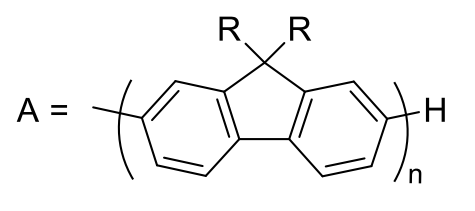

\begin{tabular}{cccc}
$\mathrm{R}=\mathrm{C}_{4} \mathrm{H}_{9}$ & \multicolumn{2}{c}{$\mathrm{R}=\mathrm{C}_{8} \mathrm{H}_{17}$} \\
T1 B: & $\mathrm{n}=1$ & T1 O: & $\mathrm{n}=1$ \\
T2 B: & $\mathrm{n}=2$ & T2 O: & $\mathrm{n}=2$ \\
T3 B: & $\mathrm{n}=3$ & T3 O: & $\mathrm{n}=3$ \\
T4 B: & $\mathrm{n}=4$ & T4 O: & $\mathrm{n}=4$ \\
& & T6 O: & $\mathrm{n}=6$
\end{tabular}

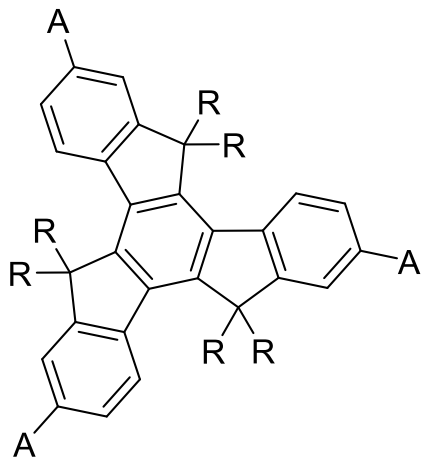

Keywords: Star-shaped molecules, oligofluorene-truxene, two-dimensional architecture, convergent synthetic strategy, Suzuki coupling. 


\section{Introduction}

Star-shaped $\pi$-functional systems consist of three or more oligomer arms joined together by a central core. They can feature two- or three-dimensional architecture depending on the geometry of the core. A planar rigid core with emanating rigid-rod-like arms provides a 2D star-shaped system, whereas non planar cores give rise to 3D structures. ${ }^{12} 1 \mathrm{D}$ conjugated oligomers exhibit anisotropic properties in their aligned molecular aggregates. When the latter are disordered in the bulk, the optical and electronic properties of these materials suffer from inhomogeneous morphology with irregular grain boundaries. The increase in dimensionality of star-shaped conjugated systems provides a series of advantages compared to their $1 \mathrm{D}$ analogues. ${ }^{13}$ The most beneficial advantage is an increased solubility which leads to excellent film-forming properties, providing homogeneous films with high values of photoluminescence quantum yield (PLQY). ${ }^{11}$

The core of the star-shaped system defines the shape and the symmetry of the whole molecule. ${ }^{12}$ If the symmetry point group of a linear oligomer repeat unit includes rotational operations with an order greater than two, the application of such symmetry operations to the whole linear molecule leads to the construction of the corresponding star-shaped system. The application of a $C_{3}$ or $C_{6}$ symmetry operation to oligo-pphenylene produces star-shaped systems with 3 or 6 arms, respectively. ${ }^{12}$ If only part of the monomer unit possesses rotational symmetry, then a new core can be generated by the symmetry transformations. In the case of oligofluorenes, the application of $\mathrm{C}_{3}$ symmetry operations at the center of the benzene fragment of the monomer leads to star-shaped systems with benzene and truxene cores. The point groups with rotational symmetry operations of order $n \geq 3$ can impart to the electronic properties of the molecule such a feature as the degeneracy of HOMO and LUMO levels. ${ }^{12}$

10,15-Dihydro-5H-diindeno[1,2-a;1', $2^{\prime}$-c]fluorene (truxene) is a planar polycyclic aromatic system with $\mathrm{C}_{3 \mathrm{~h}}$ symmetry that can be perceived as three overlapping fluorene fragments ${ }^{14}$ (Figure 1a). Truxene is an extremely insoluble compound in common organic solvents due to strong $\pi-\pi$ stacking interactions. The latter can be efficiently circumvented by alkylation at C-5, C-10 and C-15 positions, which increases the solubility and processability of the truxene based materials. The alkyl substituents in these positions are directed orthogonally to the plane of the molecule (Figure $1 \mathrm{~b}$ ) and sterically prevent any stacking interactions. When only half of the alkyl substituents are introduced, the resulting syn-5,10,15-tryalkylated truxenes self-associate in solution due to arene - arene interactions. The terminal positions of a truxene unit (C-2, C-7 and C-12) can be easily functionalized via bromination followed by C-C coupling. ${ }^{11}$

a)

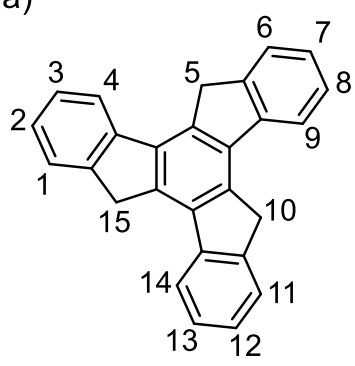

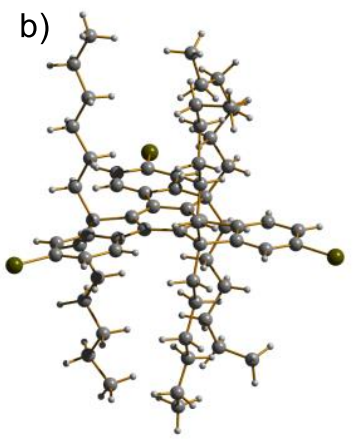

Figure 1. Numbering of the truxene fused system (a) and the orthogonal positions of hexyl substituents in tribromohexahexyltruxene (b). 
Truxene has been considered as a building block for the construction of bowl-shaped polyarenes, which could be used as the starting materials for the synthesis of fullerenes. ${ }^{15}$ The truxene core has been used to design trigonal liquid crystalline compounds, ${ }^{16}$ self-assembled organogels ${ }^{17}$ and highly absorbing truxenebased photoinitiators for polymerization. ${ }^{18}$ The $\mathrm{C}_{3 \mathrm{~h}}$ symmetry of this core makes it an attractive scaffold for the design of trigonal oligomers and dendritic truxene derivatives with $\pi$-conjugation to the aromatic core. ${ }^{11,19}$ The truxene platform has been used as a template for self-assembled subphthalocyanine films in organic solar cells. $^{20}$

Polyfluorenes have been extensively used as electroluminescent materials because they are efficient blue emitters in both the solution and solid state, they show high hole mobility, and excellent thermal and electrochemical stability. Furthermore, they are easily synthesized and their properties are tunable through modification of the structure or copolymerization. ${ }^{21}$ They have been extensively used as electroluminescent materials in polymeric light emitting diodes (PLEDs), ${ }^{22}$ photovoltaics, ${ }^{22}$ field-effect transistors (FETs) ${ }^{23}$ and solid state lasers. ${ }^{24}$

Chemical purity is of great importance for the performance of optoelectronic devices. The degradation of a polymer structure during synthesis, processing and device operation can lead to quenching of the emission. For example, polyfluorenes are prone to formation of fluorenone defects in the polymer backbone. The nonalkylated or partially alkylated methylene bridge of the fluorene monomer unit undergoes oxidative degradation which leads to the formation of a $\mathrm{C}=\mathrm{O}$ bond. ${ }^{25}$ This defect acts as a charge or energy trap and decreases the emission efficiency; an undesirable green emission appears, losing the saturated blue emission of polyfluorenes. ${ }^{26}$ The level of fluorenone defects can be reduced by an additional monomer purification before the polymerization step. In contrast to polyfluorene, the monodisperse oligofluorenes are normally purified by column chromatography after each step of the coupling, and the formation of fluorenone defects can be avoided. ${ }^{27}$

Monodisperse $\pi$-conjugated oligomers are characterized by a relatively short and uniform chain length with a well-defined structure, which controls their precise HOMO/LUMO energy levels. The superior chemical purity of this class of compounds, which can be achieved by column chromatography, makes their electronic properties $100 \%$ reproducible. ${ }^{28}$ This reproducibility of the properties brought about the study of structureproperty relationships and encouraged scientists to design a number of novel monodisperse oligofluorenes in order to obtain an insight into the photophysical properties of these conjugated systems. ${ }^{29,} 30$ Oligofluorenebased materials were applied as p-type organic semiconductors in organic field effect transistors (OFETs) ${ }^{31}$ as well as efficient light emitters in dye-doped cholesteric liquid crystal (DD CLC) lasers. ${ }^{32}$

The functionalization of truxene with oligofluorene arms at C-2, C-7 and C-12 positions provides an ideal scenario for the synthesis of virtually no-core two-dimensional star-shaped oligofluorenes (see Figure 2). ${ }^{11}$ 


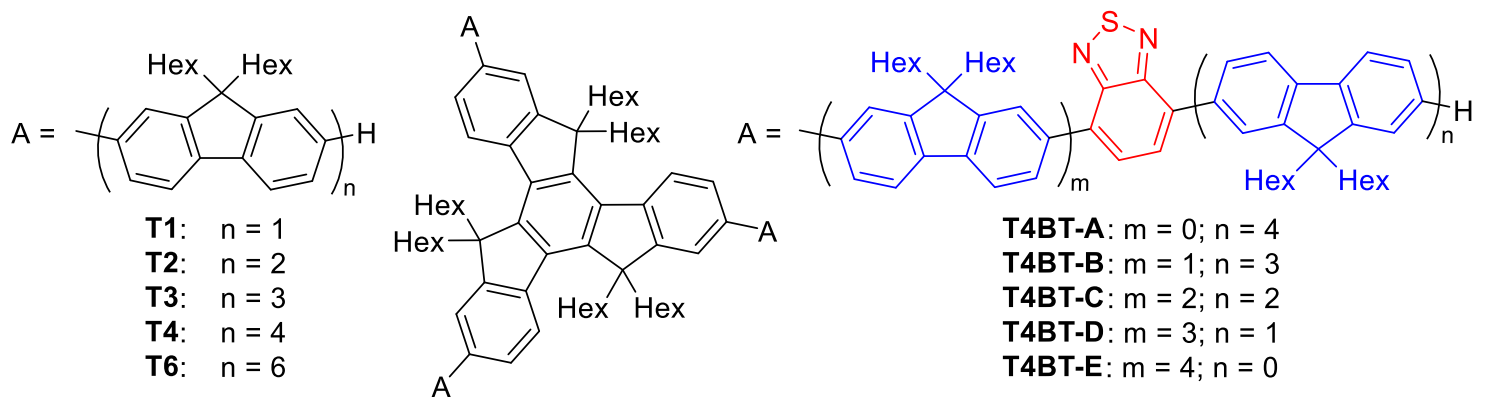

Figure 2. Oligofluorene truxenes with the arm length rising from one fluorene unit (T1) to four (T4) and six (T6) as well as oligofluorene BT truxene conjugated systems (T4BT-A-E).

These nanosized macromolecules offer advantages over conjugated polymers because they present monodisperse oligomers with a well-defined and uniform molecular structure that enables the investigation of the impact of molecular structure on photonic, electronic and morphological properties of the materials in the solid state.

Initially, hexyl-substituted oligofluorene truxenes (T1-T4) were synthesized. ${ }^{11}$ The main feature in the absorption spectra of these star-shaped oligomers both in solution and in the solid-state is a strong $\pi-\pi *$ absorption band that shifts to a long wave region as the number of fluorene units in the arms increases (the peak position shifting from $343 \mathrm{~nm}$ for T1 to $374 \mathrm{~nm}$ for T4). They are highly fluorescent both in solution and solid-state with PLQY $\left(\Phi_{\mathrm{PL}}\right)$ rising with an increase in the length of the oligofluorene arm from 0.70 (T1) to 0.86 (T4) in solution and from 0.43 (T1) to 0.59 (T4) in the solid state. These molecules are bright blue emitters and their photoluminescence (PL) spectra are red-shifted as the length of the oligofluorene arms increases $\left(\lambda_{\mathrm{PL}} \approx\right.$ $400-420 \mathrm{~nm}$ ). They all show the typical vibronic structure observed for polyfluorenes, with slight variation in relative intensity of the vibronic transitions in the solid state. ${ }^{11,33}$

Cyclic voltammetry (CV) studies revealed a high HOMO-LUMO gap (in the range of $3.20-3.40 \mathrm{eV}$ ) and confirmed good electrochemical stability towards $p$ - and $n$-doping for all the oligomers. ${ }^{33}$ DFT calculations predicted the degeneracy of HOMO and LUMO, originating from the trigonal symmetry, only for truxene and T1. ${ }^{34}$ Thermal and morphological stability are important factors for device performance. Thermogravimetric analysis (TGA) of oligofluorene truxene materials showed good thermal stability with decomposition temperature $\left(5 \%\right.$ mass loss) above $400^{\circ} \mathrm{C}$ in an inert atmosphere, rising slightly as the oligofluorene arm length increases. All the oligomers are amorphous materials at room temperature, with some crystallinity observed for T1. The DSC measurements revealed increasing glass transition temperatures from T1 to T4. ${ }^{11}$

The most efficient emitters of the T1-T4 series (T3 and T4) have been extensively studied as the gain medium for lasing applications. The distributed feedback (DFB) laser with a neat film of T4, spin-coated on a corrugated silica substrate as a resonator, exhibited a low lasing threshold of $270 \mathrm{~W} \cdot \mathrm{cm}^{-2}$, which was attributed to a low amplified spontaneous emission (ASE) threshold and a low waveguide loss coefficient of $2.3 \mathrm{~cm}^{-1} .{ }^{1}$ At that time this was the lowest waveguide loss coefficient reported for solution processed neat films of organic semiconductors, indicating that the amorphous nature of T4 films provided reduced degree of scattering which led to the low optical losses. The DFB laser showed tunability across $25 \mathrm{~nm}$, with a PLQY of the T4 neat film of 0.73. The similar DFB laser fabricated from T3 exhibited a higher threshold of $515 \mathrm{~W} \cdot \mathrm{cm}^{-2}$ but lower ASE threshold, higher net gain coefficient and the solid state PLQY (0.86), than those of T4. The T3based DFB laser exhibited a very broad wavelength tunability across $51 \mathrm{~nm}(422-473 \mathrm{~nm})$ in the deep-blue region, which was the broadest tuning range at the time of publication. ${ }^{2}$ 
Oligofluorene-truxenes have excellent solubility in common organic solvents and exhibit superior filmforming properties. However, most durable films and intricate microstructures can be created using a photolithography approach. Among photoresist materials, 1,4-cyclohexanedimethanol divinyl ether (CHDV) was proven to be the monomer compound most compatible with T3 and T4. The CHDV monomer can be cross-linked after blending with the emitter by UV irradiation in the presence of the photoacid generator (PAG) ([p-(octyloxy)phenyl](phenyl)iodonium hexafluoroantimonate). This encapsulation of the emitter reduces its photo-oxidation and enable the creation of all-organic optical devices and photonic nanostructures. The blends can be processed by direct laser writing (T4/CHDV), ${ }^{35}$ DIP-pen nanolithography (T4/CHDV) $)^{36}$ or inkjet printing (T3 /CHDV). ${ }^{37,} 38$ The T3/CHDV blend was used for the preparation of freestanding membranes. The latter were characterized by ASE, revealing ASE thresholds around $400 \mu \mathrm{J} \cdot \mathrm{cm}^{-2} .39$ The same T3/CHDV blend was employed for the fabrication of flexible DFB lasers, which showed a lasing threshold of $14.4 \mu \mathrm{J} \cdot \mathrm{cm}^{-2}\left(2.7 \mathrm{~kW} \cdot \mathrm{cm}^{-2}\right)$ and an increased degradation energy dosage of $53 \mathrm{~J} \cdot \mathrm{cm}^{-2} .40$

The 2,1,3-benzothiadiazole (BT) electron deficient unit has been incorporated at each of five possible positions of the trigonal T4 star-shaped system, which led to T4BT-A-T4BT-E oligomers (Figure 2). ${ }^{41}$ The optical properties of oligomers T4BT-A-T4BT-E make them attractive for UP-VLC applications. ${ }^{42}$ As expected, the incorporation of the BT unit led to the stabilization of the LUMO, which made the oligofluorene-BT-truxene compounds promising emitters for application in electrogenerated chemiluminescence (ECL). The $E C L$ efficiency of T4BT-B was found to be 7 times higher than that of the standard ECL emitter 9,10diphenylanthracene (DPA), ${ }^{43}$ while the quantum yield for ECL for T4 was found to be only $80 \%$ of the DPA ECL efficiency. ${ }^{33}$

The largest hexylated truxene derivative, T6, was synthesized for highly efficient two-photon absorption characteristics. T6 demonstrated a high two-photon absorption cross-section of $2200 \mathrm{GM}$, low two-photon absorption pumped ASE and frequency up-converted lasing threshold values of $2.43 \mathrm{~mJ} \mathrm{~cm}^{-2}$ and $3.1 \mathrm{~mJ} \mathrm{~cm}^{-2}$, respectively. ${ }^{44}$

As mentioned above, the star-shaped oligofluorenes with a benzene core B1-B4 (Figure 3) are related to the T1-T4 oligomers. Both systems can be generated from a linear oligofluorene by applying $\mathrm{C}_{3}$ symmetry operation. ${ }^{12}$ Star-shaped oligofluorene benzene materials (Figure 3) are deep-blue emitters and have high PLQYs both in solution and solid state $\left(\Phi_{\mathrm{PL}}=0.41-0.82\right.$ in solution and $0.43-0.58$ in films $) .{ }^{45}$ Compounds B2B4 have been tested as the gain medium in blue-emitting DFB lasers. ${ }^{46}$ The lowest lasing threshold of 1.1 $\mathrm{kW} \cdot \mathrm{cm}^{-2}$ was observed for $\mathbf{B} \mathbf{3}$, which is still twice as high as the corresponding value for T3. This was explained by the presence of six additional hexyl chains in the core of T3, which prevent intermolecular interactions in the sold state due to their orthogonal orientation (Figure 1b) and make this material a more efficient gain medium. The comparison of the lasing properties for B3-B4 and T3-T4 highlights the importance of the truxene core in the design of efficient fluorescent materials for lasing applications.
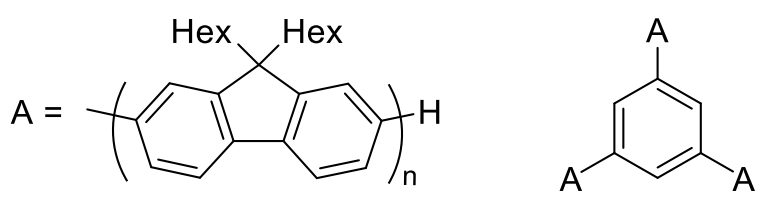

B1: $\mathrm{n}=1$

B2: $\mathrm{n}=2$

B3: $n=3$

B4: $n=4$

Figure 3. Oligofluorene benzene star shaped structures (B1-B4). 


\section{Synthetic approaches for star-shaped oligomers}

The synthesis of star-shaped oligomers can be developed by both convergent and divergent approaches (Figure 4). The divergent approach (Figure 4a) follows a repetitive sequence: (i) coupling of the monomer to the core; (ii) terminal functionalization of the arms; (iii) extension of the arms by further aryl-aryl coupling. Repetition of steps (ii) and (iii) can be performed successively until the desired length of the arms is achieved. This approach presents the advantage of coupling reactions with a simple monomer, but purification of the product from partially reacted by-products is problematic, especially when the length of the oligomer arms increases, because the properties of the components present in the reaction mixture converge when the molecular weight of the target molecule increases. ${ }^{12}$

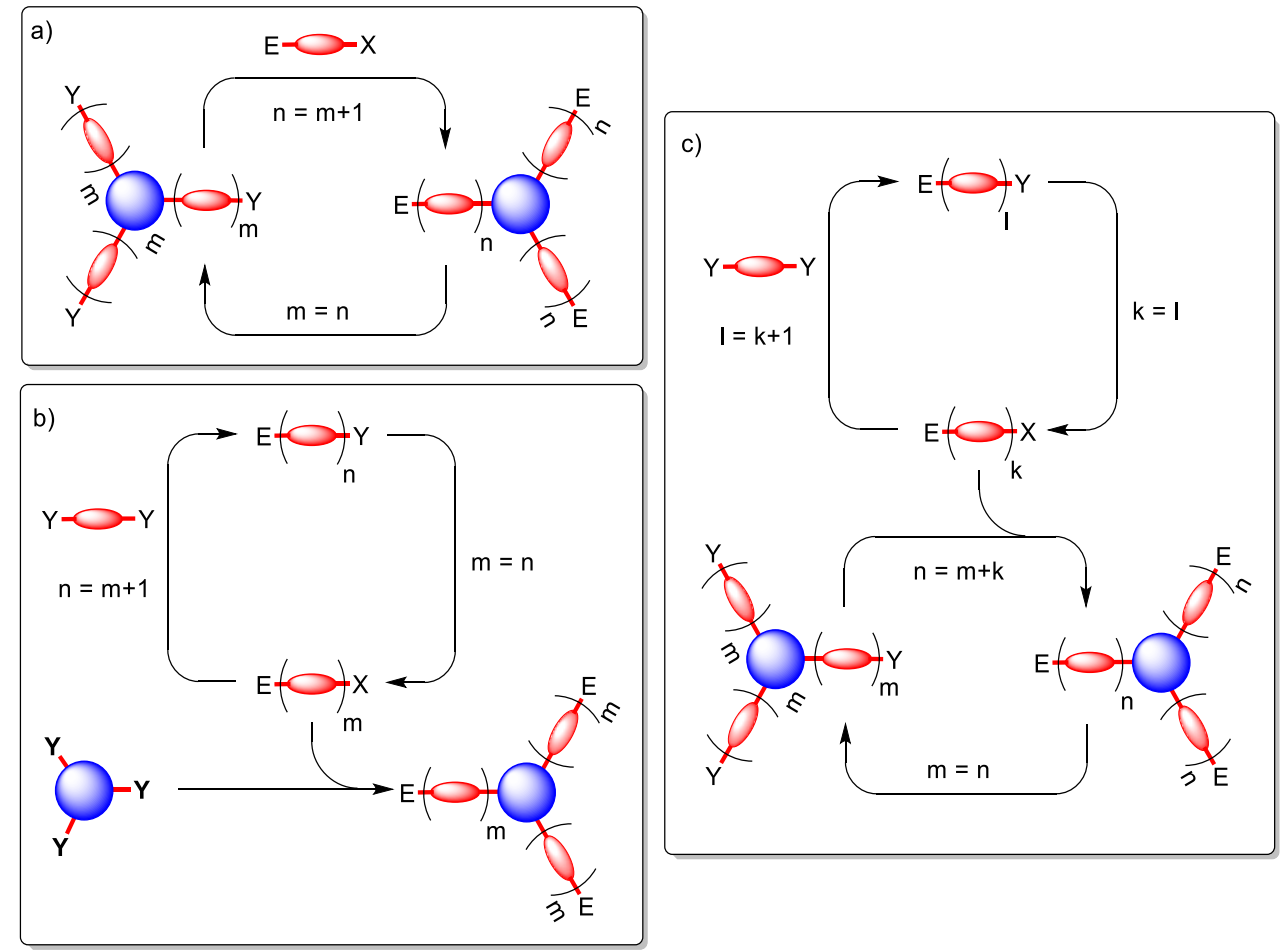

Figure 4. The strategy towards star-shaped structures: a) divergent approach; b) convergent approach; c) semi-convergent approach. $\mathrm{E}$ - end-capped group (e.g. TMS), $\mathrm{Y}$ - halogeno-substituent (e.g. Br), $\mathrm{X}$ - elementoorganic center (e.g. $\left.\mathrm{B}(\mathrm{OH})_{2}\right)$.

The convergent approach (Figure 4b) employs the same synthetic strategy for the arms as for linear oligomers. The star-shaped molecule is then synthesized in a single step by coupling the oligomeric arms to the central core. The advantages of this approach over the divergent one are: (i) the simpler synthesis of the target star-shaped system by a one-step coupling reaction of the arm precursors to the core compound with easy purification of the target compound from partially coupled by-products; (ii) the possibility of using this procedure with cores that are not stable towards halogenation; (iii) the prospect of an easy development of the whole series of different star-shaped structures by varying the core starting compounds, once a bulk amount of the arm precursor is produced..$^{12} \mathrm{~A}$ variation of the convergent method is to create the core in the final step employing suitable functionalities of the arms. ${ }^{12}$ This methodology can lead to star-shaped systems with a benzene core and three arms, (using $\mathrm{SiCl}_{4}$ - or $\mathrm{TiCl}_{4}$-mediated trimerization of oligomers with a terminal 
acetyl functionality), ${ }^{45}$ or six arms (e.g. by Diels-Alder reaction of tetrasubstituted cyclopentadienones with disubstituted acetylenes), ${ }^{47}$ or to four or eight-armed systems with porphyrin ${ }^{48}$ and phthalocyanine ${ }^{49}$ cores, $^{4}$ respectively.

In the case of the hetero-coupling based convergent strategy for high molecular weight target compounds the separation from the homo-coupled products might become a problem. To our experience this separation can be done efficiently up to the T4 oligomer. ${ }^{11}$ If larger molecules are targeted, then the semi-convergent approach (Figure 4c) is an option. Similar to the convergent method, this strategy assumes the preparation of oligomeric arm precursors. The latter are then used in sequential coupling to a core compound, followed by the modification of the arms at the terminal positions and then by coupling of the resulting halogenofunctionalized intermediate star-shaped structure with another oligomeric arm precursor. Not only does this procedure provide an easy purification of the target compound from the homo-coupled by-products, it also allows one to decrease the total number of the synthetic steps. This strategy has been successfully applied for the synthesis of compounds T4BT-A-T4BT-E. ${ }^{41}$ The highest member of the oligofluorene-truxene series (T6) was also synthesized using the semi-convergent strategy. ${ }^{44}$

\section{Results and Discussion}

In this work, our objectives were to explore the synthesis and properties of new oligofluorene truxene derivatives with alternative alkyl groups to hexyl. Ease of synthesis, solubility and tuning the physical properties of these materials, such as the glass transition temperatures, represented the motivation of this work.

\section{Synthesis}

Initially, the truxene core was synthesized following the procedure depicted in Scheme 1. The procedure involved generation of truxene by cyclization of commercially available 1-indanone under acidic conditions in high yield, followed by alkylation of the methylene positions (lithiation with $\mathrm{n}$-BuLi followed by the addition of the bromoalkane in one pot) in high yields. Final bromination of the $\mathrm{C} 2, \mathrm{C} 7$ and $\mathrm{C} 12$ positions with bromine afforded $\mathbf{2}$ B and $\mathbf{2} \mathbf{O}$ products in high yields. Note that "B" refers to butyl chain and "O" to octyl chain. This terminology will be carried throughout the rest of the section.

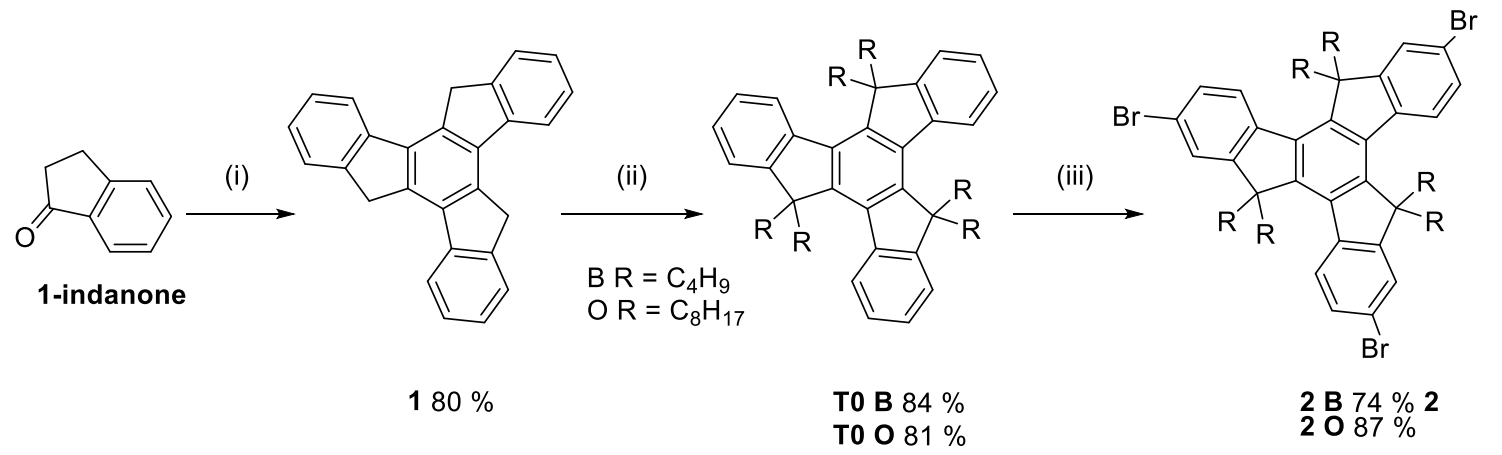

Scheme 1. Synthesis of the truxene core. Reagents and conditions: (i) $\mathrm{CH}_{3} \mathrm{COOH}, \mathrm{HCl}, 100^{\circ} \mathrm{C}, 16 \mathrm{~h}$; (ii) (1) $\mathrm{n}$ BuLi/THF (0C), (2) RBr, (3) R.T., 18 h; (iii) $\mathrm{Br}_{2} / \mathrm{CH}_{2} \mathrm{Cl}_{2}$ (R.T.), 12 h. 
For the synthesis of the oligofluorene arms (Scheme 2), initial bromination of fluorene was carried out on a large scale, instead of alkylation followed by bromination to avoid an additional step due to the use of two different alkyl chains. The bromination was carried out with bromine, and $\mathrm{KBrO}_{3}$ was added to the reaction mixture to regenerate bromine from the $\mathrm{HBr}$ that is formed during the bromination reaction. Compound $\mathbf{3}$ was obtained in high yield but the dark color of the product suggests that a small percentage of the oxidized form (fluorenone) might have been formed due to a slightly high addition rate of the $\mathrm{KBrO}_{3}$.

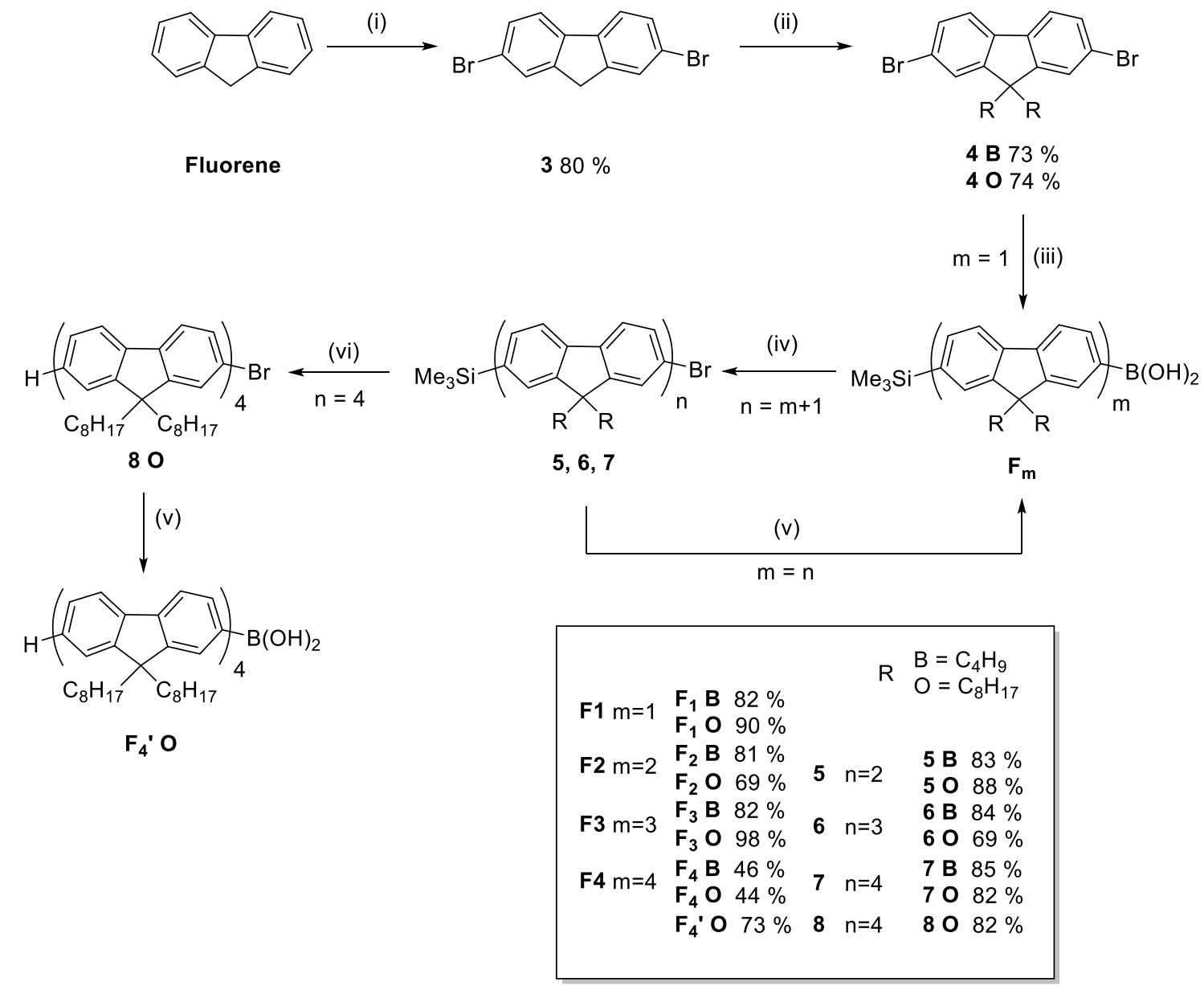

Scheme 2. Synthesis of the oligofluorene arms. Reagents and conditions: (i) $\mathrm{Br}_{2}, \mathrm{KBrO}_{3}, \mathrm{H}_{2} \mathrm{SO}_{4}, \mathrm{AcOH}, 44-55$ ${ }^{\circ} \mathrm{C}, 4 \mathrm{~h}$; (ii) RBr, THF, 'BuOK/THF, 4 h, R.T; (iii) (1) n-BuLi, THF, $-80^{\circ} \mathrm{C}$, (2) SiMe ${ }_{3} \mathrm{Cl},-95{ }^{\circ} \mathrm{C}-20{ }^{\circ} \mathrm{C}$, (3) n-BuLi, -85 ${ }^{\circ} \mathrm{C}$, (4) ('PrO) ${ }_{3} \mathrm{~B},-100{ }^{\circ} \mathrm{C}$, (5) R.T., $18 \mathrm{~h}$; (iv) (1) 4, $\mathrm{Pd}\left(\mathrm{PPh}_{3}\right)_{4}$, toluene, (2) $2 \mathrm{M} \mathrm{Na}_{2} \mathrm{CO}_{3}$ (aq), $80{ }^{\circ} \mathrm{C}, 18 \mathrm{~h}$; (v) (1) nBuLi, THF, $-80{ }^{\circ} \mathrm{C}$, (2) ('PrO) ${ }_{3} \mathrm{~B},-100{ }^{\circ} \mathrm{C}$, (3) R.T., $18 \mathrm{~h}$; (vi) $\mathrm{CF}_{3} \mathrm{COOH}, \mathrm{CH}_{2} \mathrm{Cl}_{2}$, R.T., $2 \mathrm{~h}$.

Subsequent slow addition (over $\sim 1.5 \mathrm{~h}$ ) of the potassium tert-butoxide THF solution into the solution of 3 and corresponding bromoalkane in THF at $0-5{ }^{\circ} \mathrm{C}$ followed by stirring for 4 hours at room temperature afforded the 9,9-dialkyl-2,7-dibromofluorene (4 B and 4 0), in relatively high yields. Compound 4 was used as the building block for the synthesis of the oligofluorene chain throughout the iterative Suzuki cross-coupling and conversion to boronic acid procedure that is described below.

The following step consisted of the substitution of one bromine with a trimethylsilyl group and the conversion of the other one to a boronic acid functionality in one pot, as opposed to the standard two-step procedure. ${ }^{50}$ This was achieved by lithiation of the dibromo derivative with one equivalent of $n$-BuLi, addition of chlorotrimethylsilane, and a second lithiation with one equivalent of $n$-BuLi, followed by quenching with 
triisopropylborate. Final hydrolysis with deionized water afforded $\mathbf{F}_{\mathbf{1}} \mathbf{B}$ and $\mathbf{F}_{\mathbf{1}} \mathbf{O}$ in high yields. The ${ }^{1} \mathbf{H}$ NMR of all the boronic acids described $\left(\mathbf{F}_{\mathbf{n}}\right.$ and $\mathbf{F}_{\mathbf{n}}{ }^{\prime}$ ) was complex due to a mixture of dimers of fluorenylboronic acid (formed via hydrogen bonds) and boroxines (the trimeric anhydride). Unlike in the standard synthetic path, ${ }^{11}$ the TMS protecting group was carried along the synthesis of the oligofluorene chain for two reasons: it provides easier purification and handling that makes scaling up easier and it provides a platform for easy modification of the protecting group into other functional groups, for example through bromination. The deprotection of the trimethylsilyl group was achieved by simple acid treatment followed by aqueous work-up, generating the deprotected product in almost quantitative yields without the need for purification by column chromatography. The development of oligofluorene arm precursors with a TMS protecting group as well as the deprotection procedure proved to be useful for synthesis of T4BTA-T4BTE star-shaped systems. ${ }^{41}$ The TMS-capped oligofluorene arm precursors have been exploited for the design of star-shaped oligofluorenedithienotetrathiafulvalene systems. ${ }^{51}$

The fluoreneboronic $\mathbf{F}_{\mathbf{1}} \mathbf{B}$ and $\mathbf{F}_{\mathbf{1}} \mathbf{O}$ acids were coupled via the Suzuki protocol with 2,7-dibromo-9,9dialkylfluorene derivatives (4 $\mathbf{B}$ and 40 respectively), affording the next generation of 2-bromooligofluorenes, $\mathbf{5} \mathbf{B}$ and $\mathbf{5} \mathbf{O}$, in high yields. The following steps involved repetitive lithiation-boronation sequences, yielding the boronic acids $\mathbf{F}_{\mathbf{2}}, \mathbf{F}_{\mathbf{3}}$ and $\mathbf{F}_{\mathbf{4}}$ and converting the boronic acids $\mathbf{F}_{\mathbf{2}}$ and $\mathbf{F}_{\mathbf{3}}$ into the corresponding elongated 2-bromo-oligofluorenes via palladium-catalyzed Suzuki cross-coupling with 4 . The yields obtained for the synthesis of the oligofluorene boronic acids were around $80 \%$, with the exception of $\mathbf{F}_{\mathbf{4}}$. In the case of the butyl analogue $\left(F_{4} \mathbf{B}\right)$, the large molecular weight and the short length of alkyl chain decreased the solubility of the molecules dramatically in tetrahydrofuran, especially at the low temperatures required for lithiation. As a result, the dilution factor employed had to be increased and this might have affected the yield of the reaction. Similarly, a low yield was obtained for the octyl analogue of quaterfluorenylboronic acid $\left(\mathbf{F}_{\mathbf{4}} \mathbf{O}\right)$. Deprotection of the TMS group to provide $\mathbf{8}$ in high yield, followed by conversion to the boronic acid afforded $\mathbf{F}_{4}$ ' $\mathbf{O}$ in a much more acceptable $73 \%$ yield. The yield for the synthesis of $\mathbf{F}_{\mathbf{2}} \mathbf{O}$ is also relatively low (64\%), probably due to the difficulty in handling the oily bifluorenylbromide $\mathbf{5} \mathbf{0}$, whose recrystallization was not possible because the material invariably separated as an oil despite the multiple crystallization conditions attempted. The yields obtained for the synthesis of the oligofluorene bromides were comparable with the ones described in the original publication with hexyl chains, ${ }^{11}$ compound 60 being the only lower yielding material.

Following the previously reported strategy, ${ }^{11}$ the convergent approach was chosen for the synthesis of the oligofluorene truxenes T1-T4, attaching the oligofluorene arms of different lengths directly onto the hexaalkylated brominated truxene core (2). Nevertheless, a semi-convergent route was employed for the synthesis of $\mathbf{T 6} \mathbf{O}$ by coupling a quaterfluorene boronic acid $\left(\mathbf{F}_{\mathbf{4}} \mathbf{O}\right)$ to $\mathbf{T} \mathbf{2 B r} \mathbf{O}$. This approach avoided the conversion of a quaterfluorene into a hexafluorene, saving three extra synthetic steps onto an already precious compound, itself the product of a ten-step synthetic route (Scheme 3).

T1TMS - T4TMS B and T1TMS - T3TMS 0 were synthesized following a modified Suzuki cross-coupling of the tribromotruxene $\mathbf{2}$ and the corresponding trimethylsilyl-oligofluorenyl boronic acid $\left(\mathbf{F}_{\mathbf{n}}\right)$ employing barium hydroxide as an efficient base. ${ }^{52}$ The procedure worked well previously for the synthesis of oligofluorene-BTtruxene systems. ${ }^{41}$ The solvent for this reaction was changed from dimethoxyethane to THF due to the opportunity to collect the latter from the solvent purification system, which increased the yield of the reactions. T4 $\mathbf{O}$ (octyl) was directly synthesized following the same modified Suzuki coupling procedure between the tribromotruxene $\mathbf{2} \mathbf{O}$ and the quaterfluorene boronic acid $\mathbf{F}_{\mathbf{4}} \mathbf{O}_{\mathbf{O}}$ with a low yield (54\%) despite the use of oxygen free tetrahydrofuran as a solvent for the reaction. It is worth noting that a previous attempt to synthesize T4TMS $O$ (not described here) afforded the product in an $88 \%$ yield. This is an indicator that the 
low yield achieved for T4 $\mathbf{O}$ should not imply that coupling of large oligofluorenes to the truxene core is less efficient.
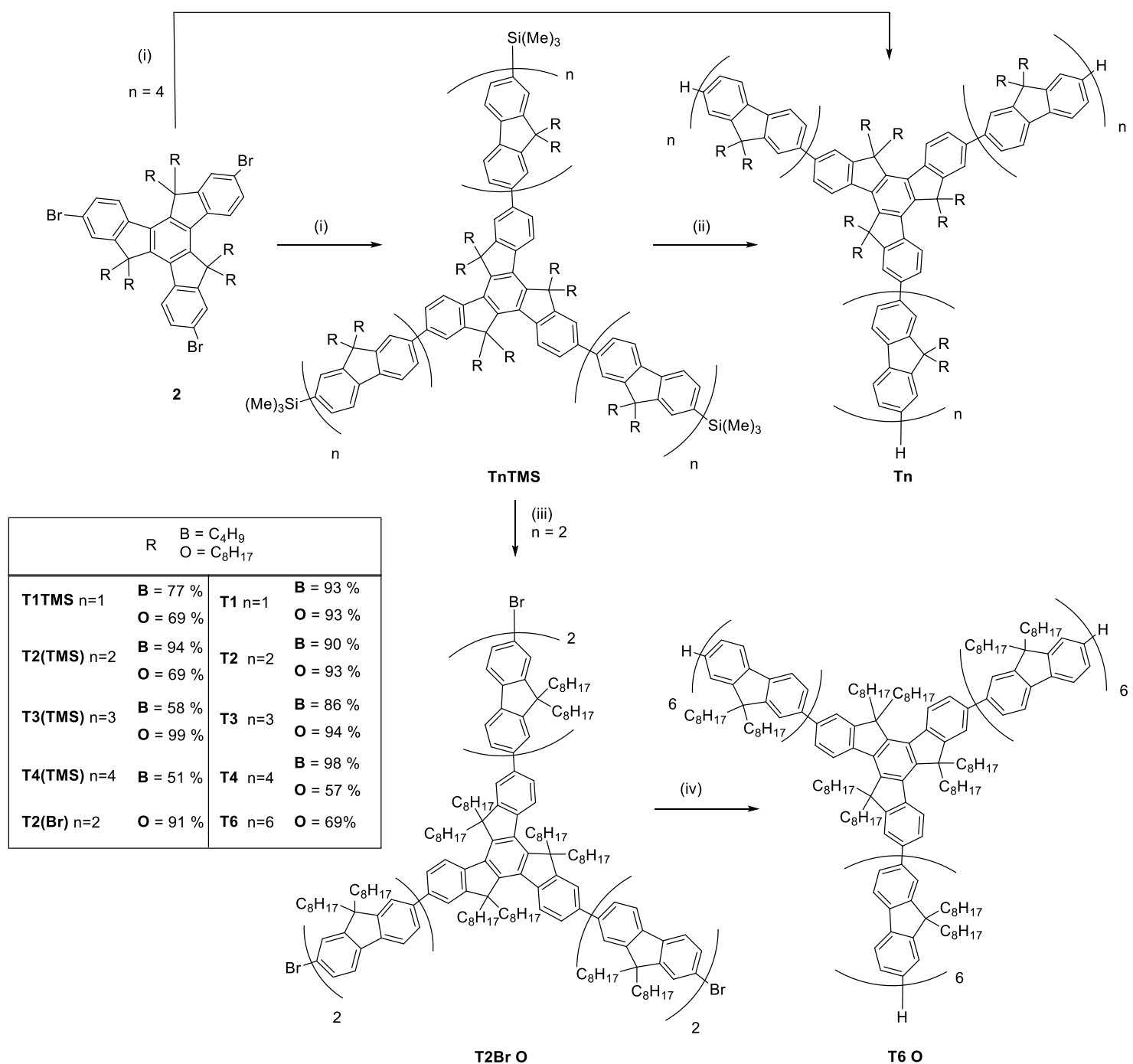

Scheme 3. Synthesis of tris(oligofluorenyl) truxenes Tn. Reagents and conditions: (i) $\mathbf{F}_{\mathbf{n}}, \operatorname{Pd}\left(\mathrm{PPh}_{3}\right)_{4}$, $\mathrm{Ba}(\mathrm{OH})_{2} \cdot 8 \mathrm{H}_{2} \mathrm{O}, \mathrm{H}_{2} \mathrm{O}$, THF or DME, $70^{\circ} \mathrm{C}, 18 \mathrm{~h}$; (ii) $\mathrm{CF}_{3} \mathrm{COOH}, \mathrm{CH}_{2} \mathrm{Cl}_{2}$, R.T., 2 h; (iii) $\mathrm{AcONa}, \mathrm{Br}_{2}$, THF, R.T., 2 h; (iv) $\mathbf{F}_{4}^{\prime} \mathbf{O}, \mathrm{Pd}\left(\mathrm{PPh}_{3}\right)_{4}, \mathrm{Ba}(\mathrm{OH})_{2} \cdot 8 \mathrm{H}_{2} \mathrm{O}, \mathrm{H}_{2} \mathrm{O}, \mathrm{THF}, 70^{\circ} \mathrm{C}, 18 \mathrm{~h}$.

T2TMS $\mathrm{O}$ was brominated under mild conditions with bromine and sodium acetate to eliminate $\mathrm{HBr}$ formed during the bromination. The yield was almost quantitative and simple recrystallization afforded the product in high purity and almost quantitative yield. The semi-convergent modified Suzuki cross-coupling of quaterfluorene boronic acid $\left(\mathbf{F}_{\mathbf{4}}^{\prime} \mathbf{O}\right)$ with $\mathbf{T} \mathbf{2} \mathbf{B r} \mathbf{O}$ yielded the largest member of the oligofluorene-truxene series, $\mathbf{T 6} \mathbf{O}$ in a moderate yield (69\%).

The synthesis of the materials proceeded with good yields in general but it is noteworthy to mention the difficulties associated in handling the butyl and octyl oligofluorenes. In general, the butyl analogues seemed more crystalline and the yields obtained during the synthesis were generally lower than for the octyl series. This resulted in the need to repeat the whole synthetic sequence several times in order to obtain large enough quantities of oligofluorenes for the final couplings with truxene. The main problem arose during the synthesis 
of the boronic acids in which the low temperatures required tended to trigger the precipitation of the materials from solution. Nevertheless, their purification did not cause major problems.

The octyl derivatives, on the other hand, were very soluble in common organic solvents but their longer alkyl chains made the purification of the compounds much harder. For example, in the Suzuki coupling reactions for the synthesis of the oligofluorenyl bromides (5 0, 60 and $\mathbf{7 0}$ ), the separation of the product from the homocoupling product was very poor, resulting in the need to perform several column purifications or use large quantities of silica for the column and employ very slow polarity increases. Furthermore, after the column the oligofluorene bromides were normally recrystallized from acetone to eliminate any traces of impurities or silicon grease from the column. Despite the multiple attempts of recrystallization of $\mathbf{F}_{\mathbf{2}} \mathbf{O}$ an oil was consistently obtained. Low temperature treatment with liquid nitrogen triggered the material to solidify but upon reaching room temperature, it once again became an oil.

The petroleum ether employed in the column chromatography was previously distilled to remove the grease that is often present in the grade of solvent employed. Despite these efforts to avoid grease, the octyl chains often trapped traces of it that could be observed in the ${ }^{1} \mathrm{H}$ NMR and several recrystallizations were necessary in order to obtain the pure product.

\section{Physical properties}

The properties of the Tn (hexyl) series have previously been described. ${ }^{11,33,44}$. All the T1-T6 materials presented excellent film-forming properties, but the solubility of the butyl analogues at low temperature was lower than for the octyl and hexyl analogues. The thermal behavior and molecular weights of the materials are presented in Table 1.

The thermal stability of the materials was studied by TGA upon heating the samples under argon from $0^{\circ} \mathrm{C}$ to $600^{\circ} \mathrm{C}$. All the compounds are stable and show a $5 \%$ mass loss above $400^{\circ} \mathrm{C}$. The only compound that had a slightly lower stability was T4 B (butyl), with a $5 \%$ mass loss at $370^{\circ} \mathrm{C}$. The main mass loss for the butyl analogues was $35-38 \%$ of the total mass. For the hexyl analogues it was $45-50 \%{ }^{11}$ and for the octyl analogues $50-55 \%$. This is in good agreement with the loss of the alkyl chains.

The materials were also studied by DSC to have a better insight on their morphology. All the materials are amorphous, with no hint of crystallization and this was also confirmed by powder X-ray diffraction (XRD) experiments.

Focusing first on each series of alkyl chain, the glass transition temperature $\left(T_{g}\right)$ increases with the addition of every fluorene unit, but the effect is more noticeable for the first addition, i.e. from T1 to T2 $\left(\Delta \mathrm{T}_{\mathrm{g}}=29,23\right.$ and $23{ }^{\circ} \mathrm{C}$ for butyl, hexyl and octyl, respectively). Thereafter the increase in $\mathrm{T}_{\mathrm{g}}$ per fluorene unit is more moderate (around $14^{\circ} \mathrm{C}$ for $\mathrm{T} 3$ and between 4 and $15^{\circ} \mathrm{C}$ for T4). As expected, the modification of the length of the alkyl chains by two methylene units also affects the glass transition temperature because longer alkyl moieties have a larger free volume, which results in lower $\mathrm{T}_{\mathrm{g}}$. This has a major impact on the materials, especially for the octyl derivatives, that present very low glass transition temperatures from $11^{\circ} \mathrm{C}$ for $\mathbf{T 1} \mathbf{O}$ (it is a very sticky oil at room temperature) to $56^{\circ} \mathrm{C}$ for $\mathrm{T} 6 \mathrm{O}$. This is detrimental for device fabrication, where a stable morphology is required. When the materials are employed as the gain medium in an optically pumped laser, the incident energy and the non-radiative losses will cause the gain material to heat. If the materials heat up above their glass transition temperature, the film can become rubbery, allowing the molecules to move slightly. This may induce greater losses and therefore increased lasing thresholds, resulting in poorer device performance. On the other hand, the butyl derivatives present exceptionally high glass transition temperatures, from $126^{\circ} \mathrm{C}$ for $\mathbf{T 1} \mathbf{B}$ to $163^{\circ} \mathrm{C}$ for $\mathbf{T 4} \mathbf{B}$. This is promising for their device performance, but the difficulty of their synthesis makes the use of these compounds as gain media for OSLs unfeasible on a larger scale. 
Table 1. Physical properties of the Tn (butyl, hexyl and octyl) series. $M_{w}$ is the molecular weight of the compounds; $T_{\mathrm{g}}$ is the glass transition temperature of the compounds as measured by differential scanning calorimety; $T_{d}$ is the decomposition temperature measured by thermogravimetric analysis (TGA)

\begin{tabular}{cccc}
\hline Compound & $\mathrm{M}_{\mathrm{w}}\left(\mathrm{g} \cdot \mathrm{mol}^{-1}\right)$ & $\mathrm{T}_{\mathrm{g}}\left({ }^{\circ} \mathrm{C}\right)$ & $\mathrm{T}_{\mathrm{d}}\left({ }^{\circ} \mathrm{C}\right)$ [TGA, 5\% mass loss $]$ \\
\hline T1 (butyl) & 1287.51 & 126 & 419 \\
T1 (hexyl) & 1844.95 & 63 & 401 \\
T1 (octyl) & 2179.90 & 11 & 414 \\
T2 (butyl) & 2337.56 & 155 & 429 \\
T2 (hexyl) & 2842.52 & 86 & 408 \\
T2 (octyl) & 3347.48 & 34 & 422 \\
T3 (butyl) & 3166.81 & 169 & 427 \\
T3 (hexyl) & 3840.08 & 101 & 410 \\
T3 (octyl) & 4511.75 & 47 & 421 \\
T4 (butyl) & 3996.05 & 163 & 370 \\
T4 (hexyl) & 4837.65 & 116 & 413 \\
T4 (octyl) & 5679.20 & 51 & 434 \\
T6 (hexyl) & 6862.85 & 106 & 436 \\
T6 (octyl) & 8011.01 & 56 & 428 \\
\hline
\end{tabular}

Based on the thermal data presented here, it seems that the hexyl chain, the alkyl chain initially chosen for developing star-shaped oligofluorene truxenes, was the best choice due to easier synthesis and purification, as well as good thermal properties.

\section{Electrochemical properties}

The electrochemical properties of the materials were studied by cyclic voltammetry in $\approx 10^{-4} \mathrm{M}$ solutions of the materials in 1:2 acetonitrile:benzene. Despite the compounds being soluble in most common organic solvents, it is known from the previous studies performed on the Tn (hexyl) family that the electrochemical reduction of the compounds occurs at lower potentials than the reduction of those solvents. Acetonitrile has a lower reduction potential than the Tn compounds but it is not able to solvate them. Benzene assists in the solvation of the materials and does not interfere in the electrochemical study. Therefore it was found that the ideal solvent mixture for the electrochemical studies was 1:2 acetonitrile:benzene.

The oxidation waves of the Tn (butyl) and Tn (octyl) compounds are presented in Figure 5 and Figure 7, respectively, and all the electrochemical properties are summarized in Table 2 . In both cases, the smallest analogues (T1 and T2) present two well-resolved oxidations separated by 0.22 to $0.25 \mathrm{~V}$, one of which is a reversible wave and the other a quasi-reversible one. These transitions are one-electron processes and are well defined. T3 also presents two consecutive reversible oxidation waves separated by around 0.14 to $0.16 \mathrm{~V}$. The T4 analogues showed a more complex electrochemical behavior with poor resolution between the first 
two oxidation peaks. T4 (butyl) presents a hint of a third irreversible peak. Note that the irreversible peak at around $+1.40 \mathrm{~V}$ is probably related to oxidation of the solvent rather than that of T4. T6 also has two quasireversible oxidation peaks separated by $0.20 \mathrm{~V}$ from each other with a rather broadened profile. The increase in the size of the molecules generally involves a lowering of the oxidation potentials in the Tn series. For comparison, Table 2 present published data on Tn (hexyl). ${ }^{11,33}$

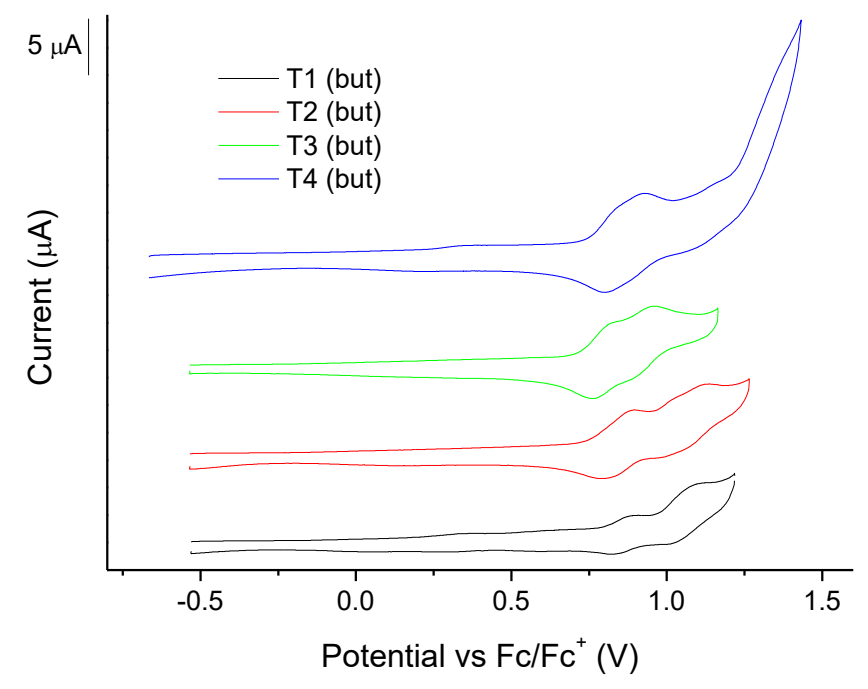

Figure 5. Oxidation waves of the Tn (butyl) series in 1:2 acetonitrile:benzene. The cyclic voltammogram was obtained employing a glassy carbon working electrode, a platinum wire counter electrode and a silver wire reference electrode. All the waves were referenced to ferrocene.

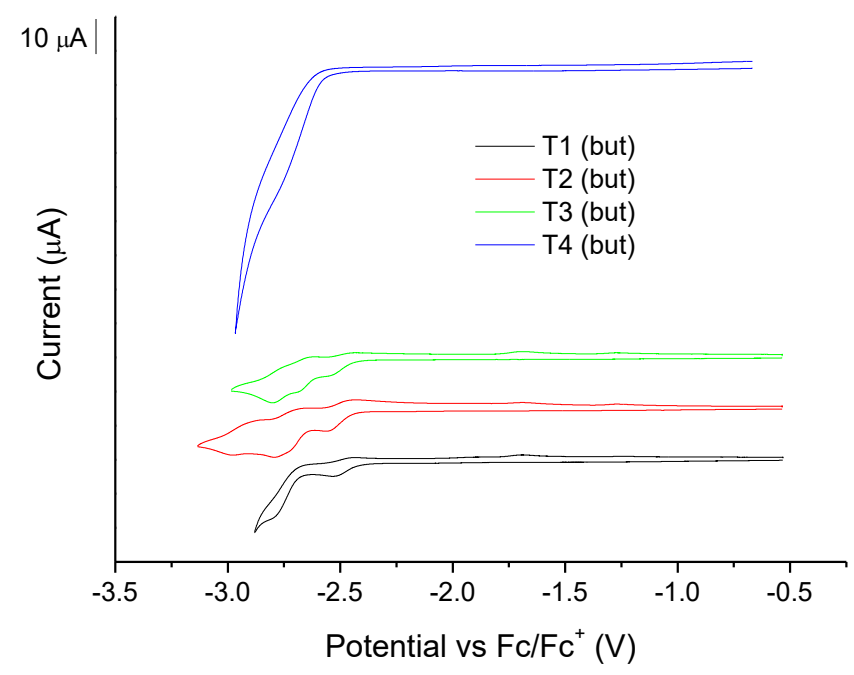

Figure 6. Reduction waves of the Tn (butyl) series in 1:2 acetonitrile:benzene. The cyclic voltammogram was obtained employing a glassy carbon working electrode, a platinum wire counter electrode and a silver wire reference electrode. All the waves were referenced to ferrocene. 


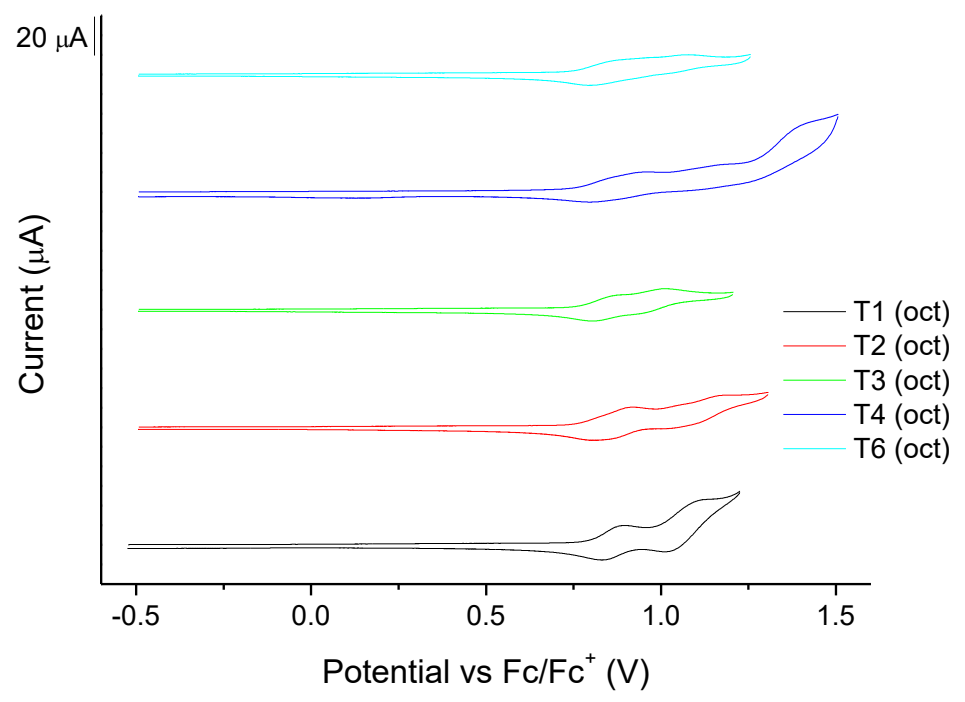

Figure 7. Oxidation waves of the Tn (octyl) series in 1:2 acetonitrile:benzene. The cyclic voltammogram was obtained employing a glassy carbon working electrode, a platinum wire counter electrode and a silver wire reference electrode. All the waves were referenced to ferrocene.

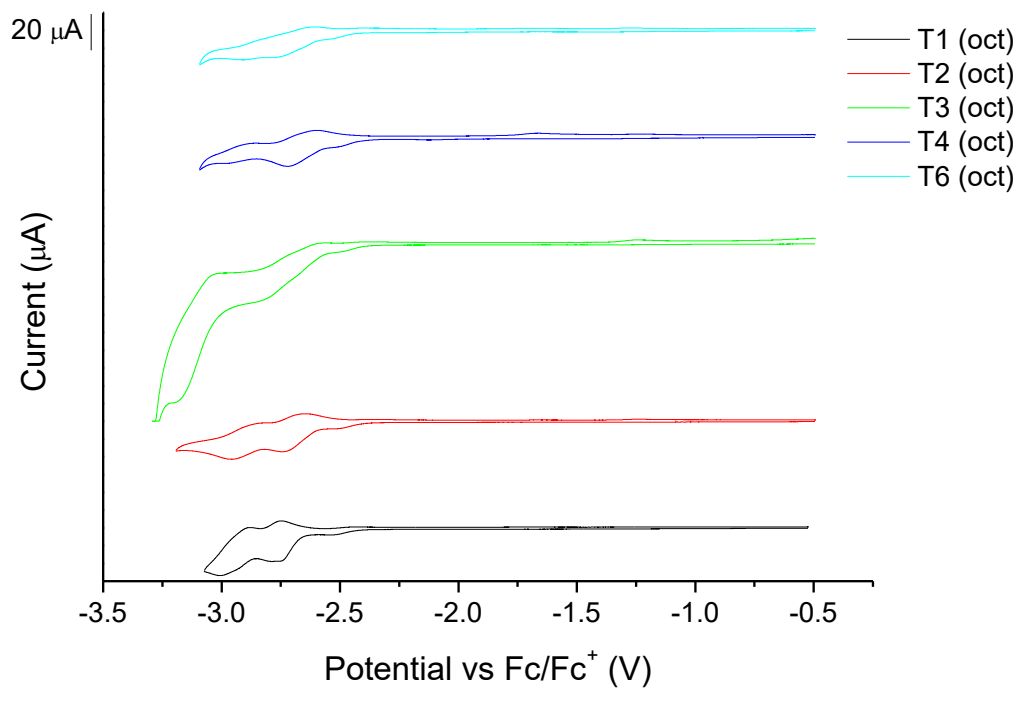

Figure 8. Reduction waves of the Tn (octyl) series in 1:2 acetonitrile:benzene. The cyclic voltammogram was obtained employing a glassy carbon working electrode, a platinum wire counter electrode and a silver wire reference electrode. All the waves were referenced to ferrocene. 
Table 2. Cyclic voltammetry results in 1:2 acetonitrile:benzene for the Tn (butyl, hexyl and octyl) series. HOMO and LUMO levels were calculated from the onset of the corresponding redox wave and are referenced to ferrocene, which has a HOMO of $-4.8 \mathrm{eV}$. The electrochemical HOMO-LUMO gap ( $\left.E_{g}, c v\right)$ is the energy gap between the HOMO and LUMO levels. The optical HOMO-LUMO gap ( $\left.E_{g, \text { opt }}\right)$ is calculated from the onset of the red-edge of the absorption band

\begin{tabular}{|c|c|c|c|c|c|c|}
\hline Compound & $\begin{array}{c}\mathrm{E}_{\mathrm{pa}}{ }^{\mathrm{ox}} \mathrm{vs} \mathrm{Fc} / \mathrm{Fc}^{+} \\
(\mathrm{V})\end{array}$ & $\begin{array}{c}\mathrm{E}_{\mathrm{pc}}{ }^{\text {red }} \mathrm{vs} \mathrm{Fc} / \mathrm{Fc}^{+} \\
(\mathrm{V})\end{array}$ & HOMO (eV) & LUMO (eV) & $E_{g, c v}(e V)$ & $E_{g, \text { opt }}(e V)$ \\
\hline T1 (butyl) & $+0.90,+1.13$ & $-2.50,-2.80$ & 5.53 & 2.36 & 3.17 & 3.05 \\
\hline T1 (hexyl) & $+0.86,+1.09$ & -2.94 & - & - & 3.40 & 3.29 \\
\hline T1 (octyl) & $+0.89,+1.11$ & $\begin{array}{c}-2.53,-2.76,- \\
3.00\end{array}$ & 5.59 & 2.37 & 3.22 & 3.27 \\
\hline T2 (butyl) & $+0.90,+1.14$ & $\begin{array}{c}-2.56,-2.79,- \\
2.97\end{array}$ & 5.54 & 2.36 & 3.18 & 3.11 \\
\hline T2 (hexyl) & $+0.82,+1.06$ & -2.83 & - & - & 3.30 & 3.14 \\
\hline T2 (octyl) & $+0.92,+1.17$ & $\begin{array}{c}-2.50,-2.74,- \\
3.00\end{array}$ & 5.56 & 2.41 & 3.15 & 3.12 \\
\hline T3 (butyl) & $+0.82,+0.96$ & $\begin{array}{c}-2.54,-2.68,- \\
2.80\end{array}$ & 5.51 & 2.38 & 3.13 & 3.12 \\
\hline T3 (hexyl) & $+0.82,+0.98$ & $-2.72,-2.88$ & - & - & 3.24 & 3.08 \\
\hline T3 (octyl) & $+0.87,+1.01$ & $\begin{array}{c}-2.49,-2.84,- \\
3.20\end{array}$ & 5.56 & 2.41 & 3.15 & 3.05 \\
\hline T4 (butyl) & $\begin{array}{c}+0.84,+0.93 \\
+1.16\end{array}$ & -2.75 & 5.54 & 2.22 & 3.33 & 3.03 \\
\hline T4 (hexyl) & $\begin{array}{c}+0.81,+0.93 \\
+1.12\end{array}$ & $\begin{array}{c}-2.65,-2.73 \\
2.99\end{array}$ & - & - & 3.20 & 3.05 \\
\hline T4 (octyl) & $+0.95,+1.17$ & $\begin{array}{c}-2.50,-2.72,- \\
2.97\end{array}$ & 5.55 & 2.41 & 3.14 & 3.01 \\
\hline T6 (hexyl) & $\begin{array}{c}+0.91,+0.98 \\
+1.09\end{array}$ & $-2.71,-2.87$ & 5.55 & 2.38 & 3.14 & 3.01 \\
\hline T6 (octyl) & $+0.88,+1.08$ & $\begin{array}{c}-2.52,-2.77,- \\
2.91\end{array}$ & 5.55 & 2.37 & 3.18 & 2.99 \\
\hline
\end{tabular}

The reduction voltammograms for Tn (butyl) and Tn (octyl) are presented in Figure 6 and Figure 8, respectively. The reduction peak around $-2.5 \mathrm{~V}$ (highlighted in italics in Table 2) is present in the voltammograms of all the Tn (butyl and octyl) series, but its intensity differs between voltammograms and is not consistent with a one-electron process. This observation, together with the fact that such a peak was not present in the electrochemical studies of the Tn (hexyl) family, might be an indication that it is a process that does not belong to the $\mathrm{Tn}$ molecules and it might be due to environmental factors such as the reduction of some impurity of the solvent or the electrolyte. For this reason, these peaks are not taken into account in the discussion of the electrochemical properties of these materials. T1 (butyl) presents an irreversible reduction peak at $-2.80 \mathrm{~V}$, whilst T1 (octyl) has two quasi-reversible reduction peaks (-2.76 V and $-3.00 \mathrm{~V}$, respectively). Similarly, T2 (butyl and octyl) present two quasi-reversible processes at around $-2.76 \mathrm{~V}$ and $-3.00 \mathrm{~V}$, respectively. The reduction of T3 (butyl) presents two quasi-reversible peaks at $-2.68 \mathrm{~V}$ and $-2.80 \mathrm{~V}$ whereas 
the voltammogram of T3 (octyl) features an irreversible reduction at $-2.84 \mathrm{~V}$, and a final irreversible reduction at $-3.20 \mathrm{~V}$ that might be caused by the reduction of the solvent. The reduction of T4 (butyl) involves a single irreversible wave at $-\mathbf{2 . 7 5} \mathrm{V}$, whereas T4 (octyl) presents two well-defined quasi-reversible reduction peaks at $2.72 \mathrm{~V}$ and $-2.97 \mathrm{~V}$ (the first reduction process seems to involve more than one electron). Similarly, T6 (octyl) shows two quasi-reversible reduction peaks that are not very well resolved at $-2.77 \mathrm{~V}$ and $-2.91 \mathrm{~V}$.

All the compounds have relatively high HOMO-LUMO gaps (around $3.18 \mathrm{eV}$ ) that are generally slightly reduced with the increase of the conjugation length in the arms. The optical HOMO-LUMO gap was calculated from the onset of the absorption band and in general there is a good agreement between it and the electrochemical HOMO-LUMO gap, the latter being generally slightly higher.

\section{Optical and photophysical properties}

The optical properties of the materials were studied in solutions of the compounds in 1:2 acetonitrile:benzene (in order to compare the optical and electrochemical HOMO-LUMO gaps), and concentrations were in the region of $10^{-6} \mathrm{M}$.

The normalized absorption and emission spectra of the Tn (butyl) family are depicted in Figure 9 and for the Tn (octyl) series in Figure 10. The data for the absorption and emission maxima as well as the logarithm of the molar absorptivity of each material $(\log (\varepsilon))$, are presented in Table 3, together with the results previously obtained for the Tn (hexyl) series. ${ }^{33,44}$ As expected, the length of the solubilizing alkyl chain does not have a major effect on the optical properties of the series in solution. For each member of the family, the results are comparable for butyl, octyl and hexyl chains.

The increase in the number of fluorenes in the arms results in a red shift of the absorption. This effect is greater for the first fluorene addition (there is a shift of $\approx 19 \mathrm{~nm}$ from T1 to T2) and it decreases as the number of fluorene units increases. The addition of two more fluorenes from T4 to T6 does not have a great effect on the energy of the absorption. This effect denotes the fact that 6 fluorene units are close to the saturation of the conjugation length for the absorption in star-shaped oligofluorene truxenes (the effective conjugation length for linear oligofluoenes reported by Jo and co-workers is fourteen fluorene units). ${ }^{53} \mathrm{~A}$ further increase in the number of fluorenes (e.g. T8, T10 or T12) would be beneficial to determine the exact conjugation length of these systems. Figure 11 represents the plot of the energy of the maximum of absorption (in eV) versus $1 / n$, where $\mathrm{n}$ is the number of fluorene units. This type of representation has previously been employed to determine the conjugation length in oligomeric systems. ${ }^{53}, 54$ The energies are in linear correlation with the inverse of the number of fluorenes for each of the three series with alkyl chains $\left(r^{2}=0.991-0.998\right)$, and the absorption maxima extrapolated to $n=\infty$ would be $\lambda_{n=\infty}=399 \mathrm{~nm}$ for the octyl series and $402 \mathrm{~nm}$ for the hexyl series. These peak values fall in the region of the extrapolated value for linear oligofluorenes $\left(\lambda_{n}=\infty=401\right.$ $\mathrm{nm})$ and are higher than the experimental value for poly $(9,9)$-dihexylfluorene $\left(\lambda_{\max }=383 \mathrm{~nm}\right) .{ }^{53}$ 
Table 3. Optical properties of the Tn (butyl, hexyl and octyl) series. $\lambda_{\text {abs }}$ is the wavelength of maximum absorbance; $\lambda_{\mathrm{em}}$ is the wavelength of maximum emission; $\varepsilon$ is the molar absorptivity

\begin{tabular}{lccccc}
\hline Compound & $\lambda_{\text {abs, solution }}(\mathrm{nm})$ & $\lambda_{\text {abs, film }}(\mathrm{nm})$ & $\lambda_{\text {em,sol }}(\mathrm{nm})$ & $\lambda_{\text {em, film }}(\mathrm{nm})$ & $\log (\varepsilon)$ \\
\hline T1 (butyl) & 344 & 343 & - & - & 5.64 \\
T1 (hexyl) & 343 & 343 & $377,398,416$ & $380,398,420$ & 5.07 \\
T1 (octyl) & 344 & 343 & - & - & 5.26 \\
T2 (butyl) & 364 & 363 & $405,431,461$ & $407,426,454$ & 5.47 \\
T2 (hexyl) & 362 & 359 & $400,424,452$ & $404,426,449$ & 5.24 \\
T2 (octyl) & 362 & 363 & $406,429,463$ & $405,427,454$ & 5.24 \\
T3 (butyl) & 373 & 373 & $411,432,463$ & $417,437,467$ & 5.58 \\
T3 (hexyl) & 372 & 369 & $410,434,457$ & $417,436,462$ & 5.41 \\
T3 (octyl) & 370 & 373 & $410,430,464$ & $416,438,469$ & 5.58 \\
T4 (butyl) & 377 & 378 & $416,438,470$ & $420,442,475$ & 5.72 \\
T4 (hexyl) & 377 & 372 & $414,438,467$ & $422,442,467$ & 5.46 \\
T4 (octyl) & 376 & 379 & $414,441,467$ & $423,444,471$ & 5.72 \\
T6 (hexyl) & 381 & 374 & $416,439,470$ & $420,446,480$ & 5.87 \\
T6 (octyl) & 381 & 376 & $415,437,470$ & $420,446,478$ & 5.84 \\
\hline
\end{tabular}

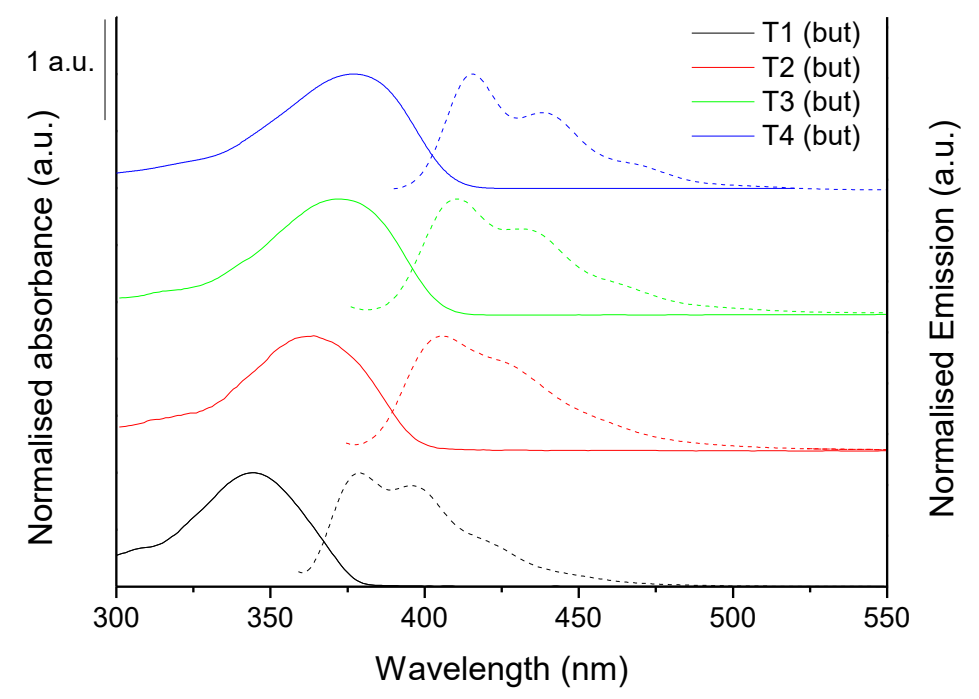

Figure 9. Normalized absorption (continuous line) and emission (dashed line) spectra of the members of the Tn (butyl) family ( $10^{-6} \mathrm{M}$ solutions in 1:2 acetonitrile:benzene). 


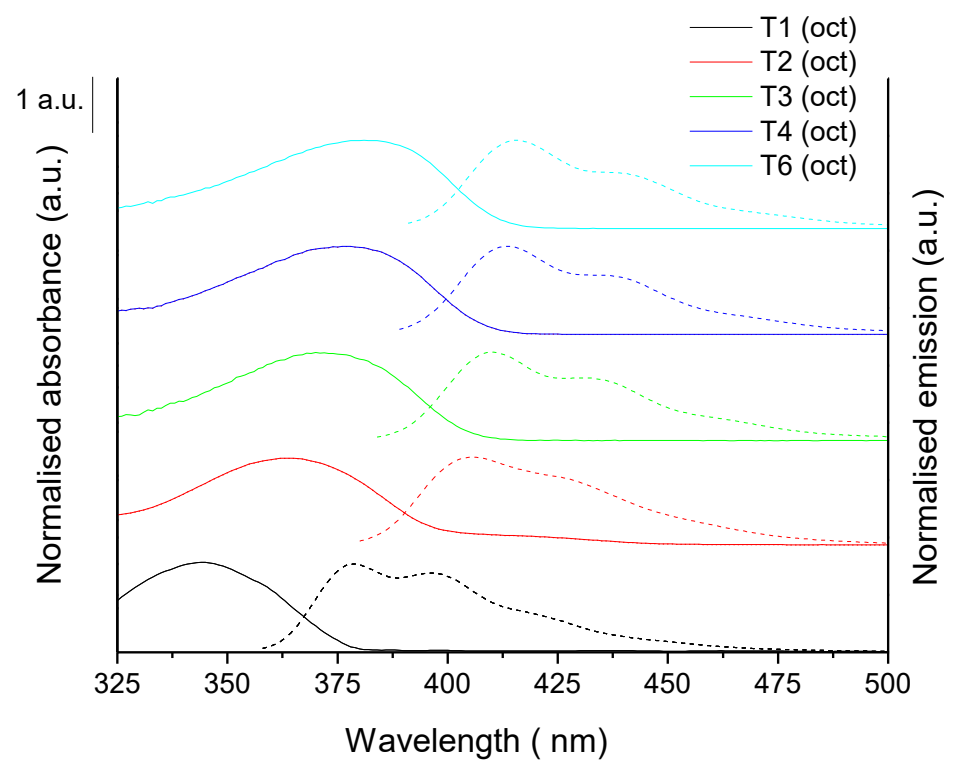

Figure 10. Normalized absorption (continuous line) and emission (dashed line) spectra of the members of the Tn (octyl) family $\left(10^{-6} \mathrm{M}\right.$ solutions in 1:2 acetonitrile:benzene). $\lambda_{\mathrm{ex}}=\lambda_{\max }$.

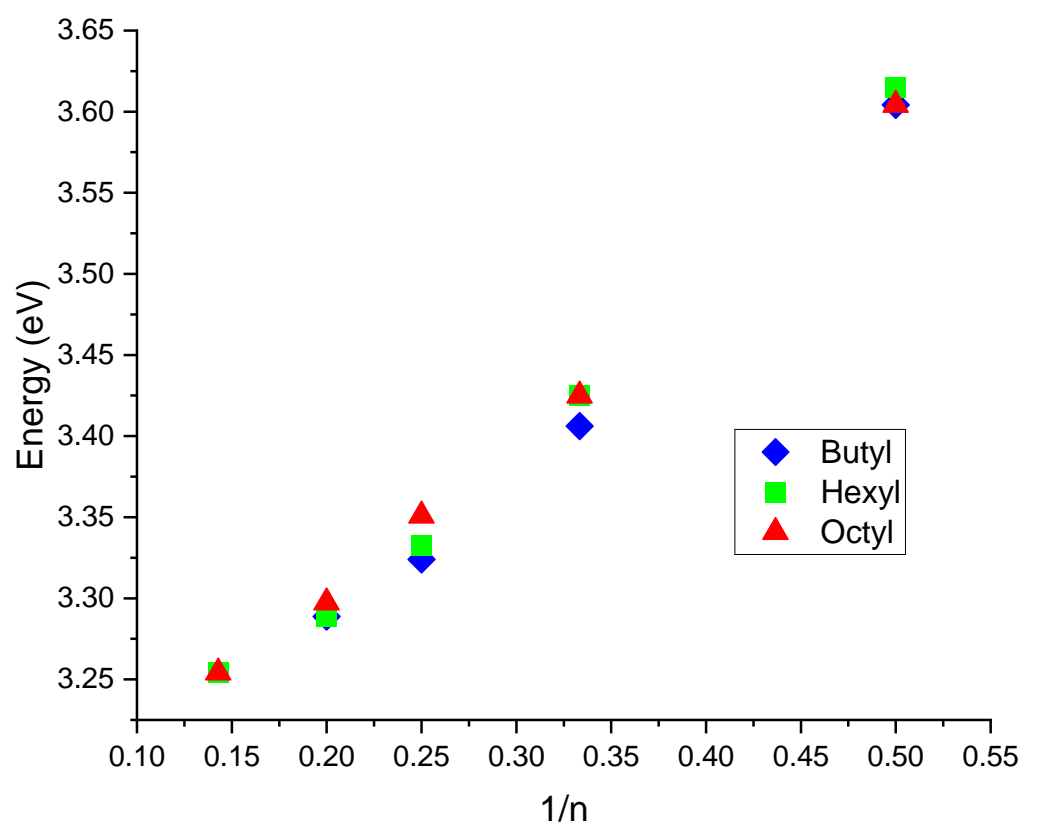

Figure 11. Representation of the energy of absorption (eV) versus the number of fluorene units in the arm and one fluorene from the truxene core in the Tn (butyl, octyl and hexyl) series.

All the compounds exhibit large molar absorptivities that increase with the length of the arm. There is certain variation in the molar absorptivity of the same member of the Tn family with different alkyl chains. As previously discussed in a study performed on the hexyl analogues, the length of the alkyl chain should not affect the optical properties as demonstrated by DFT calculations performed on benzene-cored star-shaped 
oligofluorenes with three arms. Calculations of the molecules with the full hexyl chain and with methyl groups in the C9 position of the fluorenes only changed the absorption energy and transition dipole of the molecules by $0.6 \%$ to $2.4 \%$, depending on the basis set employed for the calculation. ${ }^{55}$ It should be then concluded that the observed differences must be due to experimental errors, but the trends observed for the each arm length are still maintained. Taking into account that the truxene core increases the effective conjugation length of each arm by one fluorene, an arm of T1 is comparable with bifluorene, T2 with terfluorene, etc. The same publication by Montgomery and co-workers also discussed the direct threefold increase of the molar absorptivity of the Tn compounds compared to the corresponding oligofluorenes. This is easily explained by the fact that the truxene molecules absorb energy with three oligofluorene arms simultaneously. ${ }^{55}$ The effective conjugation of truxene with oligofluorene arms can also be confirmed by analyzing the frontier orbitals levels calculated by DFT for monofluorene (F1), bifluorene (F2), truxene (T0) and oligofluorenetruxenes (T1 and T2). ${ }^{34}$ The destabilization/stabilization of the HOMO/LUMO levels by 0.38/0.46 eV for F1 $\rightarrow$ F2 evolution is almost twice as high as that for $\mathrm{T} 1 \rightarrow \mathrm{T} 2(0.17 / 0.25 \mathrm{eV})$ and much more similar to the one for T0 $\rightarrow$ T1 $(0.35 / 0.55 \mathrm{eV})$.

The absorption spectra for the Tn series present a broad featureless band arising from strong $\pi-\pi^{*}$ interactions between the HOMO and LUMO of the molecules. The loss of spectral vibronic resolution compared with TO arises from the lack of rigidity of the structure, in which the C-C single bonds between fluorenes allow for rotation, as previously discussed by Moreno Oliva and co-workers. ${ }^{34}$ Their theoretical study predicted that the $S_{0}-S_{1}$ transition is forbidden and the first dipole-allowed transition is the $S_{0}-S_{2}$, with a large oscillator strength, which would explain the large molar absorptivities associated with these molecules.

All the molecules in the Tn series present efficient fluorescence behavior represented by a broad band with vibrational structure (a main band corresponding to the 0-0 vibronic emission and two red-shifted shoulders related to the $0-1$ and $0-2$ transitions, respectively). ${ }^{53}$ TD-DFT calculations previously reported assigned the fluorescence to the $S_{2}-S_{0}$ transition. The authors imply that the efficient fluorescence of these molecules might arise from the strong coupling between the $S_{2}$ and the ground state. ${ }^{34}$ The theoretical calculations performed in the same study also predicted that in the excited quinoidal-state the $\mathrm{C}-\mathrm{C}$ bonds between the fluorene units and between truxene and fluorene have a bonding nature that enables greater conjugation and rigidifies the system. ${ }^{34}$ This could be the reason behind the vibronic structure of the fluorescence band.

For every member of the series there is a large Stokes shift between the absorption and the emission maxima (an average of $38 \mathrm{~nm}$ ), with little spectral overlap. This is beneficial for optical applications because it minimizes the re-absorption of the emission, thus maximizing the photoluminescence quantum efficiency and improving the device performance. The increase of the number of fluorene units in the arms induces a bathochromic shift in the emission which, as observed in the absorption properties, is more pronounced for the first fluorene addition ( $\approx 26 \mathrm{~nm}$ shift from T1 to T2) than for the larger members of the series $(\approx 7 \mathrm{~nm}$ shift from T2 to T3, $\approx 4 \mathrm{~nm}$ from T3 to T4 and $1 \mathrm{~nm}$ from T4 to T6). This effect was also discussed by Montgomery and co-workers, that attributed the smaller transition energies (both for absorption and emission) in compounds $\mathbf{T 2}$ to $\mathbf{T 4}$ than in T1, to the fact that the core is a greater fraction of the molecule in the smaller members of the series. ${ }^{55}$ Interestingly, the same publication described a TD-DFT study on the change in electron density by absorption of circularly polarized light and/or fluorescence for a benzene-cored analogue to T2 (B2). They concluded that the change in electron density during absorption and emission was larger in the middle of the arms, but for the absorption it was delocalized over the entire molecule while in the emission it was localized on a single arm. They found three equivalent energy minima in the excited state, which would imply that the emission in benzene or truxenes-cored tris(oligofluorenes) could come from any of the three arms, but only from one arm at a time. ${ }^{55}$ 


\section{Conclusions}

In conclusion, a series tris(oligofluorene) truxenes (Tn) with butyl and octyl chain were synthesized in order to study the effect of the length of the solubilizing side chains in the properties of the materials, through morphological variations. The synthesis of the butyl analogues proved to be difficult due to the reduced solubility of the materials in organic solvents, especially at low temperatures. On the other hand, the purification of the octyl derivatives was more challenging due to poorer separation from their byproducts on silica and their tendency to trap grease.

The compounds are thermally stable and amorphous materials with decomposition temperatures above $400^{\circ} \mathrm{C}$ except for $\mathbf{T 4}$ (butyl), which shows Td (TGA, 5\% mass loss) of $370^{\circ} \mathrm{C}$. The glass transition temperature $\left(T_{g}\right)$ is an important characteristic of an organic semiconductor, which should be taken into account during device fabrication. For efficient materials with a stable performance, the $T_{g}$ values should be well beyond the ambient temperature and above the temperature of a device which would be expected taking into account some heat dissipation upon the device operation. The length of the solubilizing alkyl chains affects the glass transition temperatures dramatically. The $T_{g}$ values of the butyl and octyl analogues of T3 (hexyl) and T4 (hexyl) (compounds which were extensively used for lasing applications), increase by a factor of 1.5 for T3 (butyl) and T4 (butyl), and decrease two-fold for T3 (octyl) and T4 (octyl). For the octyl derivatives the $\mathrm{T}_{\mathrm{g}}$ values are so low that it could affect their device performance, e.g. if the pumped DFB laser is heated to the temperature close to $T_{g}$ during its operation. The change in the morphology, the film thickness, or the amplitude of spatial modulation of the effective refractive index in the direction of the grating periodicity would lead to an uncontrollable variation in the lasing threshold value and/or in the position of the emission peak.

The electrochemical properties of the compounds are not largely affected by the length of the solubilizing chains, although this would be confirmed by further investigation. The optical properties of the materials in solution are very similar, but their photophysical characteristics of the condensed state can be greatly affected by the size of the alkyl chain. These photophysical studies form a major study and will be reported elsewhere.

\section{Experimental Section}

General. ${ }^{1} \mathrm{H}$ and ${ }^{13} \mathrm{C}$ NMR spectra were recorded on a Bruker Avance DPX400 at 400.13 and $100.61 \mathrm{MHz}$ or a Bruker Avance DRX500 at $500 \mathrm{MHz}$ and $125.75 \mathrm{MHz}$ in $\mathrm{CDCl}_{3}$. Proton NMR chemical shifts are reported as $\delta$ values in ppm relative to deuterated solvents, $\mathrm{CDCl}_{3}(7.26) .{ }^{56}$ Data are presented as follows: chemical shift, integration, multiplicity ( $s=$ singlet, b.s. = broad singlet, $d=$ doublet, $t=$ triplet, $q=$ quartet, $m=$ multiplet), and coupling constant(s) $(J)$ are in $\mathrm{Hz}$. Multiplets are reported over the range (in ppm) they appeared. Carbon NMR data were collected and calibrated to the solvent signals $\mathrm{CDCl}_{3}$ (77.36). MS MALDI-TOF spectra were recorded on a Shimadzu Axima-CFR spectrometer (mass range 1-150 $000 \mathrm{Da}$ ). Elemental analyses were obtained on a PERKIN ELMER 2400 elemental analyser. Commercial TLC plates (Silica gel 60 F254) were used for TLC chromatography and column chromatography was carried out on silica gel Zeoprep $60 \mathrm{Hyd}$ (40-63 $\mu \mathrm{m}$ mesh). Solvents were removed using a rotary evaporator (vacuum supplied by low vacuum pump) and, when necessary, a high vacuum pump was used to remove residual solvent. Distillation to remove excess 1bromoalkane was performed on a Kugelrohr Z24 with a high vacuum pump. Dry solvents (dichloromethane, tetrahydrofuran, toluene, hexane and diethyl ether) were obtained from a solvent purification system (SPS 400, innovative technologies) using alumina as the drying agent; any other dry solvents were purchased from 
Sigma Aldrich. All reagents and solvents were purchased commercially from Sigma Aldrich or Alfa Aesar and were used without any purification, with the exception of petroleum ether, which was distilled in a rotary evaporator at atmospheric pressure prior to its use as eluent for column chromatography. Tetrakis(triphenylphosphine)palladium(0) was synthesized following known procedure. ${ }^{57}$

Optical properties. UV-Vis absorption spectra were recorded on a UNICAM UV 300, a Jasco V-660 or a Shimazdu UV-2600 spectrophotometer. Baselines of solvents were measured before analysis and solution spectra were recorded in $1 \mathrm{~cm}$ or $1 \mathrm{~mm}$ path length quartz cells between 190 and $900 \mathrm{~nm}$. Emission spectra were measured on a Perkin Elmer LS45 or a Jasco FP-6500 fluorescence spectrometers. Films for studying the optical properties of star-shaped molecules were prepared from $30 \mathrm{mg} / \mathrm{mL}$ toluene solutions, which were spin cast onto spectrosil quartz substrates (UQG optics). Absorption measurements were taken using a Shimadzu UV2550 spectrophotometer, with a clean spectrosil quartz substrate as reference. Photoluminescence measurements were taken using a Jobin-Yvon Fluoromax-3 spectrometer.

Electrochemistry. CV measurements were performed on a $\mathrm{CH}$ Instruments 660A electrochemical workstation with $i R$ compensation using anhydrous solvents (dichloromethane or 1:2 acetonitrile:benzene). The electrodes were glassy carbon, platinum wire, and silver wire as the working, counter, and reference electrodes, respectively. All solutions were degassed ( $\mathrm{Ar}$ ) and contained monomer substrates in concentrations ca. $10^{-4} \mathrm{M}$, together with $\operatorname{TBAPF}_{6}(0.1 \mathrm{M})$ as the supporting electrolyte. All measurements are referenced against the $\mathrm{E}_{1 / 2}$ of the $\mathrm{Fc} / \mathrm{Fc}^{+}$redox couple.

Thermogravimetric Analysis. The sample (approx. $5 \mathrm{mg}$ ) was placed on a standard platinum pan and loaded at $35^{\circ} \mathrm{C}$ to be analysed with a Perkin Elmer Thermogravimetric Analyzer TGA7 under a constant flow of helium (20 $\mathrm{mL} / \mathrm{min}$ ). The temperature was raised to $50^{\circ} \mathrm{C}$ followed by an isothermal period of 5 minutes. The temperature was raised again at a rate of $10^{\circ} \mathrm{C} / \mathrm{min}$ until $500^{\circ} \mathrm{C}$ when the material was left for an isothermal period of 30 minutes. The percentage weight loss over time was recorded at this temperature and the data was processed using the Pyris Series Software.

Differential Scanning Calorimetry was conducted on a TA Instruments Q1000 with a RC-90 refrigerated cooling unit attached. The calibration was conducted using Indium (melt temperature $156.42^{\circ} \mathrm{C}, \Delta \mathrm{Hf} 28.42$ $\mathrm{J} / \mathrm{g}$ ). The test procedure used was a standard Heat-Cool-Reheat, this allows the removal of thermal history on the first heat allowing examination of any thermal processes on the cooling and second heat scan. The temperature range was from $-50^{\circ} \mathrm{C}$ to $300^{\circ} \mathrm{C}$ at $10^{\circ} \mathrm{C} / \mathrm{min}$.

2,7-Dibromofluorene (3) 58

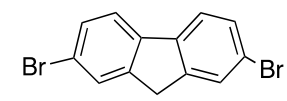

To a mechanically stirred solution of fluorene $(97.30 \mathrm{~g}, 0.58 \mathrm{~mol})$ in acetic acid $(870 \mathrm{~mL}) \mathrm{H}_{2} \mathrm{SO}_{4}(95-97 \%, 9 \mathrm{~mL})$ was slowly added at $70^{\circ} \mathrm{C}$. The reaction was cooled to $55^{\circ} \mathrm{C}$ and a solution of bromine $(50 \mathrm{~mL}, 0.97 \mathrm{~mol}) \mathrm{in}$ acetic acid $\left(67 \mathrm{~mL}\right.$ ) was added dropwise for $3 \mathrm{~h}$, keeping the temperature at $40-55^{\circ} \mathrm{C}$ to avoid crystallisation of the fluorene. After the addition of $\sim 1 / 3$ of the amount of bromine, $\mathrm{KBrO}_{3}(33.34 \mathrm{~g}, 0.20$ mol) was added in small portions with vigorous stirring to promote the precipitation of 2,7-dibromofluorene. The rest of the bromine was then added dropwise. The mixture was stirred at $50^{\circ} \mathrm{C}$ for $4 \mathrm{~h}$ and then allowed to reach room temperature before cooling down to $10^{\circ} \mathrm{C}$. The white precipitate was filtered off, washed with $70 \%$ acetic acid $(1000 \mathrm{~mL})$ and water until a $\mathrm{pH}$ of 7 was reached, yielding $177.71 \mathrm{~g}$ of crude solid. The material was purified by stirring in acetic acid ( $340 \mathrm{~mL}$ ) at reflux under $\mathrm{N}_{2}$ for $4 \mathrm{~h}$. The solid was left to reach room temperature, filtered 
off, washed with acetic acid and dried to afford 3 as a dark creamy solid (151.70 g, $0.47 \mathrm{~mol}, 80 \%) .{ }^{1} \mathrm{H}$ NMR $\left(\mathrm{CDCl}_{3}\right) \delta(\mathrm{ppm}): 7.68(2 \mathrm{H}, \mathrm{s}), 7.62(2 \mathrm{H}, \mathrm{d}, \mathrm{J}=8.0 \mathrm{~Hz}), 7.52(2 \mathrm{H}, \mathrm{d}, \mathrm{J}=8.0 \mathrm{~Hz}), 3.88(2 \mathrm{H}, \mathrm{s})$. The analysis was comparable with that from the literature. ${ }^{59}$

General procedure A: Synthesis of 2,7-dibromo-9,9-dialkylfluorene (4 B, 4 0) 58, 60

To a mixture of 2,7-dibromofluorene (3) (1 eq) and 1-bromoalkane (4 eq) in tetrahydrofuran (8 $\mathrm{mL}$ per gram), a solution of potassium tert-butoxide $(2.25 \mathrm{eq})$ in dry tetrahydrofuran $(200 \mathrm{~mL})$ was added dropwise at $0^{\circ} \mathrm{C}-$ $+5^{\circ} \mathrm{C}$ over $1.5 \mathrm{~h}$ with vigorous stirring. The reaction was then stirred at room temperature for $4 \mathrm{~h}$ and the mixture was filtered through a silica plug to remove the $\mathrm{KBr}$ precipitate, and was washed with dichloromethane. After evaporation of the solvent, the crude residue was treated with activated carbon in hot $\mathrm{n}$-hexane and filtered through a silica plug to remove coloured by-products. After evaporation of the solvent, the crude product was treated with activated carbon in methanol, filtered by gravity and allowed to crystallize, obtaining the product that was recrystallized from hexane to remove traces of methanol.

2,7-Dibromo-9,9-dibutylfluorene (4 B)

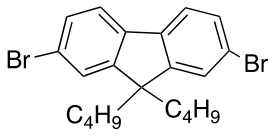

Using the general procedure $A$, the quantities used were: 2,7-Dibromofluorene (2.3) (26 g, $0.08 \mathrm{~mol}$ ), 1Bromobutane $(34 \mathrm{~mL}, 0.32 \mathrm{~mol})$, tetrahydrofuran $(200 \mathrm{~mL})$, potassium tert-butoxide $(20.20 \mathrm{~g}, 0.18 \mathrm{~mol})$ in dry tetrahydrofuran $(200 \mathrm{~mL})$. The product was afforded as white crystals $\left(25.67 \mathrm{~g}, 59 \cdot 10^{-3} \mathrm{~mol}, 73 \%\right) .{ }^{1} \mathrm{H} \mathrm{NMR}$ $\left(\mathrm{CDCl}_{3}\right) \delta(\mathrm{ppm}): 7.53(2 \mathrm{H}, \mathrm{d}, J=8.0 \mathrm{~Hz}), 7.45(4 \mathrm{H}, \mathrm{d}, J=8.0 \mathrm{~Hz}), 1.95-1.91(4 \mathrm{H}, \mathrm{m}), 1.09(4 \mathrm{H}, \mathrm{m}), 0.70(6 \mathrm{H}, \mathrm{t}$, $J=8.0 \mathrm{~Hz}$ ), 0.62-0.54 (4 H, m). Anal. calcd. for $\mathrm{C}_{21} \mathrm{H}_{22} \mathrm{Br}_{2}$ : C, 57.82; $\mathrm{H}, 5.55, \mathrm{Br}$; 36.63. Found: $\mathrm{C}, 57.85 ; \mathrm{H}, 5.43$; $\mathrm{Br}, 36.44$. The analysis was comparable with that from the literature. ${ }^{61}$

2,7-Dibromo-9,9-dioctylfluorene (4 0)

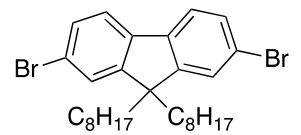

Using the general procedure A, the quantities used were: 2,7-Dibromofluorene (2.3) (26 g, $0.08 \mathrm{~mol})$, 1Bromooctane $(55 \mathrm{~mL}, 0.31 \mathrm{~mol})$ tetrahydrofuran $(200 \mathrm{~mL})$, solution of potassium tert-butoxide $(20.20 \mathrm{~g}, 0.18$ $\mathrm{mol})$ in tetrahydrofuran $(200 \mathrm{~mL})$. After evaporation of the solvent, residual 1-bromooctane was removed in vacuo $\left(45^{\circ} \mathrm{C}, 1.6 \cdot 10^{-3} \mathrm{~atm}\right)$. The product as was afforded as a white-yellowish solid $\left(32.563 \mathrm{~g}, 59.3 \cdot 10^{-3} \mathrm{~mol}\right.$, 74\%). ${ }^{1} \mathrm{H}$ NMR $\left(\mathrm{CDCl}_{3}\right) \delta(\mathrm{ppm}): 7.53(2 \mathrm{H}, \mathrm{d}, J=8.0 \mathrm{~Hz}), 7.46(4 \mathrm{H}, \mathrm{d}, J=8.0 \mathrm{~Hz}), 1.94-1.89(4 \mathrm{H}, \mathrm{m}), 1.28-1.06$ $(20 \mathrm{H}, \mathrm{m}), 0.84(6 \mathrm{H}, \mathrm{t}, J=8.0 \mathrm{~Hz}), 0.65-0.54(4 \mathrm{H}, \mathrm{m})$. The analysis was comparable with that from the literature. 61

General procedure B: Synthesis of 9,9-Dialkyl-7-trimethylsilylfluoren-2-ylboronic acid $\left(\mathbf{F}_{\mathbf{1}}\right)^{41}$

A solution of 2,7-Dibromo-9,9-dialkylfluorene $(4,6)(1 \mathrm{eq})$ in dry tetrahydrofuran (20 $\mathrm{mL}$ per gram) was prepared under $\mathrm{N}_{2}$ and at $-80^{\circ} \mathrm{C}$ a solution of $\mathrm{n}$-BuLi in $\mathrm{n}$-hexanes (1 eq) was added dropwise, carefully maintaining the temperature below $-78{ }^{\circ} \mathrm{C}$. The reaction mixture was stirred at $-80{ }^{\circ} \mathrm{C}$ for 5 min and then cooled down to $-95^{\circ} \mathrm{C}$. Chlorotrimethylsilane $(1 \mathrm{eq})$ was added dropwise and the mixture was left to warm up to room temperature and cooled back to $-80^{\circ} \mathrm{C}$. A second portion of $n$-BuLi in hexanes (1.2 eq) was added dropwise. At $-100^{\circ} \mathrm{C}$, triisopropylborate ( $3 \mathrm{eq}$ ) was added slowly and the system allowed to reach room temperature and stirred for $18 \mathrm{~h}$. The mixture was poured over deionized water and extracted with diethyl 
ether (4 times). The combined organic fractions were washed with water, dried over anhydrous $\mathrm{MgSO}_{4}$ and the solvent evaporated to yield the crude material. The product was purified by flash chromatography with a silica gel column eluting first with toluene to isolate the by-products, then by elution with diethyl ether to isolate the product.

9,9-Dibutyl-7-trimethylsilylfluoren-2-ylboronic acid ( $\left.\boldsymbol{F}_{\mathbf{1}} \mathbf{B}\right)$

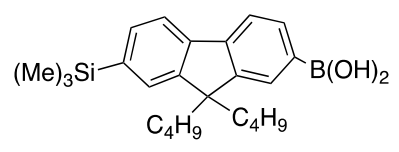

Using the general procedure B, the quantities used were: 2,7-dibromo-9,9-dibutylfluorene (4 B) (12.20 g, 28.07 $\mathrm{mmol})$, dry tetrahydrofuran $(250 \mathrm{~mL}), \mathrm{n}$-BuLi $\left(2.38 \mathrm{M}\right.$ in hexanes, $\left.11.8 \mathrm{~mL}, 28.07 \cdot 10^{-3} \mathrm{~mol}\right)$, chlorotrimethylsilane $\left(3.6 \mathrm{~mL}, 28.07 \cdot 10^{-3} \mathrm{~mol}\right), \mathrm{n}$-BuLi $\left(2.38 \mathrm{M}\right.$ in hexanes, $\left.14.15 \mathrm{~mL}, 33.68 \cdot 10^{-3} \mathrm{~mol}\right)$, triisopropylborate $\left(19.8 \mathrm{~mL}, 84.20 \cdot 10^{-3} \mathrm{~mol}\right)$. The product was obtained as a white foamy solid $(9.11 \mathrm{~g}$, 23.10·10-3 mol, 82\%). ${ }^{1} \mathrm{H} \mathrm{NMR}\left(\mathrm{CDCl}_{3}\right) \delta(\mathrm{ppm}):$ 8.32-8.24 $(1 \mathrm{H}, \mathrm{m}), 8.18-7.68(3 \mathrm{H}, \mathrm{m}), 7.10-7.45(2 \mathrm{H}, \mathrm{m}), 2.20-$ $1.92(4 \mathrm{H}, \mathrm{m}), 1.25-0.90(4 \mathrm{H}, \mathrm{m}), 0.62-0.54(10 \mathrm{H}, \mathrm{m}), 0.32(9 \mathrm{H}, \mathrm{s})$. The analysis was comparable with that from the literature. ${ }^{62}$

9,9-Dioctyl-7-trimethylsilylfluoren-2-ylboronic acid $\left(\mathbf{F}_{\mathbf{1}} \mathbf{O}\right)$

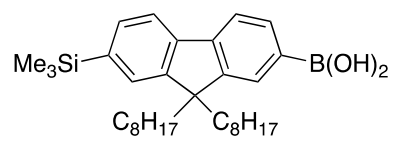

Using the general procedure B, the quantities used were: 2,7-dibromo-9,9-dioctylfluorene (4 0) (8.04 $\mathrm{g}, 15 \cdot 10^{-}$ $\left.{ }^{3} \mathrm{~mol}\right)$, tetrahydrofuran $(100 \mathrm{~mL}), \mathrm{n}$-butyllithium (2.5 M in n-hexanes, $\left.6 \mathrm{~mL}, 15 \cdot 10^{-3} \mathrm{~mol}\right)$, chlorotrimethylsilane (1.9 mL, $\left.15 \cdot 10^{-3} \mathrm{~mol}\right)$, n-BuLi $\left(2.5 \mathrm{M}\right.$ in n-hexanes, $\left.7.3 \mathrm{~mL}, 18 \cdot 10^{-3} \mathrm{~mol}\right)$, triisopropylborate $\left(10.6 \mathrm{~mL}, 46 \cdot 10^{-3}\right.$ mol). The product was afforded as a white foamy solid $\left(6.25 \mathrm{~g}, 12 \cdot 10^{-3} \mathrm{~mol}, 90 \%\right) .{ }^{1} \mathrm{H} \mathrm{NMR}\left(\mathrm{CDCl}_{3}\right) \delta(\mathrm{ppm})$ : $8.32(1 \mathrm{H}, \mathrm{d}, J=8.0 \mathrm{~Hz}), 8.24(1 \mathrm{H}, \mathrm{s}), 7.91(1 \mathrm{H}, \mathrm{d}, J=8.0 \mathrm{~Hz}), 7.81(1 \mathrm{H}, \mathrm{t}, J=8.0 \mathrm{~Hz}), 7.57-7.53(2 \mathrm{H}, \mathrm{m}), 2.18-$ $2.04(4 \mathrm{H}, \mathrm{m}), 1.05-0.96(18 \mathrm{H}, \mathrm{m}), 0.80(6 \mathrm{H}, \mathrm{t}, \mathrm{J}=8.0 \mathrm{~Hz}), 0.78-0.65(4 \mathrm{H}, \mathrm{m}), 0.35(9 \mathrm{H}, \mathrm{t}, \mathrm{J}=8.0 \mathrm{~Hz})$. The analysis was comparable with that from the literature. ${ }^{63}$

General procedure C: Synthesis of (bromooligofluorenyl)trimethylsilanes (TMS- $\mathbf{F}_{\mathbf{n}}-\mathbf{B r}$ ) by Suzuki cross-coupling $(5,6,7,8,)^{11,41}$

A solution of 2,7-dibromo-9,9-dialkylfluorene (4) (3 eq) and $\mathrm{Pd}\left(\mathrm{PPh}_{3}\right)_{4}(0.03 \mathrm{eq})$ in dry toluene $(2.6 \mathrm{~mL}$ per gram) was stirred under a $\mathrm{N}_{2}$ atmosphere for $20 \mathrm{~min}$. A solution of trimethylsilyloligofluorenylboronic acid ( $\boldsymbol{F}_{\mathbf{n}}$ ) (1 eq) in dry toluene $\left(2.5 \mathrm{~mL}\right.$ per gram) was added to the mixture. The flask previously containing $\mathbf{F}_{\mathbf{n}}$ was washed with an additional portion of dry toluene and added to the reaction mixture. A $2 \mathrm{M}$ aqueous solution of $\mathrm{Na}_{2} \mathrm{CO}_{3}\left(2.3 \mathrm{eq}\right.$ ) was added and the system was stirred under $\mathrm{N}_{2}$ at $80^{\circ} \mathrm{C}$ for $18 \mathrm{~h}$. The reaction mixture was washed with water and extracted with dichloromethane (5 times). The combined organic fractions were washed with water, dried over anhydrous $\mathrm{MgSO}_{4}$ and the solvent evaporated yielding the crude product as a yellow oil. The material was purified by column chromatography on silica gel and then crystallized in acetone to afford the product. 


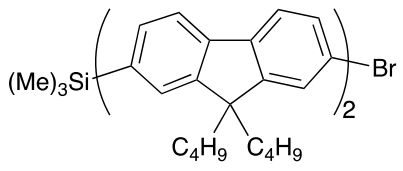

Using the general procedure $C$, the quantities used were: 2,7-dibromo-9,9-dibutylfluorene (4 B) (26.69 g, $\left.61.19 \cdot 10^{-3} \mathrm{~mol}\right), \mathrm{Pd}\left(\mathrm{PPh}_{3}\right)_{4}\left(0.707 \mathrm{~g}, 6.12 \cdot 10^{-4} \mathrm{~mol}\right)$, dry toluene $(70 \mathrm{~mL}), 9,9$-dibutyl-7-trimethylsilylfluoren-2ylboronic acid $\left(\mathbf{F}_{\mathbf{1}} \mathbf{B}\right)\left(8.049 \mathrm{~g}, 20.40 \cdot 10^{-3} \mathrm{~mol}\right)$, dry toluene $(40 \mathrm{~mL}), 2 \mathrm{M}$ aqueous solution of $\mathrm{Na}_{2} \mathrm{CO}_{3}(24 \mathrm{~mL}$, $\left.47.94 \cdot 10^{-3} \mathrm{~mol}\right)$. Column chromatography petroleum ether. The product was obtained as a white crystalline solid (10.41 g, $14.74 \mathrm{mmol}, 72 \%) .{ }^{1} \mathrm{H} \mathrm{NMR}\left(\mathrm{CDCl}_{3}\right) \delta(\mathrm{ppm})$ : 7.80-7.72 (3 H, m), 7.67-7.59 (5 H, m), 7.54-7.47 (4 $\mathrm{H}, \mathrm{m}), 2.10-1.95(8 \mathrm{H}, \mathrm{m}), 1.18-1.08(8 \mathrm{H}, \mathrm{m}), 0.79-0.67(20 \mathrm{H}, \mathrm{m}), 0.34(9 \mathrm{H}, \mathrm{t}, J=8.0 \mathrm{~Hz}) .{ }^{13} \mathrm{C} \mathrm{NMR}\left(\mathrm{CDCl}_{3}\right) \delta$ (ppm): 150.60, 149.67, 140.84, 140.46, 139.96, 139.79, 139.35, 138.70, 138.63, 131.37, 129.50, 127.13, $125.73,125.70,125.38,120.95,120.86,120.59,120.48,119.54,119.51,118.52,54.95,54.45,39.65,39.46$, 25.56, 25.47, 22.53, 13.33, 13.29, -1.33. (MALDI/TOF, $\mathrm{m} / \mathrm{z}$ ): $\left[\mathrm{M}^{+}\right]$calcd. for $\mathrm{C}_{45} \mathrm{H}_{57} \mathrm{BrSi}$ : 705.9; found, 704.4 . Anal. calcd. for $\mathrm{C}_{45} \mathrm{H}_{57} \mathrm{BrSi}$ : C, 76.56; $\mathrm{H}, 8.14, \mathrm{Br} ; 11.32$. Found: $\mathrm{C}, 76.74 ; \mathrm{H}, 8.53 ; \mathrm{Br}, 11.23$.

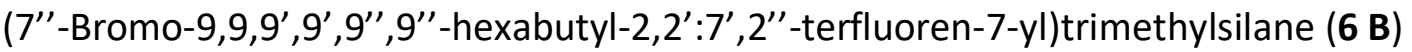

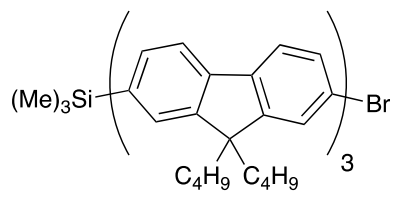

Using the general procedure $C$, the quantities used were: 2,7-dibromo-9,9-dibutylfluorene (4 B) (13.07 g, 29.96.10-3 mol), $\mathrm{Pd}\left(\mathrm{PPh}_{3}\right)_{4}\left(346 \mathrm{mg}, 3.00 \cdot 10^{-4} \mathrm{~mol}\right)$, toluene $(70 \mathrm{~mL}), 9,9,9^{\prime}, 9^{\prime}$-tetrabutyl-7'-trimethylsilyl-2,2'bifluoren-7-ylboronic acid ( $\left.\mathbf{F}_{\mathbf{2}} \mathbf{B}\right)\left(6.70 \mathrm{~g}, 23.47 \cdot 10^{-3} \mathrm{~mol}\right)$, toluene $(60 \mathrm{~mL}), 2 \mathrm{M}$ solution of $\mathrm{Na}_{2} \mathrm{CO}_{3}(11.73 \mathrm{~mL}$, $\left.23.47 \cdot 10^{-3} \mathrm{~mol}\right)$. Column chromatography with petroleum ether. The product was obtained as a white solid (6 g, 6.11·10 $\left.{ }^{-3} \mathrm{~mol}, 61 \%\right) .{ }^{1} \mathrm{H} \mathrm{NMR}\left(\mathrm{CDCl}_{3}\right) \delta(\mathrm{ppm}):$ 7.85-7.58 $(12 \mathrm{H}, \mathrm{m}), 7.55-7.46(6 \mathrm{H}, \mathrm{m}), 2.18-1.94(12 \mathrm{H}, \mathrm{m})$, 1.23-1.06 $(12 \mathrm{H}, \mathrm{m}), 0.85-0.65(30 \mathrm{H}, \mathrm{m}), 0.34(9 \mathrm{H}, \mathrm{s}) .{ }^{13} \mathrm{C} N M R\left(\mathrm{CDCl}_{3}\right) \delta(\mathrm{ppm}): 153.60,152.19,152.12$, $152.05,151.48,141.75,141.30,140.90,140.86,140.71,140.54,140.26,140.20,139.58,139.40,132.20$, 130.36, 127.98, 126.57, 126.46, 126.32, 121.81, 121.74, 121.42, 121.33, 120.36, 120.33, 119.34, 55.80, 55.61,

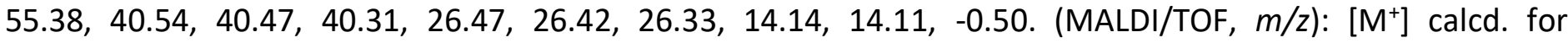
$\mathrm{C}_{90} \mathrm{H}_{129} \mathrm{BrSi}: 1318.9$; found, 1318.3. Anal. calcd. for $\mathrm{C}_{90} \mathrm{H}_{129} \mathrm{BrSi}$ : C, 8.70; $\mathrm{H}, 8.31$, Found: C, 8.05; $\mathrm{H}, 6.93$.

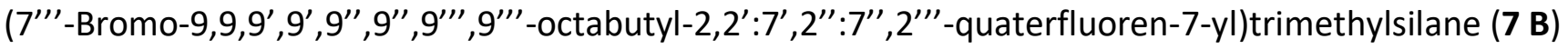

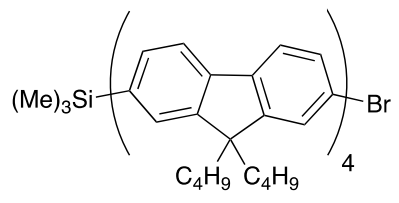

Using the general procedure $C$, the quantities used were: 2,7-dibromo-9,9-dibutylfluorene (2.4) (1.38 g, 3.17·10-3 mol), $\mathrm{Pd}\left(\mathrm{PPh}_{3}\right)_{4}\left(37 \mathrm{mg}, 3.20 \cdot 10^{-5} \mathrm{~mol}\right.$ ), toluene $(25 \mathrm{~mL}), 9,9,9^{\prime}, 9^{\prime}, 9^{\prime \prime}, 9^{\prime \prime}$-hexabutyl-2,2'-terfluorenyl-7trimethylsilyl-boronic acid $\left(\mathbf{F}_{3} \mathbf{B}\right)\left(1.00 \mathrm{~g}, 1.06 \cdot 10^{-3} \mathrm{~mol}\right)$, toluene $(6 \mathrm{~mL}), 2 \mathrm{M}$ solution of $\mathrm{Na}_{2} \mathrm{CO}_{3}(1.24 \mathrm{~mL}$, $\left.2.48 \cdot 10^{-3} \mathrm{~mol}\right)$. Column chromatography eluting first with petroleum ether and then 30:1 petroleum ether:toluene. The product was afforded as a creamy solid, with low solubility in most solvents $(0.697 \mathrm{~g}$, 
3.71-10-3 mol, 52\%). ${ }^{1} \mathrm{H} \mathrm{NMR}\left(\mathrm{CDCl}_{3}\right) \delta$ (ppm): 7.88-7.59 $(20 \mathrm{H}, \mathrm{m}), 7.57-7.47(4 \mathrm{H}, \mathrm{m}), 2.19-1.95(16 \mathrm{H}, \mathrm{m})$, 1.23-1.08 (16 H, m), 0.87-0.63 (40 H, m), $0.34(9 \mathrm{H}, \mathrm{s}) .{ }^{13} \mathrm{C}\left(\mathrm{CDCl}_{3}\right) \delta(\mathrm{ppm}): 140.44,140.02,139.88,139.85$, $139.70,139.59,139.49,139.46,139.35,138.76,138.55,131.37,129.53,127.14,125.74,125.63,125.49$, $120.96,120.89,120.60,120.51,119.54,118.51,54.97,54.78,54.55,39.74,39.66,39.49,25.64,25.58,25.49$, 22.62, 22.55, 13.36, 13.33, 13.30, -1.32. (MALDI/TOF, $\mathrm{m} / \mathrm{z}$ ): $\left[\mathrm{M}^{+}\right]$calcd. for $\mathrm{C}_{66} \mathrm{H}_{81} \mathrm{BrSi}:$ 1258.0; Found: 1259.0; Anal. calcd. for $\mathrm{C}_{66} \mathrm{H}_{81} \mathrm{BrSi}$ : C, 83.01; $\mathrm{H}, 8.41 ; \mathrm{Br}, 6.35$; Found: $\mathrm{C}, 81.80 ; \mathrm{H}, 8.24 ; \mathrm{Br}, 6.12$.

(7'-Bromo-9,9,9',9' -tetraoctyl-2,2'-bifluoren-7-yl)trimethylsilane (5 0)

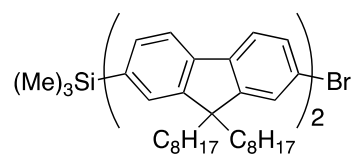

Using the general procedure $C$, the quantities used were: 2,7-dibromo-9,9-dioctylfluorene (4 0) (19.74 g, $\left.36 \cdot 10^{-3} \mathrm{~mol}\right), \mathrm{Pd}\left(\mathrm{PPh}_{3}\right)_{4}\left(416 \mathrm{mg}, 3.60 \cdot 10^{-4} \mathrm{~mol}\right)$, toluene $(40 \mathrm{~mL}), 9,9-$ dioctyl-7-trimethylsilylfluoren-2-ylboronic acid $\left(\mathbf{F}_{\mathbf{1}} \mathbf{O}\right)\left(6.05 \mathrm{~g}, 12 \cdot 10^{-3} \mathrm{~mol}\right)$, toluene $(20 \mathrm{~mL}), 2 \mathrm{M}$ solution of $\mathrm{Na}_{2} \mathrm{CO}_{3}\left(14 \mathrm{~mL}, 28 \cdot 10^{-3} \mathrm{~mol}\right)$. Column chromatography with petroleum ether. The product was obtained as a ropy oil $\left(8.06 \mathrm{~g}, 8.67 \cdot 10^{-3} \mathrm{~mol}, 88 \%\right) .{ }^{1} \mathrm{H}$ $\operatorname{NMR}\left(\mathrm{CDCl}_{3}\right) \delta(\mathrm{ppm}): 7.78(1 \mathrm{H}, \mathrm{d}, J=8.0 \mathrm{~Hz}), 7.73(2 \mathrm{H}, \mathrm{t}, J=6.0 \mathrm{~Hz}), 7.66-7.59(5 \mathrm{H}, \mathrm{m}), 7.53-7.47(4 \mathrm{H}, \mathrm{m})$, 2.05-1.93 $(8 \mathrm{H}, \mathrm{m}), 1.20-1.09(40 \mathrm{H}, \mathrm{m}), 0.84-0.66(20 \mathrm{H}, \mathrm{m}), 0.34(9 \mathrm{H}, \mathrm{m}) .{ }^{13} \mathrm{C} \mathrm{NMR}\left(\mathrm{CDCl}_{3}\right) \delta(\mathrm{ppm}): 39.77$, 39.62, 31.28, 29.43, 28.66, 28.61, 23.28, 22.11, 13.58, 3.00. (MALDI/TOF, $\mathrm{m} / z$ ): $\left[\mathrm{M}^{+}\right]$for $\mathrm{C}_{53} \mathrm{H}_{73} \mathrm{BrSi}$ : 930.6. The analysis was comparable with that from the literature. ${ }^{64}$

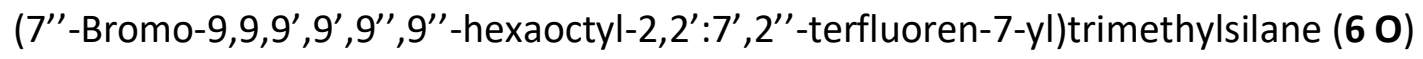

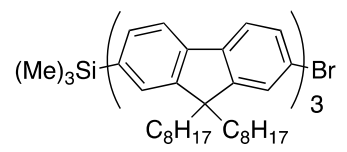

Using the general procedure $C$, the quantities used were: 2,7-dibromo-9,9-dioctylfluorene (4 0) (17.77 g, $\left.32.40 \cdot 10^{-3} \mathrm{~mol}\right), \mathrm{Pd}\left(\mathrm{PPh}_{3}\right)_{4}\left(374 \mathrm{mg}, 3.00 \cdot 10^{-5} \mathrm{~mol}\right)$, toluene $(60 \mathrm{~mL}), 9,9,9^{\prime}, 9^{\prime}$-tetraoctyl-7'-trimethylsilyl-2,2' bifluoren-7-ylboronic acid $\left(\mathbf{F}_{\mathbf{2}} \mathbf{O}\right)\left(9.71 \mathrm{~g}, 10.80 \cdot 10^{-3} \mathrm{~mol}\right)$, toluene $(40 \mathrm{~mL}), \mathrm{Na}_{2} \mathrm{CO}_{3}\left(2 \mathrm{M}, 13 \mathrm{~mL}, 25.92 \cdot 10^{-3}\right.$ mol). Column chromatography eluting with petroleum ether. The product as was obtained as a white crystalline solid (10.98 g, 8.01·10-3 mol, 74\%). ${ }^{1} \mathrm{H} \mathrm{NMR}\left(\mathrm{CDCl}_{3}\right) \delta(\mathrm{ppm}): 7.84-7.74(5 \mathrm{H}, \mathrm{m}), 7.67-7.61(9 \mathrm{H}, \mathrm{m})$, 7.55-7.49 (4 H, m), 2.14-1.97 (12 H, m), 1.28-1.60 (60 H, m), 0.89-0.67 (30 H, m), $\left.0.35(9 \mathrm{H}, \mathrm{s}) .{ }^{13} \mathrm{C} \mathrm{NMR} \mathrm{(CDCl}\right)$ $\delta$ (ppm): 140.91, 140.53, 140.09, 139.82, 139.75, 139.68, 139.40, 139.36, 138.71, 138.49, 131.35, 129.50, 127.16, 125.78, 125.73, 125.66,125.52, 120.99, 120.92, 120.57, 120.47, 119.49, 119.46, 118.51, 55.04, 54.84, 54.61, 39.86, 38.78, 39,65, 31.28, 29.52, 29.45, 28.70, 28.62, 23.40, 23.31, 23.27, 22.10, $13.56,-1.34$. (MALDI/TOF, $\mathrm{m} / \mathrm{z}$ ): $\left[\mathrm{M}^{+}\right.$] calcd. for $\mathrm{C}_{90} \mathrm{H}_{129} \mathrm{BrSi}: 1318.9$; found, 1318.3. Anal. calcd. for $\mathrm{C}_{90} \mathrm{H}_{129} \mathrm{BrSi}: \mathrm{C}, 81.95 ; \mathrm{H}$, 9.86, Br, 6.06; Found: C, 82.11; $\mathrm{H}, 9.75 ; \mathrm{Br}, 6.50$.

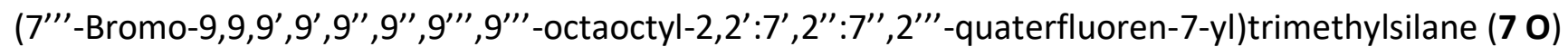

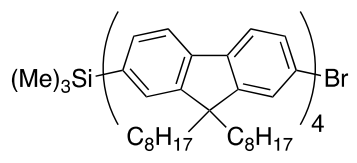

Using the general procedure $C$, the quantities used were: 2,7-dibromo-9,9-dioctylfluorene (2.4 0) (7.48 g, 13.63 $\left.10^{-3} \mathrm{~mol}\right), \mathrm{Pd}\left(\mathrm{PPh}_{3}\right)_{4}\left(158 \mathrm{mg}, 1.40 \cdot 10^{-4} \mathrm{~mol}\right)$, toluene $(60 \mathrm{~mL}), 9,9,9^{\prime}, 9^{\prime}, 9^{\prime \prime}, 9^{\prime \prime}$-hexaoctyl-7"'-trimethylsilyl- 
$2,2^{\prime}: 7^{\prime}: 2^{\prime \prime}$-terfluoren-7-ylboronic acid $\left(\mathbf{F}_{3} \mathbf{O}\right)\left(6.06 \mathrm{~g}, 4.54 \cdot 10^{-3} \mathrm{~mol}\right)$, toluene $(50 \mathrm{~mL}), \mathrm{Na}_{2} \mathrm{CO}_{3}(\mathrm{aq})(2 \mathrm{M}, 6.8 \mathrm{~mL}$, $13.63 \mathrm{mmol})$. Column chromatography eluting first with petroleum ether and then petroleum ether:toluene (30:1). The product was afforded as a creamy solid $\left(6.32 \mathrm{~g}, 3.71 \cdot 10^{-3} \mathrm{~mol}, 82 \%\right) .{ }^{1} \mathrm{H} \mathrm{NMR}\left(\mathrm{CDCl}_{3}\right) \delta(\mathrm{ppm}): 7.86-$ $7.61(20 \mathrm{H}, \mathrm{m}), 7.57-7.48(4 \mathrm{H}, \mathrm{m}), 2.19-1.96(16 \mathrm{H}, \mathrm{m}), 1.32-1.07(80 \mathrm{H}, \mathrm{m}), 0.91-0.67(40 \mathrm{H}, \mathrm{m}), 0.36(9 \mathrm{H}, \mathrm{s})$. The analysis was comparable with that from the literature. ${ }^{64}$

General procedure D: Deprotection of the trimethylsilane group of (bromooligofluorenyl)trimethylsilanes (8) 41

To a solution of (bromooligofluorenyl)trimethylsilane (TMS- $\mathbf{F}_{\mathbf{n}}-\mathbf{B r}$ ) (1 eq) in dichloromethane (16 mL per gram), $\mathrm{CF}_{3} \mathrm{COOH}(15 \mathrm{eq}$ ) was added and the mixture stirred at room temperature for $2 \mathrm{~h}$. Basic work up was carried out with water (2 times), saturated $\mathrm{NaHCO}_{3}$ solution (2 times) and final washing with water. The organic fraction was dried over anhydrous $\mathrm{MgSO}_{4}$ and filtered through a silica plug to remove polar by-products and crystallized from acetone to yield the product.

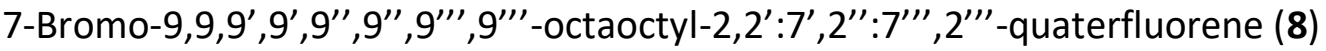

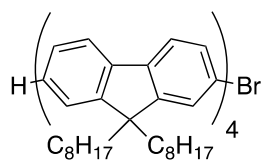

Using the general procedure $D$, the quantities used were: (7'"-bromo-9,9,9',9',9", 9', $9^{\prime \prime \prime}, 9^{\prime \prime \prime}$-octaoctyl$2,2^{\prime}: 7^{\prime}, 2^{\prime \prime}: 7^{\prime \prime}, 2^{\prime \prime \prime}$-quaterfluoren-7-yl)trimethylsilane (7 0) (2.96 g, 1.74.10-3 mol), dichloromethane (56 mL), $\mathrm{CF}_{3} \mathrm{COOH}(1.8 \mathrm{~mL})$. The product was obtained as a white crystalline solid $\left(2.74 \mathrm{~g}, 1.68 \cdot 10^{-3} \mathrm{~mol}, 96 \%\right) .{ }^{1} \mathrm{H} \mathrm{NMR}$ $\left(\mathrm{CDCl}_{3}\right) \delta$ (ppm): 7.86-7.59 (20 H, m), 7.52-7.30 (5 H, m), 2.20-1.96 (16 H, m), 1.29-1.05 (80 H, m), 0.90-0.65 (40 $\mathrm{H}, \mathrm{m}) .{ }^{13} \mathrm{C} \mathrm{NMR}\left(\mathrm{CDCl}_{3}\right) \delta(\mathrm{ppm}): 140.78,140.75,140.68,140.56,140.48,140.38,140.27,140.19,140.16$, $140.07,139.44,130.22,129.00,127.43,127.21,127.01,126.50,126.38,126.26,123.15,121.70,121.62$, $121.29,121.21,120.21,120.10,119.94,55.76,55.56,55.39,40.61,40.51,32.02,30.26,30.18,29.45,24.13$, 24.05, 23.99, 22.86, 22.80, 14.30. TOF/MALDI [M+] calcd. for $\mathrm{C}_{116} \mathrm{H}_{162} \mathrm{Br}$ 1636.4, found 1635.6. HRMS El cald. for $\mathrm{C}_{116} \mathrm{H}_{162} \mathrm{Br}$ 1634.1860, found 1634.1812.

General procedure E: Synthesis of oligofluorenylboronic acid $\left(\mathbf{F}_{\mathbf{n}}\right)^{11}$

To a solution of bromooligofluorene $(5,6,7,8,7,8,10,11,12)(1 \mathrm{eq})$ in dry tetrahydrofuran, n-BuLi (1.3 eq) was added dropwise under a $\mathrm{N}_{2}$ atmosphere at $-80^{\circ} \mathrm{C}$. The mixture was stirred at $-80{ }^{\circ} \mathrm{C}$ for 10 min and then cooled down to $-100{ }^{\circ} \mathrm{C}$. Triisopropylborate ( $3 \mathrm{eq}$ ) was added and the reaction mixture was allowed to warm up to room temperature and stirred for $18 \mathrm{~h}$. The reaction mixture was poured onto crushed ice, acidified with $\mathrm{HCl}$ to $\mathrm{pH}$ 2-3 when the TMS functionality was present or quenched with water when it was not. The mixture was then extracted with diethyl ether (4 times) and the combined organic fractions were washed with water, dried over anhydrous $\mathrm{MgSO}_{4}$ and the solvent evaporated. The residue was purified by flash chromatography on a silica gel column with elution first by toluene to remove by-products and then with diethyl ether to recover the product.

9,9,9', $9^{\prime}$-Tetrabutyl-7'-trimethylsilyl -2,2' -bifluoren-7-ylboronic acid ( $\left.\mathbf{F}_{\mathbf{2}} \mathbf{B}\right)$

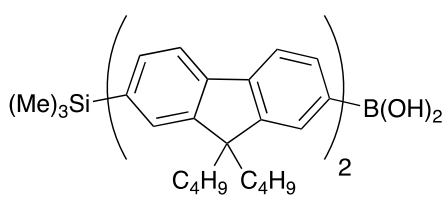


Using the general procedure $E$, the quantities used were: (7'-Bromo-9,9,9',9'-tetrabutyl-2,2'-bifluoren-7$\mathrm{yl}$ )trimethylsilane (5 B) $\left(10.41 \mathrm{~g}, 14.70 \cdot 10^{-3} \mathrm{~mol}\right)$, tetrahydrofuran $(260 \mathrm{~mL}), \mathrm{n}$-BuLi $(1.5 \mathrm{M}$ solution in $\mathrm{n}$ hexanes, $\left.11.8 \mathrm{~mL}, 17.60 \cdot 10^{-3} \mathrm{~mol}\right)$, triisopropylborate $\left(10.4 \mathrm{~mL}, 44.10 \cdot 10^{-3} \mathrm{~mol}\right)$. The product was afforded as a white foamy solid (7.99 g, 11.90·10-3 mol, 81\%). ${ }^{1} \mathrm{H} \mathrm{NMR}\left(\mathrm{CDCl}_{3}\right) \delta(\mathrm{ppm}): 8.44-8.23(2 \mathrm{H}, \mathrm{m}), 7.85-7.62(2 \mathrm{H}$, m), 7.84-7.26 (6 H, m), 7.57-7.48 (2 H, m), 2.29-1.99 (8H, m), 1.56-1.07 (8 H, m), 0.86-0.64 (20 H, m), $0.34(9 \mathrm{H}$, s). ${ }^{13} \mathrm{C} \mathrm{NMR}\left(\mathrm{CDCl}_{3}\right) \delta$ (ppm): 152.88, 152.48, 152.19, 150.89, 150.65, 145.73, 144.40, 141.88, 141.82, 140.95, $140.88,140.36,139.57,135.16,132.72,132.31,130.31,129.48,128.28,128.10,126.64,126.52,122.00$, 121.95, 121.12, 120.85, 120.50, 119.80, 119.48, 55.59, 55.51, 40.65, 40.41, 26.59, 26.54, 26.48, 23.56, 23.47, 14.29, 14.25, 14.22, -0.40. (MALDI/TOF, $m / z$ ): $\left[\mathrm{M}^{+}\right]$calcd. for $\mathrm{C}_{45} \mathrm{H}_{59} \mathrm{BO}_{2} \mathrm{Si}$ : 670.8; found, 670.9. Anal. calcd. for $\mathrm{C}_{45} \mathrm{H}_{59} \mathrm{BO}_{2} \mathrm{Si}: \mathrm{C}, 80.57 ; \mathrm{H}, 8.86$. Found: $\mathrm{C}, 81.52 ; \mathrm{H}, 8.35$.

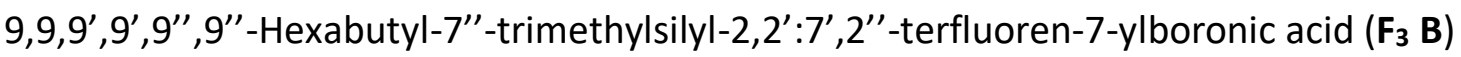

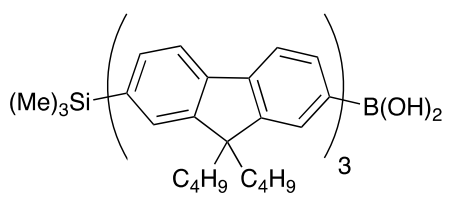

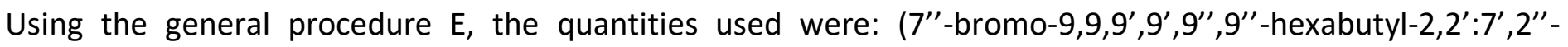
terfluoren-7-yl)trimethylsilane (6 B) $\left(6.0 \mathrm{~g}, 6.11 \cdot 10^{-3} \mathrm{~mol}\right)$, tetrahydrofuran (170 mL), n-BuLi (1.52 M solution in n-hexanes, $\left.5.2 \mathrm{~mL}, 7.94 \cdot 10^{-3} \mathrm{~mol}\right)$, triisopropylborate $\left(4.2 \mathrm{~mL}, 18.32 \cdot 10^{-3} \mathrm{~mol}\right)$. The product was afforded as a white foamy solid $\left(4.77 \mathrm{~g}, 5.04 \cdot 10^{-3} \mathrm{~mol}, 82 \%\right)$. The compound could not be properly characterised as a boronic acid because it had trapped ether in the structure. It was converted to boronic ester for characterisation purposes $\left(\mathbf{F}_{3} \mathbf{B E} \mathbf{B}\right)$.

$9,9,9^{\prime}, 9^{\prime}, 9^{\prime \prime}, 9^{\prime \prime}, 9^{\prime \prime \prime}, 9^{\prime \prime \prime}$-Octabutyl-7"''-trimehylsilyl-2,2':7',2": $7^{\prime \prime}, 2^{\prime \prime \prime}$-quaterfluoren-7-ylboronic acid $\left(\mathbf{F}_{4} \mathbf{B}\right)$

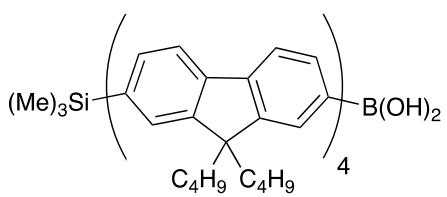

Using the general procedure $E$, the quantities used were: (7'"'-bromo-9,9,9',9',9",9", 9'", $9^{\prime \prime \prime}$-octabutyl$2,2^{\prime}: 7^{\prime}, 2^{\prime \prime}: 7^{\prime \prime}, 2^{\prime \prime \prime}$-quaterfluoren-7-yl)trimethylsilane (7 B) (0.650 g, 5.20·10-4 mol), tetrahydrofuran (170 mL), nBuLi (2.2 M solution in $n$-hexanes, $0.30 \mathrm{~mL}, 6.70 \cdot 10^{-4} \mathrm{~mol}$ ), triisopropylborate $\left(0.36 \mathrm{~mL}, 1.5 \cdot 10^{-3} \mathrm{~mol}\right)$. The product was obtained as a white foamy solid $\left(292 \mathrm{mg}, 2.40 \cdot 10^{-4} \mathrm{~mol}, 46 \%\right) .{ }^{1} \mathrm{H} \mathrm{NMR}\left(\mathrm{CDCl}_{3}\right) \delta(\mathrm{ppm}): 8.44-8.25$ $(1 \mathrm{H}, \mathrm{m})$, , 8.01-7.92 $(1 \mathrm{H}, \mathrm{m}), 7.92-7.62(20 \mathrm{H}, \mathrm{m}), 7.55-7.48(2 \mathrm{H}, \mathrm{m}), 2.26-1.20(16 \mathrm{H}, \mathrm{m}), 1.30-1.07(16 \mathrm{H}, \mathrm{m})$, 0.90-0.64 (40 H, m), $0.34(9 \mathrm{H}, \mathrm{s})$. (MALDI/TOF, $\mathrm{m} / \mathrm{z})$ : [M+] calcd. for $\mathrm{C}_{87} \mathrm{H}_{107} \mathrm{BO}_{2} \mathrm{Si}:$ 1223.7; Found: 1224.0; Anal. calcd. for $\mathrm{C}_{87} \mathrm{H}_{107} \mathrm{BO}_{2} \mathrm{Si}$ : C, 85.39; $\mathrm{H}, 8.81$; Found: $\mathrm{C}, 85.40 ; \mathrm{H}, 8.58$.

$9,9,9^{\prime}, 9^{\prime}$-Tetraoctyl-7'-trimethylsilyl-2,2'-bifluoren-7-boronic acid $\left(\mathbf{F}_{\mathbf{2}} \mathbf{O}\right)$

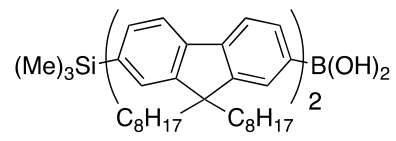

Using the general procedure $E$, the quantities used were: (7'-bromo-9,9,9', 9' -tetraoctyl-2,2'-bifluoren-7$\mathrm{yl}$ )trimethylsilane $(\mathbf{5} \mathbf{0})\left(8.96 \mathrm{~g}, 9.62 \cdot 10^{-3} \mathrm{~mol}\right)$, tetrahydrofuran $(100 \mathrm{~mL}), \mathrm{n}$-BuLi $(1.95 \mathrm{M}$ solution in $\mathrm{n}$-hexanes, $6.41 \mathrm{~mL}, 12.51 \cdot 10^{-3} \mathrm{~mol}$, triisopropylborate $\left(6.7 \mathrm{~mL}, 28.86 \cdot 10^{-3} \mathrm{~mol}\right)$. The product was afforded as a white 
foamy solid $\left(5.94 \mathrm{~g}, 6.63 \cdot 10^{-3} \mathrm{~mol}, 69 \%\right) .{ }^{1} \mathrm{H}$ NMR $\left(\mathrm{CDCl}_{3}\right) \delta(\mathrm{ppm}): 8.38(1 \mathrm{H}, \mathrm{d}, J=7.6 \mathrm{~Hz}), 7.96(1 \mathrm{H}, \mathrm{d}, J=7.6$ $\mathrm{Hz}), 7.93(1 \mathrm{H}, \mathrm{d}, J=8.0 \mathrm{~Hz}), 7.84(1 \mathrm{H}, \mathrm{d}, J=7.6 \mathrm{~Hz}), 7.77-7.68(6 \mathrm{H}, \mathrm{m}), 7.56-7.93(2 \mathrm{H}, \mathrm{d}, J=8.8 \mathrm{~Hz}), 2.30-2.04$ $(8 \mathrm{H}, \mathrm{m}), 1.26-1.07(40 \mathrm{H}, \mathrm{m}), 0.88-0.75(20 \mathrm{H}, \mathrm{m}), 0.36(9 \mathrm{H}, \mathrm{s})$. The analysis was comparable with that from the literature. ${ }^{64}$

$9,9,9^{\prime}, 9^{\prime}, 9^{\prime \prime}, 9^{\prime \prime}$-Hexaoctyl-7"'-trimethylsilyl-2,2':7',2'"-terfluoren-7-ylboronic acid ( $\left.\mathbf{F}_{3} \mathbf{O}\right)$

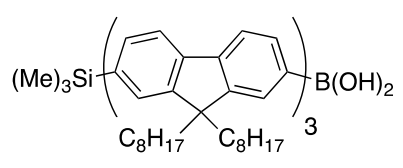

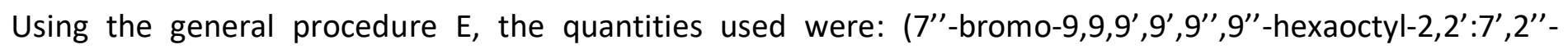
terfluoren-7-yl)trimethylsilane (6 0) $\left(8 \mathrm{~g}, 5.73 \cdot 10^{-3} \mathrm{~mol}\right)$, tetrahydrofuran $(170 \mathrm{~mL}), \mathrm{n}$-BuLi $(2.39 \mathrm{M}$ solution in n-hexanes, $\left.3.11 \mathrm{~mL}, 7.45 \cdot 10^{-3} \mathrm{~mol}\right)$, triisopropylborate $\left(4 \mathrm{~mL}, 17.85 \cdot 10^{-3} \mathrm{~mol}\right)$. The product was obtained as a white foamy solid $\left(1.61 \mathrm{~g}, 1.33 \cdot 10^{-3} \mathrm{~mol}, 98 \%\right) .{ }^{1} \mathrm{H}$ NMR $\left(\mathrm{CDCl}_{3}\right) \delta(\mathrm{ppm}): 8.41-8.15(2 \mathrm{H}, \mathrm{m}), 8.00-7.64(14 \mathrm{H}$, m), 7.57-7.51 (2 H, m), 2.31-2.00 (12 H, m), 1.32-1.07 (60 H, m), 0.92-0.70 (30 H, m), 0.36 (9 H, s). ${ }^{13} \mathrm{C} \mathrm{NMR}$ $\left(\mathrm{CDCl}_{3}\right) \delta(\mathrm{ppm}):$ 150. 47, 145.59, 141.77, 141.71, 140.90, 140.67, 140.61, 140.50, 140.23, 139.27, 136.07, $135.03,132.13,130.07,127.95,126.53,126.47,126.32,125.81,121.86,121.80,120.95,120.27,119.64$, 119.29, 55.65, 55.53, 55.40, 40.68, 40.44, 32.08, 30.62, 30.38, 30.33, 30.23, 29.51, 29.45, 29.41, 24.22, 24.11, 22.90, 14.41, 14.35. (MALDI/TOF, $m / z)$ : calcd. for $\mathrm{C}_{90} \mathrm{H}_{131} \mathrm{BO}_{2} \mathrm{Si}-\mathrm{BOH}: 1238.9$; Found: $1238.5\left(\left[\mathrm{M}-\mathrm{B}(\mathrm{OH})_{2}\right]^{+}\right)$. Anal. calcd. for $\mathrm{C}_{90} \mathrm{H}_{131} \mathrm{BO}_{2} \mathrm{Si}$ : C, 84.19; $\mathrm{H}, 10.28$; Found: $\mathrm{C}, 83.90 ; \mathrm{H}, 10.14$.

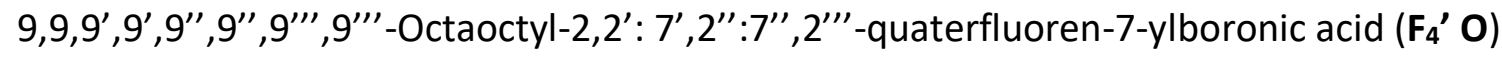

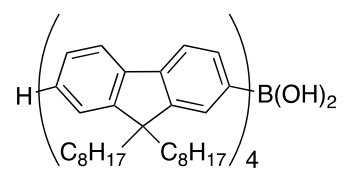

Using the general procedure $E$, the quantities used were: 7-bromo-9,9,9',9',9', 9', $9^{\prime \prime \prime}, 9^{\prime \prime \prime}$-octaoctyl-2,2': $7^{\prime}, 2^{\prime \prime}: 7^{\prime \prime}, 2^{\prime \prime \prime}$-quaterfluorene $(8 \mathrm{0})$ (406 mg, 2.50·10-4 mol), tetrahydrofuran ( $6 \mathrm{~mL}$ ), n-BuLi (2.45 M solution in $\mathrm{n}$ hexanes, $\left.0.15 \mathrm{~mL}, 3.20 \cdot 10^{-4} \mathrm{~mol}\right)$, triisopropylborate $\left(0.20 \mathrm{~mL}, 7.50 \cdot 10^{-4} \mathrm{~mol}\right)$. The product was obtained as a white foamy solid (370 mg, 2.30·10-4 mol, 73\%). ${ }^{1} \mathrm{H} \mathrm{NMR}\left(\mathrm{CDCl}_{3}\right) \delta(\mathrm{ppm}): 8.39(1 \mathrm{H}, \mathrm{d}, J=8.0 \mathrm{~Hz}), 8.31(1 \mathrm{H}, \mathrm{s})$, 8.10-7.62 $(20 \mathrm{H}, \mathrm{m}), 7.41-7.30(3 \mathrm{H}, \mathrm{m}), 2.32-1.98(16 \mathrm{H}, \mathrm{m}), 1.28-1.02(80 \mathrm{H}, \mathrm{m}), 0.92-0.67(40 \mathrm{H}, \mathrm{m}) .{ }^{13} \mathrm{C} \mathrm{NMR}$ $\left(\mathrm{CDCl}_{3}\right) \delta(\mathrm{ppm}): 125.90,39.87,31.29,29.54,28.71,23.44,22.10,13.55$. (MALDI/TOF, $\mathrm{m} / \mathrm{z}$ ): $\left[\mathrm{M}^{+}\right]$calcd. for $\mathrm{C}_{116} \mathrm{H}_{163} \mathrm{BO}_{2}$ : 1600.4; found, 1601.0; Anal. calcd. for $\mathrm{C}_{116} \mathrm{H}_{163} \mathrm{BO}_{2}$ : C, 87.06; $\mathrm{H}, 10.27$; Found: C, 87.32; $\mathrm{H}, 10.20$. $9,9,9^{\prime}, 9^{\prime}, 9^{\prime \prime}, 9^{\prime \prime}, 9^{\prime \prime \prime}, 9^{\prime \prime \prime}$-Octaoctyl-7'"'-trimethylsilyl-2,2':7',2':7", 2'"'-quaterfluoren-7-ylboronic acid $\left(\mathbf{F}_{4} \mathbf{O}\right)$

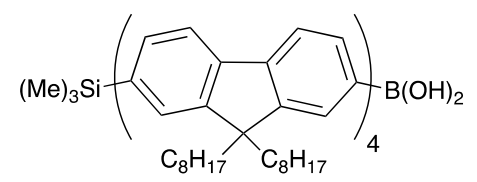

Using the general procedure $E$, the quantities used were: (7"'-bromo-9,9,9',9',9",9", 9'", 9'"'-octaoctyl$2,2^{\prime}: 7^{\prime}, 2^{\prime \prime}: 7^{\prime \prime}, 2^{\prime \prime \prime}$-quaterfluoren-7-yl)trimethylsilane (7 0) (1.50 g, 9.20.10-4 mol), tetrahydrofuran (40 mL), nBuLi (2.5 M solution in $n$-hexanes, $\left.0.44 \mathrm{~mL}, 1.10 \cdot 10^{-3} \mathrm{~mol}\right)$, triisopropylborate $\left(0.65 \mathrm{~mL}, 2.74 \cdot 10^{-3} \mathrm{~mol}\right)$. The

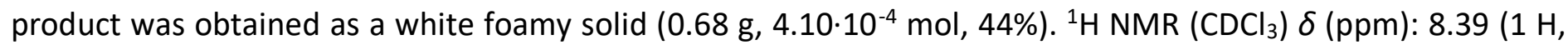
$\mathrm{d}, J=8.0 \mathrm{~Hz}), 8.30(1 \mathrm{H}, \mathrm{s}), 8.10-7.60(20 \mathrm{H}, \mathrm{m}), 7.55-7.48(2 \mathrm{H}, \mathrm{m}), 2.29-1.98(16 \mathrm{H}, \mathrm{m}), 1.32-1.04(80 \mathrm{H}, \mathrm{m})$, 
0.93-0.66 (40 H, m), $0.34(9 \mathrm{H}, \mathrm{s}) .{ }^{13} \mathrm{C} \mathrm{NMR}\left(\mathrm{CDCl}_{3}\right) \delta(\mathrm{ppm}): 125.80,125.70,121.10,121.00,119.60,119.50$, 109.50, 108.90, 103.70, 48.50, 39.90, 31.27, 29.43, 27.70, 23.40, 23.20, 22.08, 13.54.

General procedure F: Synthesis of oligofluorenylboronic ester ( $\left.\mathbf{F}_{3} \mathbf{B E} \mathbf{B}, \mathbf{F}_{4}{ }^{\prime} \mathbf{B E} \mathbf{O}\right)$

9,9-Dialkyl-oligofluorenylboronic acid $\left(\mathbf{F}_{n}-\mathbf{B}(\mathbf{O H})_{2}\right.$ and $\left.\mathbf{T M S}-\mathbf{F}_{\mathbf{n}}-\mathbf{B}(\mathbf{O H})_{2}\right)(1 \mathrm{eq})$ and a diol $(1.2 \mathrm{eq})$ were dissolved in dry toluene $(10 \mathrm{~mL})$ and the mixture was stirred at $120{ }^{\circ} \mathrm{C}$ for $18 \mathrm{~h}$. Solvent evaporation yielded the white foamy product.

(9,9,9', 9', 9"',9'--Hexabutyl-7"'-(4,4,5,5-tetramethyl-1,3,2-dioxaborolan-2-yl)-9H,9' H,9"H-[2,2':7',2"'-terfluoren]7-yl)trimethylsilane $\left(F_{3} B E B\right)$

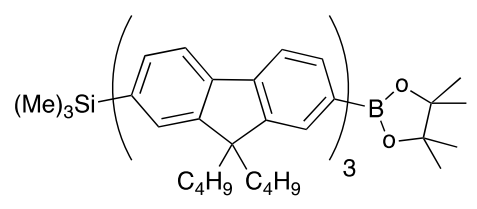

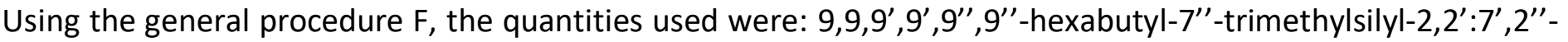
terfluoren-7-ylboronic acid ( $\left.\mathbf{F}_{3} \mathbf{B}\right)\left(300 \mathrm{mg}, 3.20 \cdot 10^{-4} \mathrm{~mol}\right)$, pinacol $\left(45 \mathrm{mg}, 3.80 \cdot 10^{-4} \mathrm{~mol}\right)$, toluene $(10 \mathrm{~mL})$. White foamy product $\left(0.31 \mathrm{~g}, 2.99 \cdot 10^{-4} \mathrm{~mol}, 94 \%\right) .{ }^{1} \mathrm{H} \mathrm{NMR}\left(\mathrm{CDCl}_{3}\right) \delta(\mathrm{ppm}):$ 7.88-7.64 (16 H, m), 7.57-7.49 (2 $\mathrm{H}, \mathrm{m}), 2.20-2.00(12 \mathrm{H}, \mathrm{m}), 1.42(12 \mathrm{H}, \mathrm{s}), 1.21-1.08(12 \mathrm{H}, \mathrm{m}), 0.86-0.65(30 \mathrm{H}, \mathrm{m}), 0.36(9 \mathrm{H}, \mathrm{s}) .{ }^{13} \mathrm{C} \mathrm{NMR}$ $\left(\mathrm{CDCl}_{3}\right) \delta(\mathrm{ppm}): 152.46,152.15,152.04,144.16,141.77,141.26,140.87,140.82,140.74,140.68,140.52$, $140.43,140.33,138.38,134.18,132.20,129.24,127.98,126.46,126.33,121.82,120.71,120.37,120.32$, 119.40, 119.35, 84.09, 55.60, 55.53, 55.38, 40.57, 40.49, 40.33, 26.47, 26.42, 26.35, 25.31, 23.44, 23.38, 14.19, 14.13, -0.48. (MALDI/TOF, $m / z$ ): $\left[\mathrm{M}^{+}\right.$] calcd. for $\mathrm{C}_{72} \mathrm{H}_{93} \mathrm{BO}_{2} \mathrm{Si}$ : 1029.4; Found: 1029.5; Exact mass calcd. for $\mathrm{C}_{72} \mathrm{H}_{93} \mathrm{BO}_{2} \mathrm{Si}: 1028.7047$; Found: 1028.7044.

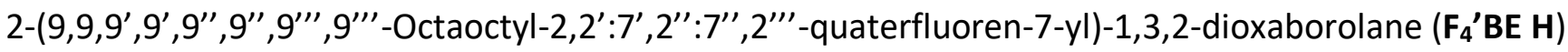

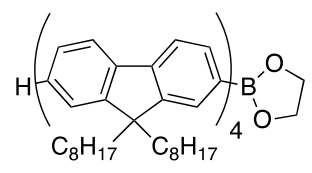

Using the general procedure $F$, the quantities used were: $9,9,9^{\prime}, 9^{\prime}, 9^{\prime \prime}, 9^{\prime \prime}, 9^{\prime \prime \prime}, 9^{\prime \prime \prime}$-octaoctyl-2,2':7', $2^{\prime \prime}: 7^{\prime \prime}, 2^{\prime \prime \prime}$ quaterfluoren-7-ylboronic acid $\left(\mathbf{F}_{4}{ }^{\prime} \mathbf{O}\right)\left(0.18 \mathrm{~g}, 1.11 \cdot 10^{-4} \mathrm{~mol}\right)$, ethyleneglycol $\left(0.07 \mathrm{~mL}, 1.33 \cdot 10^{-4} \mathrm{~mol}\right)$, toluene $(30 \mathrm{~mL})$. White foamy product $\left(172 \mathrm{mg}, 1.06 \cdot 10^{-4} \mathrm{~mol}, 95 \%\right) .{ }^{1} \mathrm{H} \mathrm{NMR}\left(\mathrm{CDCl}_{3}\right) \delta(\mathrm{ppm}): 8.45-8.27(1 \mathrm{H}, \mathrm{m}), 8.00-$ $7.62(21 \mathrm{H}, \mathrm{m}), 7.42-7.31(3 \mathrm{H}, \mathrm{m}), 4.45(2 \mathrm{H}, \mathrm{s}), 2.27-1.97(16 \mathrm{H}, \mathrm{m}), 1.54(2 \mathrm{H}, \mathrm{s}), 1.25-1.06(80 \mathrm{H}, \mathrm{m}), 0.91-$ $0.66(40 \mathrm{H}, \mathrm{m}) .{ }^{13} \mathrm{C} \mathrm{NMR}\left(\mathrm{CDCl}_{3}\right) \delta(\mathrm{ppm}): 151.85,151.52,151.05,150.33,141.20,140.85,140.58,140.06$, 133.85, 129.12, 127.02, 126.82, 126.20, 125.56, 122.97, 121.54, 120.46, 120.00, 119.75, 119.44, 66.09, 55.38,

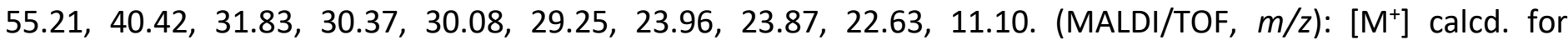
$\mathrm{C}_{118} \mathrm{H}_{165} \mathrm{BO}_{2}$ : 1626.4; found, 1626.5; Anal. calcd. for $\mathrm{C}_{118} \mathrm{H}_{165} \mathrm{BO}_{2}: \mathrm{C}, 87.14 ; \mathrm{H}, 10.23$; Found: $\mathrm{C}, 86.75 ; \mathrm{H}, 10.47$. 10,15-Dihydro-5H-diindeno[1,2- $\left.a ; 1^{\prime}, 2^{\prime}-c\right]$ fluorene] (1)

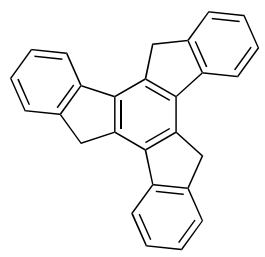


1-Indanone (13.6 g, $104 \mathrm{mmol})$ was added to a mixture of acetic acid $(60 \mathrm{~mL})$ and concentrated hydrochloric acid $(30 \mathrm{~mL})$. The solution was stirred for $16 \mathrm{~h}$ at $100^{\circ} \mathrm{C}$, then poured onto ice. The precipitate was washed with water, acetone and dichloromethane to yield a white powder $(9.73 \mathrm{~g}, 28.4 \mathrm{mmol}, 80 \%) .{ }^{1} \mathrm{H} \mathrm{NMR}\left(\mathrm{CDCl}_{3}\right) \delta$ (ppm): $7.97(3 \mathrm{H}, \mathrm{d}, J=7.2 \mathrm{~Hz}), 7.70(3 \mathrm{H}, \mathrm{d}, J=7.6 \mathrm{~Hz}), 7.51(3 \mathrm{H}, \mathrm{t}, J=7.6 \mathrm{~Hz}), 7.40(3 \mathrm{H}, \mathrm{t}, J=7.6 \mathrm{~Hz}), 4.29(6$ $\mathrm{H}, \mathrm{s})$. The analysis was comparable with that from the literature. ${ }^{15}$

General procedure G: Synthesis of hexaalkyltruxene (TO B, TO H) ${ }^{11}$

To a stirred suspension of truxene (1) (1 eq) in tetrahydrofuran (5.4 mL per gram) under nitrogen, n-BuLi (3.8 eq) was added dropwise at $0^{\circ} \mathrm{C}$ over $30 \mathrm{~min}$, not allowing the temperature to rise over $15^{\circ} \mathrm{C}$. The solid was dissolved and the colour changed to deep red. The solution was stirred at room temperature for $30 \mathrm{~min}$ and 1 bromoalkane $\left(3.8 \mathrm{eq}\right.$ ) was added over $10 \mathrm{~min}$ at $0^{\circ} \mathrm{C}$. The mixture was stirred at room temperature for $4 \mathrm{~h}$ and a second portion of BuLi (3.8 eq) was added dropwise at $0^{\circ} \mathrm{C}$ over $30 \mathrm{~min}$. After $30 \mathrm{~min}$ stirring at room temperature, 1-bromoalkane $(3.8 \mathrm{eq})$ was added over $10 \mathrm{~min}$ at $0^{\circ} \mathrm{C}$ and the reaction mixture was stirred at room temperature for $18 \mathrm{~h}$ (TLC monitoring). Upon reaction completion, it was quenched with saturated aqueous ammonium chloride and extracted with petroleum ether (5 times). The combined organic fractions were washed with water, dried over anhydrous $\mathrm{MgSO}_{4}$, and the solvent evaporated. The material was purified by column chromatography on silica gel, eluting with petroleum ether to yield the product.

Hexabutyltruxene TO B

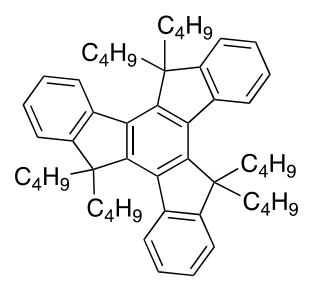

Using the general procedure $\mathrm{G}$, the quantities used were: truxene (1) $\left(3.19 \mathrm{~g}, 9.31 \cdot 10^{-3} \mathrm{~mol}\right)$, tetrahydrofuran $(50 \mathrm{~mL})$, n-BuLi (1.6 M solution in n-hexane, $\left.22 \mathrm{~mL}, 35.2 \cdot 10^{-3} \mathrm{~mol} x 2\right)$, 1-bromobutane $\left(3.8 \mathrm{~mL}, 35.6 \cdot 10^{-3} \mathrm{~mol} x\right.$ 2). The product was obtained as a yellow powder $\left(5.29 \mathrm{~g}, 7.73 \cdot 10^{-3} \mathrm{~mol}, 84 \%\right) .{ }^{1} \mathrm{H} \mathrm{NMR}\left(\mathrm{CDCl}_{3}\right) \delta(\mathrm{ppm}): 8.39(3$ $\mathrm{H}, \mathrm{d}, J=7.2 \mathrm{~Hz}), 7.49(3 \mathrm{H}, \mathrm{d}, J=7.0 \mathrm{~Hz}), 7.45-7.35(6 \mathrm{H}, \mathrm{m}), 3.01-3.00(6 \mathrm{H}, \mathrm{m}), 2.15-2.05(6 \mathrm{H}, \mathrm{m}), 0.94-0.86$ $(12 \mathrm{H}, \mathrm{m}), 0.47-0.30(30 \mathrm{H}, \mathrm{t}, J=7.6 \mathrm{~Hz})$. The analysis was comparable with that from the literature. ${ }^{65}$ Hexaoctyltruxene (T0 O)

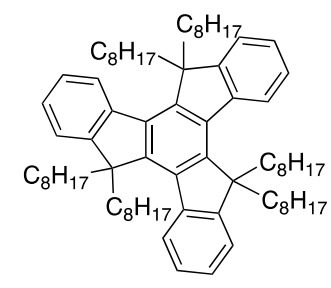

Using the general procedure $\mathrm{G}$, the quantities used were: truxene (1) $\left(3.19 \mathrm{~g}, 9.31 \cdot 10^{-3} \mathrm{~mol}\right)$, tetrahydrofuran $\left(50 \mathrm{~mL}\right.$ ), n-BuLi (1.6 M solution in $\mathrm{n}$-hexane, $\left.22 \mathrm{~mL}, 35.2 \cdot 10^{-3} \mathrm{~mol} \times 2\right)$, 1-bromooctane $\left(6.3 \mathrm{~mL}, 35.6 \cdot 10^{-3} \mathrm{~mol} x\right.$ 2). The product was obtained as a yellow solid $\left(7.67 \mathrm{~g}, 7.57 \cdot 10^{-3} \mathrm{~mol}, 81 \%\right) .{ }^{1} \mathrm{H} \mathrm{NMR}\left(\mathrm{CDCl}_{3}\right) \delta(\mathrm{ppm}): 8.36(3 \mathrm{H}$, $\mathrm{d}, J=8.0 \mathrm{~Hz}), 7.47(3 \mathrm{H}, \mathrm{d}, J=8.0 \mathrm{~Hz}), 7.41-7.34(6 \mathrm{H}, \mathrm{m}), 2.99-2.92(6 \mathrm{H}, \mathrm{m}), 2.11-2.04(6 \mathrm{H}, \mathrm{m}), 1.08-0.85(60$ $\mathrm{H}, \mathrm{m}), 0.74(18 \mathrm{H}, \mathrm{t}, J=8.0 \mathrm{~Hz}), 0.52-0.49(12 \mathrm{H}, \mathrm{m}) .{ }^{13} \mathrm{C} \mathrm{NMR}\left(\mathrm{CDCl}_{3}\right) \delta(\mathrm{ppm}): 153.15,144.53,139.85,137.82$, $125.79,125.44,124.12,121.67,55.05,36.37,31.30,29.36,28.76,28.58,23.47,22.02$, 13.53. (MALDI/TOF, 
m/z): $\left[\mathrm{M}^{+}\right]$calcd for $\mathrm{C}_{75} \mathrm{H}_{114}$ 1015.0; found 1015.0. Anal. calcd. for $\mathrm{C}_{75} \mathrm{H}_{114}: \mathrm{C}, 88.69 ; \mathrm{H}, 11.31$. Found: $\mathrm{C}, 89.18$; $\mathrm{H}, 11.53$.

General procedure H: Synthesis of tribromohexaalkyltruxene (2 B, 2 0) ${ }^{11}$

Bromine (5.3 eq) was added to a stirred solution of hexaalkyltruxene (T0) (1 eq) in dichloromethane (10 mL per gram) over $5 \mathrm{~min}$ at room temperature and under protection from light. After $12 \mathrm{~h}$ stirring, excess bromine was removed by bubbling $\mathrm{N}_{2}$ through the solution and washing the reaction mixture with a cold aqueous solution of $\mathrm{Na}_{2} \mathrm{SO}_{3}$. The mixture was extracted with dichloromethane (5 times), washed with aqueous sodium carbonate solution and then with water. The combined organic fractions were washed with water, dried over anhydrous $\mathrm{MgSO}_{4}$ and treated with activated carbon to remove the red color. The solvent was evaporated to afford the crude product, that was recrystallized from hexane.

Tribromohexabutyltruxene (2 B)

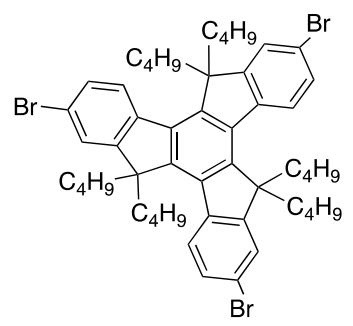

Using the general procedure $\mathrm{H}$, the quantities used were: bromine $\left(2 \mathrm{~mL}, 41.4 \cdot 10^{-3} \mathrm{~mol}\right.$ ), hexabutyltruxene (T0 B) $\left(5.13 \mathrm{~g}, 7.50 \cdot 10^{-3} \mathrm{~mol}\right)$, dichloromethane $(50 \mathrm{~mL})$. The product was obtained as a white-yellowish crystalline solid was obtained $\left(5.11 \mathrm{~g}, 5.55 \cdot 10^{-3} \mathrm{~mol}, 74 \%\right) .{ }^{1} \mathrm{H} \mathrm{NMR}\left(\mathrm{CDCl}_{3}\right) \delta(\mathrm{ppm}): 8.20(3 \mathrm{H}, \mathrm{d}, \mathrm{J}=8.0 \mathrm{~Hz}), 7.58(3 \mathrm{H}, \mathrm{s})$, $7.53(3 \mathrm{H}, \mathrm{d}, J=8.0 \mathrm{~Hz}), 2.91-2.84(6 \mathrm{H}, \mathrm{m}), 2.08-2.01(6 \mathrm{H}, \mathrm{m}), 0.99-0.84(12 \mathrm{H}, \mathrm{m}), 0.55(30 \mathrm{H}, \mathrm{m})$. (MALDI/TOF, $m / z$ ): $\left[\mathrm{M}^{+}\right.$] calcd. for $\mathrm{C}_{51} \mathrm{H}_{63} \mathrm{Br}_{3}$ 915.8; found 916.6. Anal. calcd. for $\mathrm{C}_{51} \mathrm{H}_{63} \mathrm{Br}_{3}: \mathrm{C}, 66.89 ; \mathrm{H}, 6.93, \mathrm{Br}$, 26.18. Found: $\mathrm{C}, 67.25 ; \mathrm{H}, 7.02, \mathrm{Br}, 26.62$. The analysis was comparable with that from the literature. ${ }^{65}$ Tribromohexaoctyltruxene (2 0)

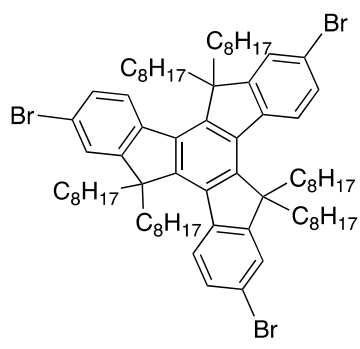

Using the general procedure $\mathrm{H}$, the quantities used were: bromine $\left(2.2 \mathrm{~mL}, 47.8 \cdot 10^{-3} \mathrm{~mol}\right)$, hexaoctyltruxene (T0 0) $\left(7.47 \mathrm{~g}, 7.36 \cdot 10^{-3} \mathrm{~mol}\right)$, dichloromethane $(50 \mathrm{~mL})$. The product was obtained as a white crystalline solid was obtained $\left(8.04 \mathrm{~g}, 6.43 \cdot 10^{-3} \mathrm{~mol}, 87 \%\right) .{ }^{1} \mathrm{H} \mathrm{NMR}\left(\mathrm{CDCl}_{3}\right) \delta(\mathrm{ppm}): 8.19(3 \mathrm{H}, \mathrm{d}, J=8.0 \mathrm{~Hz}), 7.58(3 \mathrm{H}, \mathrm{d}, J=6.0$ $\mathrm{Hz}), 7.52(3 \mathrm{H}, \mathrm{d}, J=8.0 \mathrm{~Hz}), 2.88-2.80(6 \mathrm{H}, \mathrm{m}), 2.06-1.98(6 \mathrm{H}, \mathrm{m}), 1.12-0.85(60 \mathrm{H}, \mathrm{m}), 0.76(18 \mathrm{H}, \mathrm{t}, J=8.0$ $\mathrm{Hz}), 0.38-0.58(12 \mathrm{H}, \mathrm{m}) .{ }^{13} \mathrm{C} \mathrm{NMR}\left(\mathrm{CDCl}_{3}\right) \delta$ (ppm): 36.72, 31.78, 29.68, 29.18, 29.02, 14.04. (MALDI/TOF, $\left.m / z\right)$ : $\left[\mathrm{M}^{+}\right]$calcd. for $\mathrm{C}_{75} \mathrm{H}_{111} \mathrm{Br}_{3}$ 1252.4; found, 1251.9. Anal. calcd. for $\mathrm{C}_{75} \mathrm{H}_{111} \mathrm{Br}_{3}: \mathrm{C}, 71.93 ; \mathrm{H}, 8.93, \mathrm{Br} ;$ 19.40. Found: C, 71.93; H, 9.02; Br, 19.23. 
General procedure I: Synthesis of Tris(trimethylsilyloligofluorenyl)truxene (TnTMS) by Suzuki cross-coupling (T1TMS, T2TMS, T3TMS, T4TMS (B, O) $)^{41}$

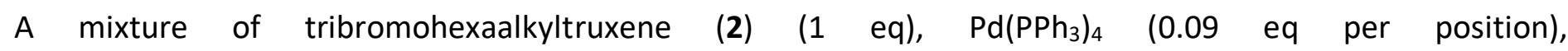
trimethylsilyloligofluorenylboronic acid $\left(\mathrm{F}_{\mathrm{n}}\right)$ (1.6 eq per position) and $\mathrm{Ba}(\mathrm{OH})_{2} \cdot 8 \mathrm{H}_{2} \mathrm{O}(1.5$ eq per boronic acid functionality) was dissolved in anhydrous tetrahydrofuran or dimethoxyethane. The solution was degassed with $\mathrm{N}_{2}$, followed by the addition of water and the system was stirred under $\mathrm{N}_{2}$ at $70^{\circ} \mathrm{C}$ for $18 \mathrm{~h}$. The reaction was quenched with a saturated aqueous solution of $\mathrm{NH}_{4} \mathrm{Cl}$ and extracted with dichloromethane (5 times). The combined organic fractions were washed with water and dried over anhydrous $\mathrm{MgSO}_{4}$. The crude product was purified by column chromatography on silica gel eluting with petroleum ether:dichloromethane, to recover a colorless oil that was dissolved in the minimum amount of dichloromethane and reprecipitated from methanol to yield the product as a white solid.

Tris(7-trimethylsilylfluoren-2-yl)truxene (butyl) (T1TMS B)

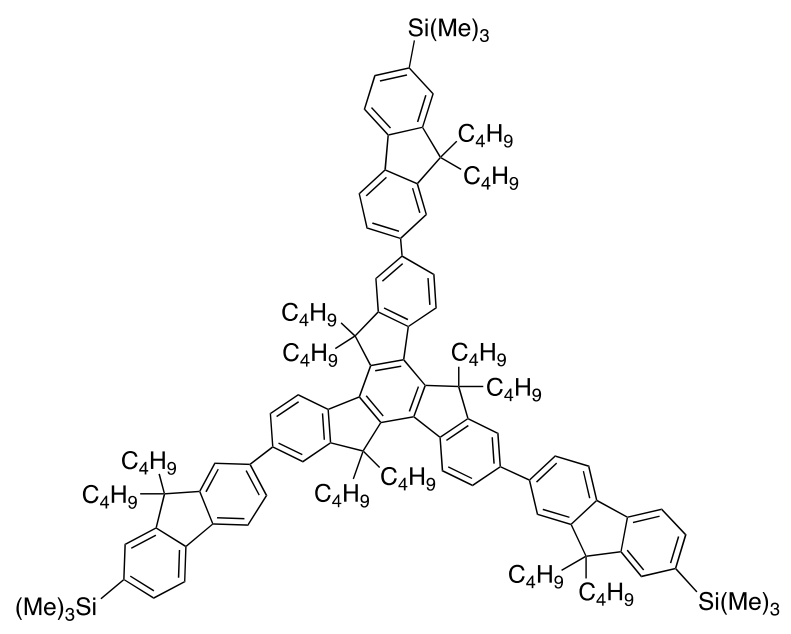

Using the general procedure I, the quantities used were: tribromohexabutyltruxene (2 B) (504 mg, 5.50·10-4 $\mathrm{mol}), \mathrm{Pd}\left(\mathrm{PPh}_{3}\right)_{4}\left(165 \mathrm{mg}, 1.40 \cdot 10^{-4} \mathrm{~mol}\right), 9,9$-dibutyl-7-trimethylsilylfluoren-2-ylboronic acid $\left(\mathbf{F}_{\mathbf{1}} \mathbf{B}\right)(1.04 \mathrm{~g}$, $\left.2.62 \cdot 10^{-3} \mathrm{~mol}\right), \mathrm{Ba}(\mathrm{OH})_{2} \cdot 8 \mathrm{H}_{2} \mathrm{O}\left(1.31 \mathrm{~g}, 4.02 \cdot 10^{-3} \mathrm{~mol}\right)$, tetrahydrofuran $(25 \mathrm{~mL})$, water $(2.25 \mathrm{~mL})$. Column chromatography eluting with petroleum ether:dichloromethane (20:1). The product was obtained as a white solid (640 mg, 4.24.10-4 mol, 77\%). The product was used without further purification.

Tris(7'-trimethylsilyl-2,2'-bifluoren-7-yl)truxene (butyl) (T2TMS B)

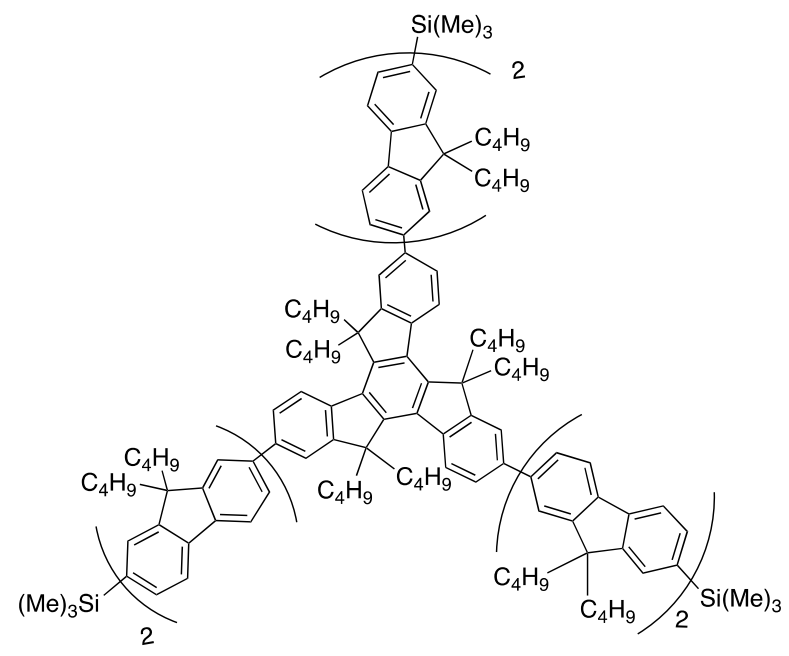


Using the general procedure I, the quantities used were: tribromohexabutyltruxene (2 B) $\left(343 \mathrm{mg}, 3.75 \cdot 10^{-4}\right.$ mol), $\mathrm{Pd}\left(\mathrm{PPh}_{3}\right)_{4}\left(113 \mathrm{mg}, 9.8 \cdot 10^{-5} \mathrm{~mol}\right), 9,9,9^{\prime}, 9^{\prime}$-tetrabutyl-7'-trimethylsilyl-2,2'-bifluoren-7-ylboronic acid ( $\mathbf{F}_{\mathbf{2}}$ B) $\left(1.20 \mathrm{~g}, 1.79 \cdot 10^{-3} \mathrm{~mol}\right), \mathrm{Ba}(\mathrm{OH})_{2} \cdot 8 \mathrm{H}_{2} \mathrm{O}\left(0.89 \mathrm{~g}, 2.74 \cdot 10^{-3} \mathrm{~mol}\right)$, tetrahydrofuran $(18 \mathrm{~mL})$, water $(1.6 \mathrm{~mL})$. Column chromatography eluting with petroleum ether:toluene $(20: 1)$, increasing the polarity gradually until petroleum ether:toluene (6:1). The product was obtained as a creamy solid (902 mg, $\left.3.53 \cdot 10^{-4} \mathrm{~mol}, 94 \%\right) .{ }^{1} \mathrm{H}$ $\operatorname{NMR}\left(\mathrm{CDCl}_{3}\right) \delta(\mathrm{ppm}): 8.55(3 \mathrm{H}, \mathrm{d}, J=8.4 \mathrm{~Hz}), 7.93-7.76(21 \mathrm{H}, \mathrm{m}), 7.78-7.64,(15 \mathrm{H}, \mathrm{m}), 7.58-7.48(6 \mathrm{H}, \mathrm{m})$, 3.22-3.03 (6 H, b.s.), 2.39-1.98 (30 H, m), 1.24-1.10 (24 H, m), 1.07-0.93 (16 H, m), 0.90-0.60 (68 H, m), $0.53(18$ $\mathrm{H}, \mathrm{t}, J=7.2 \mathrm{~Hz}$ ), $0.36(27 \mathrm{H}, \mathrm{s})$. (MALDI/TOF, $\mathrm{m} / \mathrm{z}):$ : $\left[\mathrm{M}^{+}\right]$calcd. for $\mathrm{C}_{186} \mathrm{H}_{234} \mathrm{Si}_{3}: 2554.1$; found, 2554.2. Anal. calcd. for $\mathrm{C}_{186} \mathrm{H}_{234} \mathrm{Si}_{3}: \mathrm{C}, 87.47 ; \mathrm{H}, 9.23$. Found: $\mathrm{C}, 85.60 ; \mathrm{H}, 8.54$.

Tris(7"'-trimethylsilyl-2,2':7',2'"-terfluoren-7-yl)truxene (butyl) (T3TMS B)

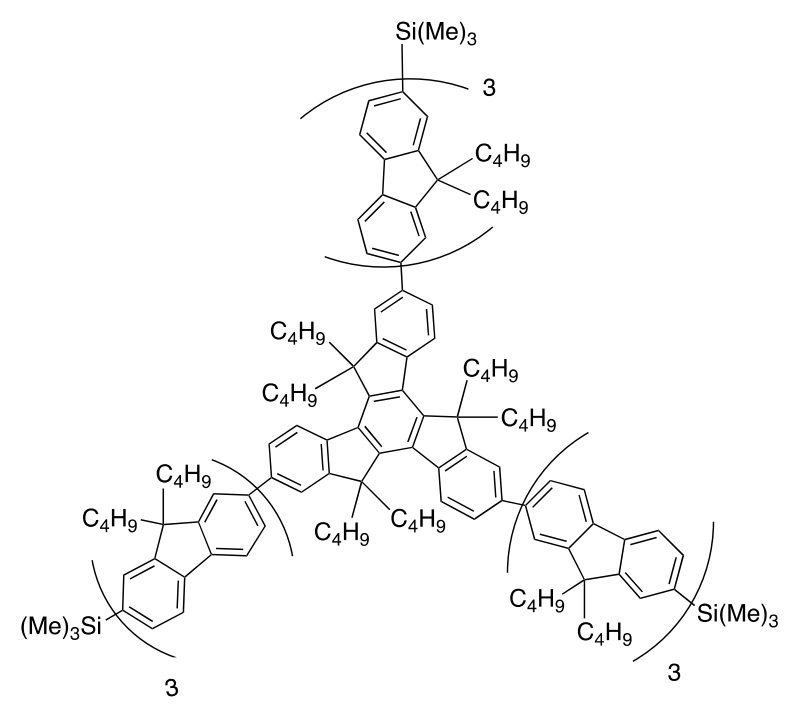

Using the general procedure I, the quantities used were: tribromohexabutyltruxene (2 B) $\left(279 \mathrm{mg}, 3.14 \cdot 10^{-4}\right.$ mol), $\mathrm{Pd}\left(\mathrm{PPh}_{3}\right)_{4}\left(99 \mathrm{mg}, 8.50 \cdot 10^{-5} \mathrm{~mol}\right), 9,9,9^{\prime}, 9^{\prime}, 9^{\prime \prime}, 9^{\prime \prime}$-hexabutyl-7''-trimethylsilyl-2,2':7',2"'-terfluoren-7ylboronic acid $\left(\mathbf{F}_{3} \mathbf{B}\right)\left(1.42 \mathrm{~g}, 1.50 \cdot 10^{-3} \mathrm{~mol}\right), \mathrm{Ba}(\mathrm{OH})_{2} \cdot 8 \mathrm{H}_{2} \mathrm{O}\left(746 \mathrm{mg}, 2.29 \cdot 10^{-3} \mathrm{~mol}\right)$, tetrahydrofuran $(24 \mathrm{~mL})$, water $(2.25 \mathrm{~mL})$. Column chromatography on silica gel eluting with petroleum ether:dichloromethane (6:1) to recover the product as a creamy solid $\left(613 \mathrm{mg}, 1.81 \cdot 10^{-4} \mathrm{~mol}, 58 \%\right) .{ }^{1} \mathrm{H} \mathrm{NMR}\left(\mathrm{CDCl}_{3}\right) \delta(\mathrm{ppm}): 8.56(3 \mathrm{H}, \mathrm{d}, \mathrm{J}=$ 8.4 Hz), 7.94-7.79 (27 H, m), 7.78-7.64, $(27 \mathrm{H}, \mathrm{m})$, 7.56-7.50 (6 H, m), 3.05-3.25 (6 H, m), 2.38-1.99 (42 H, m), 1.28-0.95 $(48 \mathrm{H}, \mathrm{m}), 0.90-0.70(102 \mathrm{H}, \mathrm{m}), 0.73(18 \mathrm{H}, \mathrm{t}, \mathrm{J}=5.6 \mathrm{~Hz}), 0.35(27 \mathrm{H}, \mathrm{s}) .\left(\mathrm{MALDI} / \mathrm{TOF}, \mathrm{m}^{\mathrm{z}} \mathrm{z}\right):\left[\mathrm{M}^{+}\right]$ calcd. for $\mathrm{C}_{249} \mathrm{H}_{306} \mathrm{Si}_{3}: 3383.35$; found, 3383.89. Anal. calcd. for $\mathrm{C}_{249} \mathrm{H}_{306} \mathrm{Si}_{3}: \mathrm{C}, 88.4 ; \mathrm{H}, 9.1$. Found: $\mathrm{C}, 87.47 ; \mathrm{H}$, 9.11 . 
$\operatorname{Tris}\left(7^{\prime \prime \prime}\right.$-trimethylsilyl-2,2':7',2":7",2'"'-quaterfluoren-7-yl)truxene (butyl) (T4TMS B)

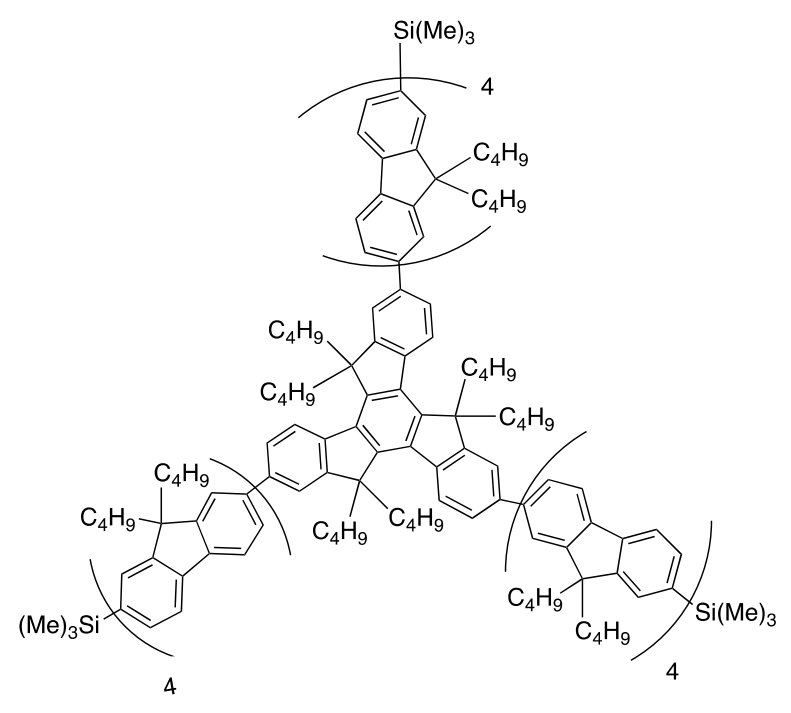

Using the general procedure I, the quantities used were: tribromohexabutyltruxene (2 B) (41.54 mg, $4.54 \cdot 10^{-5}$

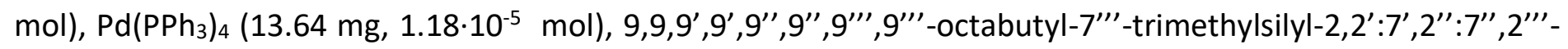
quaterfluoren-7-ylboronic acid $\left(\mathbf{F}_{4} \mathbf{B}\right)\left(265 \mathrm{mg}, 2.17 \cdot 10^{-4} \mathrm{~mol}\right), \mathrm{Ba}(\mathrm{OH})_{2} \cdot 8 \mathrm{H}_{2} \mathrm{O}\left(108 \mathrm{mg}, 3.31 \cdot 10^{-3} \mathrm{~mol}\right)$, tetrahydrofuran $(23 \mathrm{~mL})$, water $(0.32 \mathrm{~mL})$. Column chromatography on silica gel eluting with petroleum ether:dichloromethane gradient elution (from 10:1 to 5:1) to recover the product as a creamy solid (97.3 mg, 2.31·10 $\left.{ }^{-5} \mathrm{~mol}, 51 \%\right) .{ }^{1} \mathrm{H} \mathrm{NMR}\left(\mathrm{CDCl}_{3}\right) \delta(\mathrm{ppm}): 8.59(3 \mathrm{H}, \mathrm{d}, J=8.5 \mathrm{~Hz}), 8.00-7.64(72 \mathrm{H}, \mathrm{m}), 7.60-7.50(6 \mathrm{H}, \mathrm{m})$, 3.32-3.01 (6 H, m), 2.42-2.02 (54 H, m), 1.33-1.10 (54 H, m), 1.10-0.97 (12 H, m), 0.97-0.52 (144 H, m), $0.34(27$ $\mathrm{H}, \mathrm{s}) .{ }^{13} \mathrm{C} \mathrm{NMR}\left(\mathrm{CDCl}_{3}\right) \delta(\mathrm{ppm}): 154.51,151.87,151.74,150.22,145.38,141.46,140.58,140.51,140.38$, $140.10,140.05,139.71,139.48,139.07,138.29,131.89,127.67,126.16,126.02,125.25,121.51,121.29$, 120.62, 120.06, 119.04, 55.88, 55.38, 55.32, 55.07, 40.40, 40.28, 40.02, 36.97, 29.74, 26.76, 26.20, 26.12, 23.20, 23.16, 23.06, 13.98, 13.93, 13.88, 13.81, 13.75, 13.69, -0.81. (MALDI/TOF, m/z): $\left[\mathrm{M}^{+}\right]$calcd. for $\mathrm{C}_{312} \mathrm{H}_{387} \mathrm{Si}_{3}$ : 4212.6; found, 4212.7. Anal. calcd. for $\mathrm{C}_{312} \mathrm{H}_{387} \mathrm{Si}_{3}$ : C, 88.96; $\mathrm{H}, 9.04$. Found: $\mathrm{C}, 63.00 ; \mathrm{H}, 5.90$.

Tris(7-trimethylsilylfluoren-2-yl)truxene (octyl) (T1TMS 0)

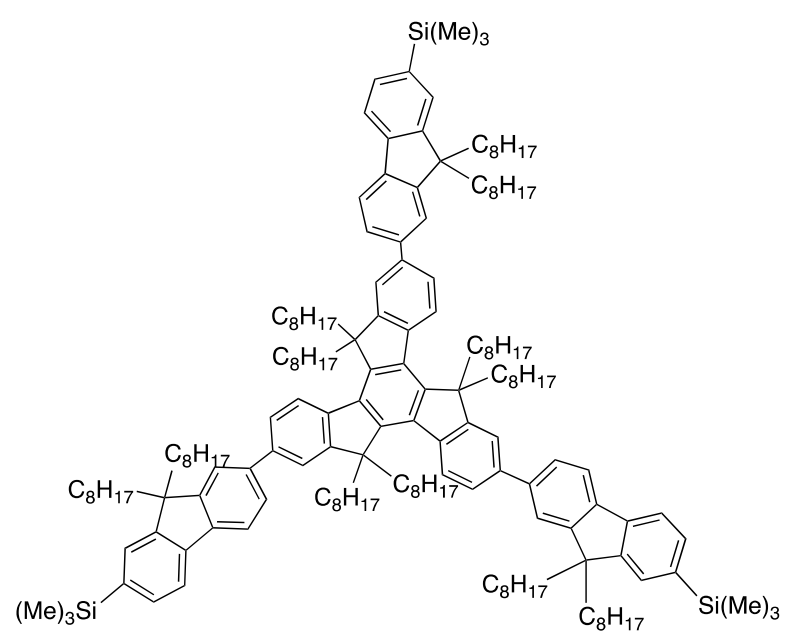

Using the general procedure I, the quantities used were: tribromohexaoctyltruxene (2 0) $\left(200 \mathrm{mg}, 1.6 \cdot 10^{-4}\right.$ $\mathrm{mol}$ ), $\mathrm{Pd}\left(\mathrm{PPh}_{3}\right)_{4}\left(48 \mathrm{mg}, 4.20 \cdot 10^{-5} \mathrm{~mol}\right), \quad 9,9-$ dioctyl-7-trimethylsilylfluoren-2-ylboronic acid $\left(\mathbf{F}_{\mathbf{1}} \mathbf{0}\right)(387 \mathrm{mg}$, 
$\left.7.60 \cdot 10^{-4} \mathrm{~mol}\right), \mathrm{Ba}(\mathrm{OH})_{2} \cdot 8 \mathrm{H}_{2} \mathrm{O}\left(380 \mathrm{mg}, 1.70 \cdot 10^{-4} \mathrm{~mol}\right)$, dimethoxyethane $(9.80 \mathrm{~mL})$, water $(0.77 \mathrm{~mL})$. Column chromatography eluting with petroleum ether:toluene (20:1), to recover the product as colourless oil (265 mg, 1.17.10-4 mol, 69\%). ${ }^{1} \mathrm{H} N M R\left(\mathrm{CDCl}_{3}\right) \delta(\mathrm{ppm}): 8.59(3 \mathrm{H}, \mathrm{d}, J=8.4 \mathrm{~Hz}), 7.96-7.78(18 \mathrm{H}, \mathrm{m}), 7.66-7.54(6 \mathrm{H}, \mathrm{m})$, 3.28-3.05 (6 H, m), 2.41-2.23 (6 H, m), $2.16(12 \mathrm{H}, \mathrm{t}, J=8 \mathrm{~Hz}), 1.28-0.95(120 \mathrm{H}, \mathrm{m}), 0.95-0.67(60 \mathrm{H}, \mathrm{m}), 0.42$ $(27 \mathrm{H}, \mathrm{s})$. (MALDI/TOF, $\mathrm{m} / z)$ : $\left[\mathrm{M}^{+}\right]$calcd. for $\mathrm{C}_{171} \mathrm{H}_{258} \mathrm{Si}_{3}$ : 2396.4; found, 2396.9.

Tris(7'-trimethylsilyl-2,2'-bifluoren-7-yl)truxene (octyl) (T2TMS O)

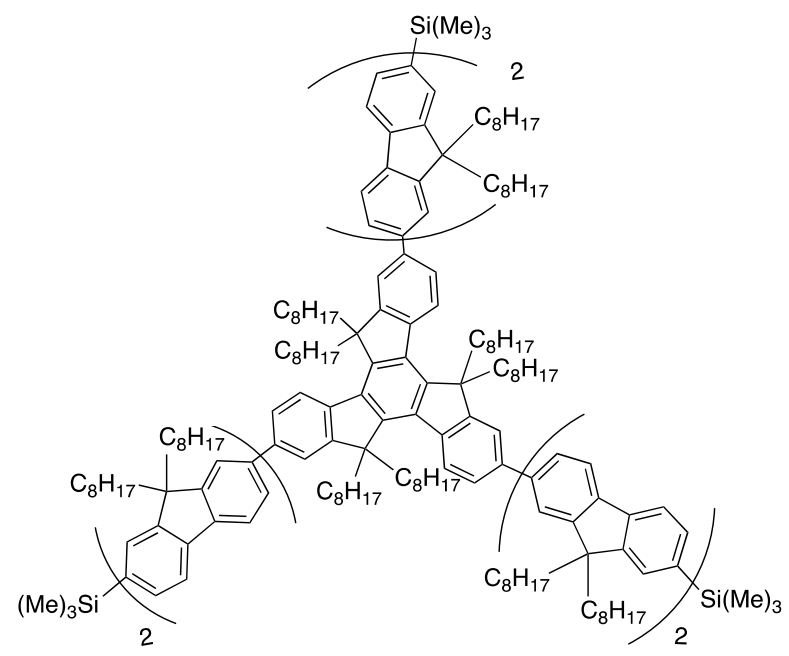

Using the general procedure I, the quantities used were: tribromohexaoctyltruxene (2 0) $\left(950 \mathrm{mg}, 7.60 \cdot 10^{-4}\right.$ mol), $\mathrm{Pd}\left(\mathrm{PPh}_{3}\right)_{4}\left(228 \mathrm{mg}, \mathbf{2 . 0 0} \cdot 10^{-4} \mathrm{~mol}\right), 9,9,9^{\prime}, 9^{\prime}$-tetraoctyl-7'-trimethylsilyl-2,2' -bifluoren-7-ylboronic acid ( $\mathbf{F}_{\mathbf{2}}$ O) $\left(3.25 \mathrm{~g}, 3.62 \cdot 10^{-3} \mathrm{~mol}\right), \mathrm{Ba}(\mathrm{OH})_{2} \cdot 8 \mathrm{H}_{2} \mathrm{O}\left(1.80 \mathrm{~g}, 5.54 \cdot 10^{-3} \mathrm{~mol}\right)$, dimethoxyethane $(31.5 \mathrm{~mL})$, water $(4.3 \mathrm{~mL})$. Column chromatography on silica gel eluting with petroleum ether:toluene (20:1), increasing the polarity with petroleum ether:toluene (10:1). The product was obtained as a creamy solid $\left(1.873 \mathrm{~g}, 5.25 \cdot 10^{-4} \mathrm{~mol}, 69 \%\right) .{ }^{1} \mathrm{H}$ $\mathrm{NMR}\left(\mathrm{CDCl}_{3}\right) \delta(\mathrm{ppm}): 8.59(3 \mathrm{H}, \mathrm{d}, J=8.0 \mathrm{~Hz}), 7.88-7.66(36 \mathrm{H}, \mathrm{m}), 7.65-7.51(6 \mathrm{H}, \mathrm{m}), 3.36-3.03(6 \mathrm{H}, \mathrm{m}), 2.46-$ $1.98(30 \mathrm{H}, \mathrm{m}), 1.46-0.65(270 \mathrm{H}, \mathrm{m}), 0.40(27 \mathrm{H}, \mathrm{s}) .{ }^{13} \mathrm{C} \mathrm{NMR}\left(\mathrm{CDCl}_{3}\right) \delta(\mathrm{ppm}): 153.97,151.36,151.30,151.27$, $149.72,144.74,140.96,140.18,140.10,139.84,139.65,139.59,139.17,139.06,138.50,137.70,131.38$, $127.19,125.66,125.56,124.78,124.47,121.04,120.78,120.05,119.52,118.54,76.84,76.52,76.20,55.38$, 54.91, 54.64, 40.03, 39.69, 36.66, 31.35, 31.31, 29.61, 29.47, 28.82, 28.77, 28.69, 28.64, 28.61, 23.66, 23.46, 23.35, 22.14, 22.04, 13.59, 13.53, -1.32. (MALDI/TOF, $m / z$ ): calcd. for $\mathrm{C}_{258} \mathrm{H}_{378} \mathrm{Si}_{3}$ : 3564.0; found, 3450.5 ([M$\left.\mathrm{C}_{8} \mathrm{H}_{17}\right]^{+}$). Anal. calcd. for $\mathrm{C}_{258} \mathrm{H}_{378} \mathrm{Si}_{3}: \mathrm{C}, 86.95 ; \mathrm{H}, 10.69$. Found: C, 85.69; $\mathrm{H}, 9.18$. 
$\operatorname{Tris}\left(7^{\prime \prime}\right.$-trimethylsilyl-2,2':7',2'-terfluoren-7-yl)truxene (octyl) (T3TMS 0)

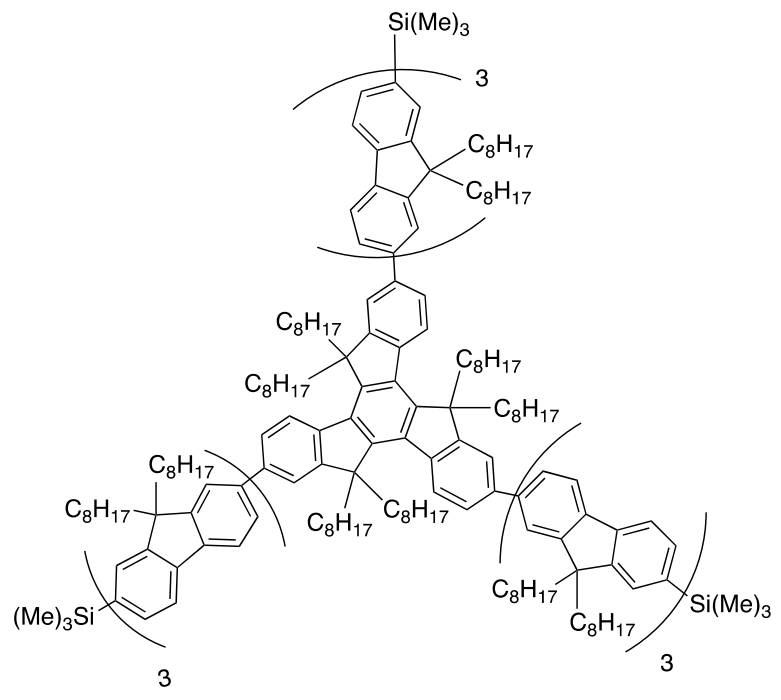

Using the general procedure I, the quantities used were: tribromohexaoctyltruxene (2 0) $\left(150 \mathrm{mg}, 1.20 \cdot 10^{-4}\right.$ mol), $\mathrm{Pd}\left(\mathrm{PPh}_{3}\right)_{4}$ (36 mg, 3.10·10-5 mol), 9,9,9',9',9",9"'-hexaoctyl-7"'-trimethylsilyl-2,2':7',2"'-terfluoren-7ylboronic acid $\left(\mathrm{F}_{3} \mathbf{O}\right)\left(763 \mathrm{mg}, 5.70 \cdot 10^{-4} \mathrm{~mol}\right), \mathrm{Ba}(\mathrm{OH})_{2} \cdot 8 \mathrm{H}_{2} \mathrm{O}\left(280 \mathrm{mg}, 8.60 \cdot 10^{-4} \mathrm{~mol}\right)$, thetrahydrofuran $(5.8$ $\mathrm{mL})$, water $(0.58 \mathrm{~mL})$. Column chromatography on silica gel eluting with petroleum ether:toluene (20:1), increasing the polarity with petroleum ether:toluene (10:1). The product was obtained as a creamy solid (562 $\left.\mathrm{mg}, 1.19 \cdot 10^{-4} \mathrm{~mol}, 99 \%\right) .{ }^{1} \mathrm{H} \mathrm{NMR}\left(\mathrm{CDCl}_{3}\right) \delta(\mathrm{ppm}): 8.55(3 \mathrm{H}, \mathrm{d}, J=8.4 \mathrm{~Hz}), 7.95-7.78(27 \mathrm{H}, \mathrm{m}), 7.78-7.63(27 \mathrm{H}$, m), 7. 59-7.48 (6 H, m), 3.23-3.00 (6 H, m), 2.48-2.00 (42 H, m), 1.25-1.92 (240 H, m), 1.92-0.63 (120 H, m), $0.36(27 \mathrm{H}, \mathrm{s}) .{ }^{13} \mathrm{C}$ NMR $\left(\mathrm{CDCl}_{3}\right) \delta(\mathrm{ppm}): 151.32,125.66,121.01,119.45,39.65,31.33,31.28,29.54,29.44$,

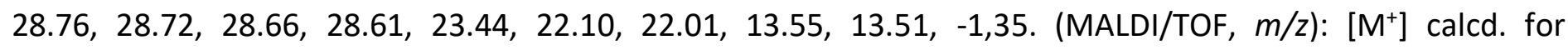
$\mathrm{C}_{345} \mathrm{H}_{498} \mathrm{Si}_{3}$ : 4729.9; found, 4727.5. Anal. calcd. for $\mathrm{C}_{345} \mathrm{H}_{498} \mathrm{Si}_{3}$ : C, 87.61; $\mathrm{H}, 10.61$. Found: C, 87.55; $\mathrm{H}, 11.04$.

Tris(7-bromo-2,2'-bifluoren-7'-yl)truxene (octyl) (T2Br O)

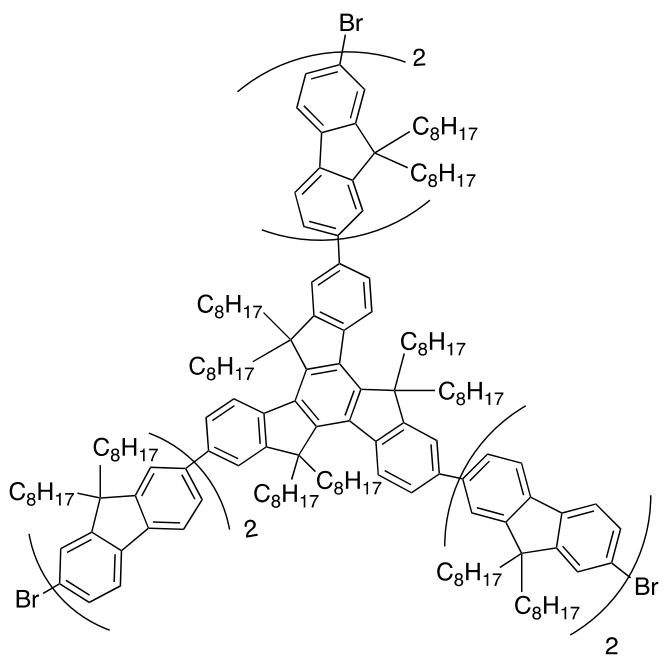

Tris(7'-trimethylsilyl-2,2'-bifluoren-7-yl)truxene (octyl) (T2TMS 0) (500 mg, 1.40.10-4 mol) and sodium acetate (35 mg, 4.20.10-4 mol) were dissolved in dry tetrahydrofuran $(14 \mathrm{~mL})$ under nitrogen and the reaction mixture was protected from the light and cooled down to $0^{\circ} \mathrm{C}$ for 30 minutes. $\mathrm{Br}_{2}\left(0.05 \mathrm{~mL}, 9.80 \cdot 10^{-4}\right.$ mol) was added 
dropwise and the reaction mixture was stirred at $0^{\circ} \mathrm{C}$ for 30 minutes. It was then quenched with triethylamine $(0.45 \mathrm{~mL})$ followed by the addition of $1 \mathrm{M} \mathrm{Na}_{2} \mathrm{SO}_{3}(\mathrm{aq})(18 \mathrm{~mL})$. The reaction mixture was washed with water and extracted with dichloromethane (5 times). The combined organic fractions were washed with a saturated solution of $\mathrm{NaHCO}_{3}(\mathrm{aq})$, dried over $\mathrm{MgSO}_{4}$ and solvent evaporated to yield a crude oil. It was then dissolved in the minimum amount of toluene and filtered through a silica plug to remove polar biproducts. After solvent evaporation the residue was dissolved in the minimum amount of dichloromethane and reprecipitated from methanol to yield the product as a creamy powder $\left(457 \mathrm{mg}, 1.28 \cdot 10^{-4} \mathrm{~mol}, 91 \%\right) .{ }^{1} \mathrm{H} \mathrm{NMR}\left(\mathrm{CDCl}_{3}\right) \delta(\mathrm{ppm}): 8.51$ $(3 \mathrm{H}, \mathrm{d}, J=8.0 \mathrm{~Hz}), 7.91-7.56(36 \mathrm{H}, \mathrm{m}), 7.54-7.44(6 \mathrm{H}, \mathrm{m}), 3.19-2.99(6 \mathrm{H}, \mathrm{m}), 2.36-1.88(30 \mathrm{H}, \mathrm{m}), 1.26-0.63$ $(270 \mathrm{H}, \mathrm{m}) .{ }^{13} \mathrm{C} \mathrm{NMR}\left(\mathrm{CDCl}_{3}\right) \delta(\mathrm{ppm}): 152.90,151.50,140.30,139.60137 .91,138.20,126.00,125.60,125.30$, $121.51,121.20,120.92,120.50,119.80,119.50,99.70,99.10,97.40,88.50,55.80,54.80,39.50,37.10,36.40$, 31.32, 31.27, 29.56, 29.45, 29.79, 28.79, 28.74, 28.69, 28.58, 22.10, 22.01, 13.56, 13.50. (MALDI/TOF, m/z): $\left[\mathrm{M}^{+}\right]$calcd. for $\mathrm{C}_{249} \mathrm{H}_{351} \mathrm{Br}_{3}$ : 3584.16; found, 3495.12 ([M-Br] $]^{+}$). Anal. calcd. for $\mathrm{C}_{249} \mathrm{H}_{351} \mathrm{Br}_{3}: \mathrm{C}, 83.4 ; \mathrm{H}, 9.87 ; \mathrm{Br}$, 6.7. Found: $\mathrm{C}, 82.83 ; \mathrm{H}, 9.50 ; \mathrm{Br}, 6.21$.

General procedure J: Synthesis of Tris(oligofluorenyl)truxene (Tn) (T1, T2, T3, T4 (B and O))

Tris(trimethylsilyloligofluorenyl)truxene (TnTMS) (1 eq) was dissolved in dichloromethane (39 $\mathrm{mL}$ per gram) and $\mathrm{CF}_{3} \mathrm{COOH}$ (5 eq per position) added. The mixture was stirred at room temperature for $2 \mathrm{~h}$ under nitrogen. Basic work up was carried out with water ( 2 times), saturated aqueous $\mathrm{NaHCO}_{3}$ solution ( 2 times) and a final washing with water. The organic fraction was dried over anhydrous $\mathrm{MgSO}_{4}$ and filtered through a silica plug to remove polar by-products. The colourless oil was dissolved in the minimum amount of dichloromethane and precipitated from methanol to yield the product as a white solid.

Tris(fluorenyltruxene) (butyl) (T1 B)

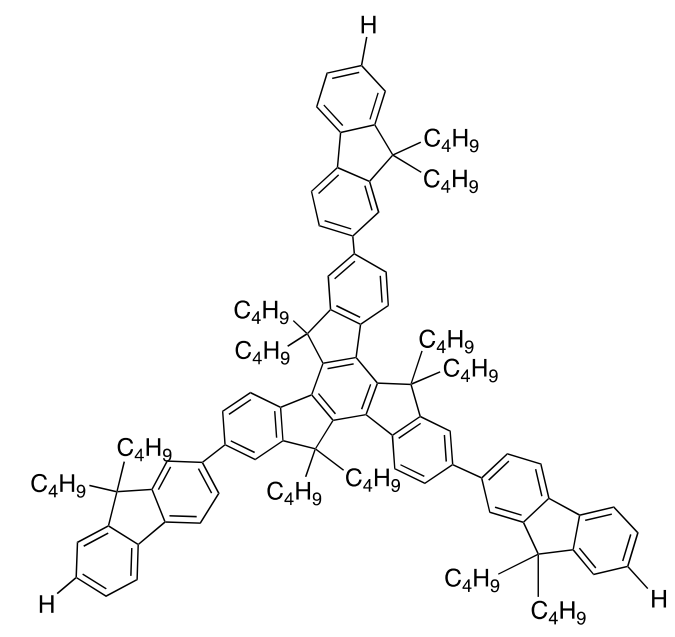

Using the general procedure J, the quantities used were: tris(7-trimethylsilylfluoren-2-yl)truxene (butyl) (T1TMS B) $\left(640 \mathrm{mg}, 4.24 \cdot 10^{-4} \mathrm{~mol}\right)$, dichloromethane $(25 \mathrm{~mL}), \mathrm{CF}_{3} \mathrm{COOH}\left(0.45 \mathrm{~mL}, 6.37 \cdot 10^{-3} \mathrm{~mol}\right)$. The product was obtained as a white solid (505 mg, 3.93·10-4 mmol, 93\%). ${ }^{1} \mathrm{H} \mathrm{NMR}\left(\mathrm{CDCl}_{3}\right) \delta(\mathrm{ppm}): 8.50(3 \mathrm{H}, \mathrm{d}, J=8.0 \mathrm{~Hz})$, 7.85-7.65 (18 H, m), 7.41-7.27 (9 H, m), 3.15-2.98 (6 H, m), 2.30-1.95 (18 H, m), 1.20-1.13 (12 H, m), 1.13-0.88 $(12 \mathrm{H}, \mathrm{m}), 0.80-0.40(60 \mathrm{H}, \mathrm{m}) .{ }^{13} \mathrm{C} \mathrm{NMR}\left(\mathrm{CDCl}_{3}\right) \delta(\mathrm{ppm}): 153.93,151.02,150.51,144.79,140.37,139.97$, 139.47, 139.12, 138.93, 137.72, 126.31, 125.46, 124.51, 122.45, 120.66, 120.02, 119.45, 119.24, 55.31, 54.66, 39.81, 36.39, 26.19, 25.56, 22.63, 22.47, 13.40, 13.34. (MALDI/TOF, $m / z$ ): [ $\left.\mathrm{M}^{+}\right]$calcd for $\mathrm{C}_{114} \mathrm{H}_{138}$ 1508.1; found 1508.0. Anal. calcd. for $\mathrm{C}_{114} \mathrm{H}_{138}$ : C, 90.78; H, 9.22. Found: $\mathrm{C}, 90.65 ; \mathrm{H}, 9.26$. 
Tris(2,2'-bifluoren-7-yl)truxene (butyl) (T2 B)

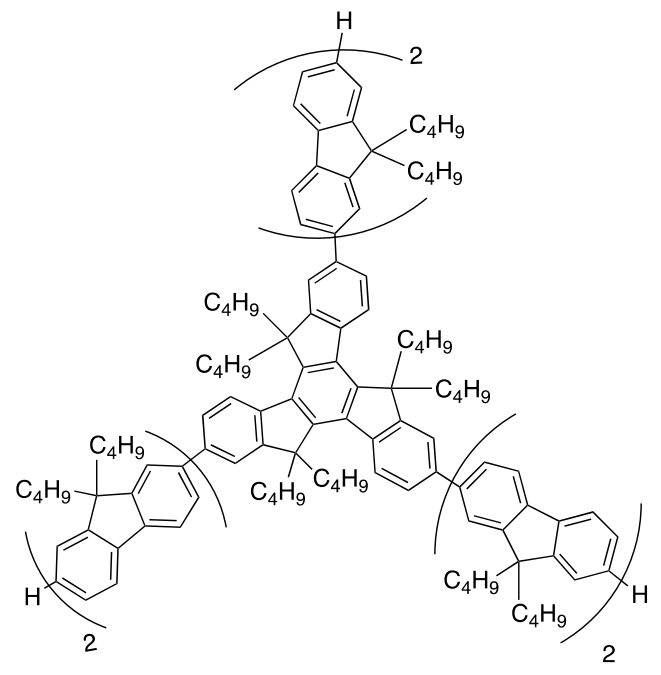

Using the general procedure J, the quantities used were: tris(7'-trimethylsil-2,2'-bifluoren-7-yl)truxene (butyl) (T2TMS B) $\left(882 \mathrm{mg}, 3.45 \cdot 10^{-4} \mathrm{~mol}\right)$, dichloromethane $(38 \mathrm{~mL}), \mathrm{CF}_{3} \mathrm{COOH}(0.37 \mathrm{~mL}, 5.18 \mathrm{mmol})$. The product was obtained as a white solid $\left(725 \mathrm{mg}, 3.10 \cdot 10^{-4} \mathrm{~mol}, 90 \%\right) .{ }^{1} \mathrm{H} \mathrm{NMR}\left(\mathrm{CDCl}_{3}\right) \delta(\mathrm{ppm}): 8.56(3 \mathrm{H}, \mathrm{d}, \mathrm{J}=8.0 \mathrm{~Hz})$, 7.93-6.65 (36 H, m), 7.58-7.30 (9 H, m), 3.21-3.06 (6 H, m), 2.37-2.00 (30 H, m), 1.30-1.10 (24 H, m), 1.10-0.94 $(16 \mathrm{H}, \mathrm{m}), 0.92-0-60(68 \mathrm{H}, \mathrm{m}), 0.55(18 \mathrm{H}, \mathrm{t}, J=7.4 \mathrm{~Hz}) .{ }^{13} \mathrm{C} N M R\left(\mathrm{CDCl}_{3}\right): \delta 153.97,151.37,151.31,151.01$, $150.53,144.84,140.32,140.00,139.94,139.89,139.67,139.58,139.49,139.17,139.94,137.75,126.53$, $126.32,125.60,125.51,124.72,124.56,122.46,120.98,120.91,120.75,119.56,119.51,119.42,119.24,55.34$, 54.84, 54.62, 39.86, 39.73, 36.43, 26.22, 25.67, 25.56, 22.67, 22.61, 22.50, 13.47, 13.44, 13.39, 13.33, 13.30, 1.33. (MALDI/TOF, $m / z$ ): $\left[\mathrm{M}^{+}\right]$calcd. for $\mathrm{C}_{177} \mathrm{H}_{210}$ : 2337.56; found, 2337.66. Anal. calcd. for $\mathrm{C}_{177} \mathrm{H}_{210}: \mathrm{C}, 90.94 ; \mathrm{H}$, 9.06. Found: $C, 90.48 ; H, 8.81$.

$\operatorname{Tris}\left(2,2^{\prime}: 7^{\prime}, 2^{\prime \prime}\right.$-terfluoren-7-yl)truxene (butyl) (T3 B)

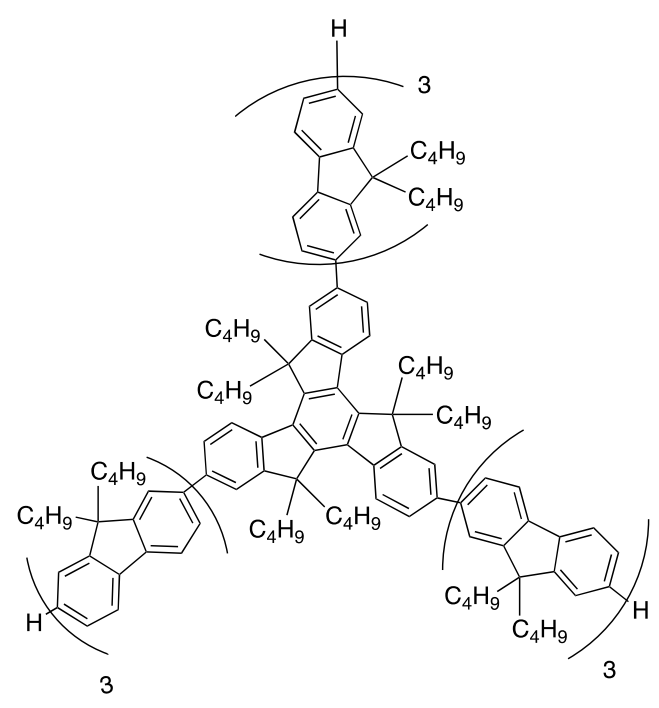

Using the general procedure $\mathrm{J}$, the quantities used were: tris(7' 'trimethyl-2,2':7',2' 'terfluoren-7-yl)truxene (butyl) (T3TMS B) $\left(571 \mathrm{mg}, 1.69 \cdot 10^{-4} \mathrm{~mol}\right)$, dichloromethane $(10 \mathrm{~mL}), \mathrm{CF}_{3} \mathrm{COOH}\left(0.18 \mathrm{~mL}, 2.53 \cdot 10^{-3} \mathrm{~mol}\right)$. The product was obtained as a white solid $\left(459 \mathrm{mg}, 1.45 \cdot 10^{-4} \mathrm{~mol}, 86 \%\right) .{ }^{1} \mathrm{H} \mathrm{NMR}\left(\mathrm{CDCl}_{3}\right) \delta(\mathrm{ppm}): 8.56(3 \mathrm{H}, \mathrm{d}, \mathrm{J}=$ 
8.0 Hz), 7.95-7.79 $(27 \mathrm{H}, \mathrm{m}), 7.79-7.64(27 \mathrm{H}, \mathrm{m})$, 7.43-7.30 (9 H, m), 3.30-3.04 (6 H, m), 2.38-1.99 (42 H, m), 1.30-1.09 $(36 \mathrm{H}, \mathrm{m}), 1.09-0.95(12 \mathrm{H}, \mathrm{m}), 0.92-0.50(120 \mathrm{H}, \mathrm{m}) .{ }^{13} \mathrm{C} \mathrm{NMR}\left(\mathrm{CDCl}_{3}\right) \delta(\mathrm{ppm}): 150.52,144.85$, $140.31,139.98,139.92,139.67,139.62,139.57,139.51,139.18,138.94,126.31,125.63,125.50,122.45$, $120.99,120.90,120.76,119.50,119.41,119.24,55.35,54.84,54.79,54.62,39.86,39.73,26.23,25.67,25.55$, 22.67, 22.69, 22.51, 13.44, 13.39, 13.33. (MALDI/TOF, $\mathrm{m} / \mathrm{z}$ ): $\left[\mathrm{M}^{+}\right]$calcd. for $\mathrm{C}_{240} \mathrm{H}_{282}$ : 3166.8; found, 3167.6 . Anal. calcd. for $\mathrm{C}_{240} \mathrm{H}_{282}$ : C, 91.02; $\mathrm{H}, 8.98$. Found: $\mathrm{C}, 90.67 ; \mathrm{H}, 8.02$.

$\operatorname{Tris}\left(2,2^{\prime}: 7^{\prime}, 2^{\prime \prime}: 7^{\prime \prime}, 2^{\prime \prime \prime}\right.$-quaterfluoren-7-yl)truxene (butyl) (T4 B)

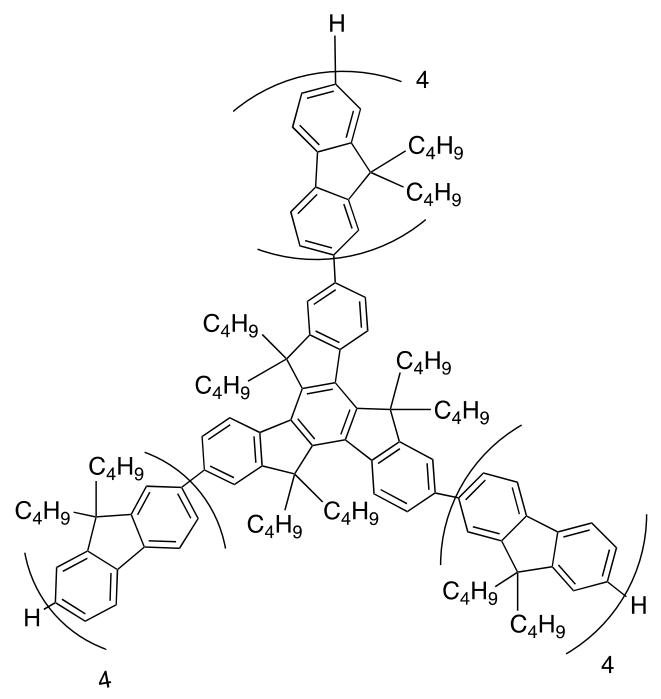

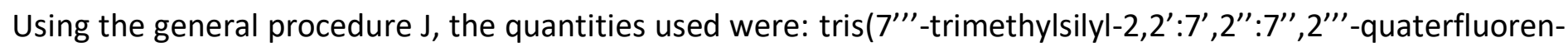
7-yl)truxene (butyl) (T4TMS B) $\left(76.1 \mathrm{mg}, 1.81 \cdot 10^{-5} \mathrm{~mol}\right)$, dichloromethane $(5 \mathrm{~mL}), \mathrm{CF}_{3} \mathrm{COOH}\left(0.5 \mathrm{~mL}, 7.14 \cdot 10^{-3}\right.$ mol). The product was obtained as a white solid $\left(71.5 \mathrm{mg}, 1.79 \cdot 10^{-5} \mathrm{~mol}, 98 \%\right) .{ }^{1} \mathrm{H} \mathrm{NMR}\left(\mathrm{CDCl}_{3}\right) \delta(\mathrm{ppm}): 8.56$ $(3 \mathrm{H}, \mathrm{d}, J=8.0 \mathrm{~Hz}), 7.93-7.79(33 \mathrm{H}, \mathrm{m}), 7.79-7.64(39 \mathrm{H}, \mathrm{m}), 7.43-7.31(9 \mathrm{H}, \mathrm{m}), 3.24-3.06(6 \mathrm{H}, \mathrm{m}), 2.40-1.97$ $(54 \mathrm{H}, \mathrm{m}), 1.30-1.10(54 \mathrm{H}, \mathrm{m}), 1.10-1.07(12 \mathrm{H}, \mathrm{m}), 1.02-0.50(144 \mathrm{H}, \mathrm{m}) .{ }^{13} \mathrm{C} \mathrm{NMR}\left(\mathrm{CDCl}_{3}\right) \delta(\mathrm{ppm}): 151.34$, $150.99,150.00,140.31,139.97,139.56,137.50,125.63,122.45,120.99,120.90,119.51,119.22,54.84,54.78$, 54.62, 39.72, 25.67, 25.55, 22.67, 22.62, 22.50, 13.43, 13.38, 13.34. (MALDI/TOF, m/z): [M+] calcd. for $\mathrm{C}_{303} \mathrm{H}_{354}$ : 3996.5; found, 3996.7. Anal. calcd. for $\mathrm{C}_{303} \mathrm{H}_{354}$ : C, 91.07; $\mathrm{H}, 8.93$. Found: $\mathrm{C}, 90.95 ; \mathrm{H}, 8.76$.

Tris(fluoren-2-yl)truxene (octyl) (T1 0)

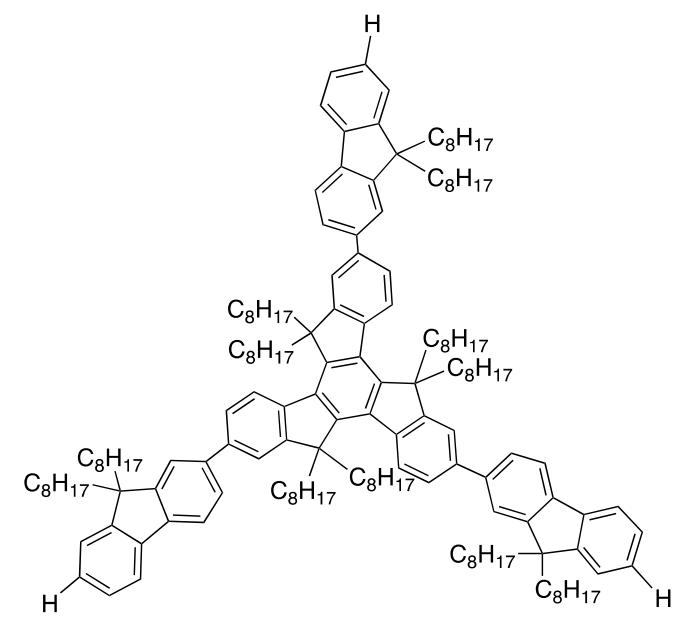


Using the general procedure J, the quantities used were: tris(7-trimethylsilylfluoren-2-yl)truxene (octyl) (T1TMS 0) $\left(511 \mathrm{mg}, 2.35 \cdot 10^{-4} \mathrm{~mol}\right)$, dichloromethane $(9.6 \mathrm{~mL}), \mathrm{CF}_{3} \mathrm{COOH}\left(0.33 \mathrm{~mL}, 3.20 \cdot 10^{-3} \mathrm{~mol}\right)$. The product was obtained as a colourless oil $\left(431 \mathrm{mg}, 1.98 \cdot 10^{-4} \mathrm{mmol}, 93 \%\right) .{ }^{1} \mathrm{H} \mathrm{NMR}\left(\mathrm{CDCl}_{3}\right) \delta(\mathrm{ppm}): 8.52(3 \mathrm{H}, \mathrm{d}, \mathrm{J}=8.4$ $\mathrm{Hz})$, 7.87-7.73 (18 H, m), 7.43-7.30 (9 H, m), 3.16-3.00 (6 H, m), 2.11-2.15 (6 H, m), 2.15-1.96 (12 H, m), $1.19-$ $0.59(180 \mathrm{H}, \mathrm{m}) .{ }^{13} \mathrm{C} \mathrm{NMR}\left(\mathrm{CDCl}_{3}\right) \delta(\mathrm{ppm}): 151.20150 .80,150.50,139.11,138.90,138.60,126.60,126.30$, $125.60,124.90,123.60,122.60,120.20,119.50,119.80,119.20,55.50,54.71,40.20,36.80,31.31,29.58$, 29.40, 28.74, 28.56, 23.60, 23.34, 22.10, 21.99, 13-56, 13.48. (MALDI/TOF, m/z): [M+] calcd. for $\mathrm{C}_{162} \mathrm{H}_{234}$ : 2181.6; found, 2181.7. Anal. calcd. for $\mathrm{C}_{162} \mathrm{H}_{234}$ : C, 89.19; $\mathrm{H}, 10.81$. Found: $\mathrm{C}, 88.94 ; \mathrm{H}, 10.81$.

Tris(2,2'-bifluoren-7-yl)truxene (octyl) (T2 O)

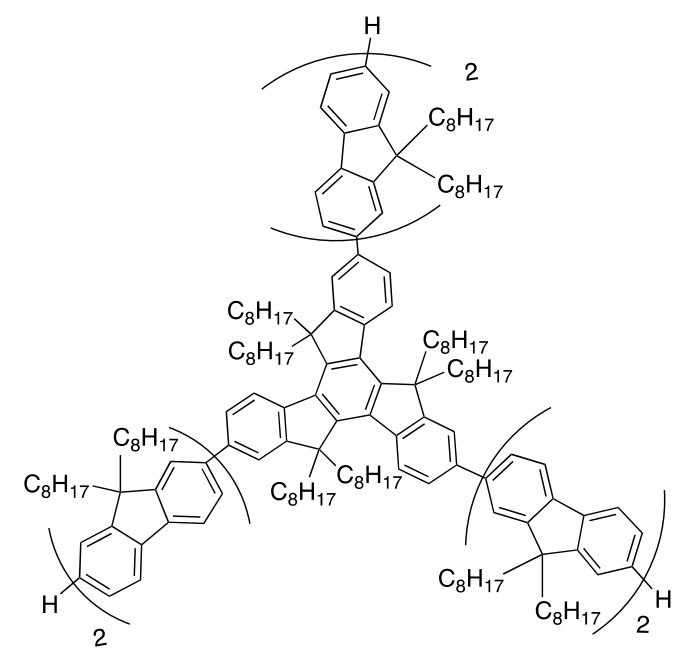

Using the general procedure J, the quantities used were: tris(7'-trimethylsilyl-2,2'-bifluoren-7-yl)truxene (T2TMS 0) (471 mg, 1.32.10-4 mol), dichloromethane $(6 \mathrm{~mL}), \mathrm{CF}_{3} \mathrm{COOH}\left(0.14 \mathrm{~mL}, 1.98 \cdot 10^{-3}\right.$ mol). The product was obtained as a creamy solid $\left(411 \mathrm{mg}, 1.13 \cdot 10^{-4} \mathrm{~mol}, 93 \%\right) .{ }^{1} \mathrm{H} \mathrm{NMR}\left(\mathrm{CDCl}_{3}\right) \delta(\mathrm{ppm}): 8.52(3 \mathrm{H}, \mathrm{d}, \mathrm{J}=8.0 \mathrm{~Hz})$, 7.90-7.62 (36 H, m), 7.41-7.30 (9 H, m), 3.18-2.98 (6 H, m), 2.35-1.95 (30 H, m), 1.30-0.60 (270 H, m). ${ }^{13} \mathrm{C} \mathrm{NMR}$ $\left(\mathrm{CDCl}_{3}\right) \delta$ (ppm): 153.98, 151.36, 151.30, 151.27, 149.72, 144.74, 140.96, 140.18, 140.10, 139.84, 139.65, $139.59,139.17,139.06,138.59,137.70,131.38,127.19,125.66,125.56,124.78,124.47,121.04,120.78$, $120.05,119.52,118.54,55.38,54.91,54.64,40.03,39.69,36.66,31.35,31.31,29.60,29.47,28.82,28.77$, 28.69, 28.65, 28.61, 23.66, 23.46, 23.35, 22.14, 22.11, 22.08, 22.04, 13.59, 13.53, -1.32. (MALDI/TOF, $\mathrm{m} / z$ ) calcd. for $\mathrm{C}_{247} \mathrm{H}_{334}$ : 3347.5; found, $3324.1\left(\left[\mathrm{M}-\mathrm{C}_{8} \mathrm{H}_{17}\right]^{+}\right)$. Anal. calcd. for $\mathrm{C}_{247} \mathrm{H}_{334}$ : C, 89.34; $\mathrm{H}, 10.66$. Found: C, 88.92; H, 10.96. 
$\operatorname{Tris}\left(2,2^{\prime}: 7^{\prime}, 2^{\prime \prime}\right.$-terfluoren-7-yl)truxene (octyl) (T3 0)

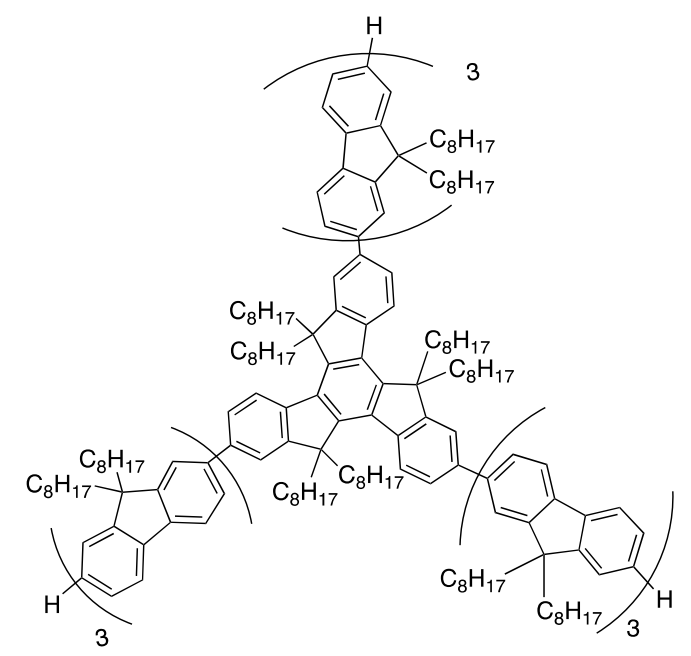

Using the general procedure J, the quantities used were: 2,7,12-tris $\left(9,9,9^{\prime}, 9^{\prime}, 9^{\prime \prime}, 9^{\prime \prime}\right.$-hexaoctyl-7"'-trimethylsilyl2,2':7',2"'-terfluoren-7-yl)-5,5,10,10,15,15-hexaoctyltruxene (T3TMS 0) (562 mg, 1.20.10-5 mol), dichloromethane $(20 \mathrm{~mL}), \mathrm{CF}_{3} \mathrm{COOH}\left(0.13 \mathrm{~mL}, 3.55 \cdot 10^{-4} \mathrm{~mol}\right)$. The product was obtained as a creamy solid (511 $\left.\mathrm{mg}, 1.11 \cdot 10^{-5} \mathrm{~mol}, 94 \%\right) .{ }^{1} \mathrm{H}$ NMR $\left(\mathrm{CDCl}_{3}\right) \delta(\mathrm{ppm}): 8.58(3 \mathrm{H}, \mathrm{d}, J=7.2 \mathrm{~Hz}), 8.50-7.60(54 \mathrm{H}, \mathrm{m}), 7.47-7.32(9 \mathrm{H}$, m), 3.35-2.95 $(6 \mathrm{H}, \mathrm{m}), 2.48-1.97(42 \mathrm{H}, \mathrm{m}), 1.45-0.65(360 \mathrm{H}, \mathrm{m}) .{ }^{13} \mathrm{C} \mathrm{NMR}\left(\mathrm{CDCl}_{3}\right) \delta(\mathrm{ppm}): 151.31,150.99$, 150.52, 140.31, 140.03, 139.94, 139.61, 137.65, 125.67, 122.45, 121.00, 119.47, 54.90, 54.85, 54.68, 39.90, $31.35,31.31,29.56,28.83,28.79,28.74,28.62,23.44,23.34,22.15,22.05,13.60 .\left(\mathrm{MALDI} / \mathrm{TOF}, \mathrm{m}^{2} \mathrm{z}\right):\left[\mathrm{M}^{+}\right]$ calcd. for $\mathrm{C}_{336} \mathrm{H}_{474}$ : 4498.3; found, 4498.7. Anal. calcd. for $\mathrm{C}_{336} \mathrm{H}_{474}$ : C, 89.45; $\mathrm{H}, 10.55$. Found: $\mathrm{C}, 88.29 ; \mathrm{H}$, 11.02.

$\operatorname{Tris}\left(2,2^{\prime}: 7^{\prime}, 2^{\prime \prime}: 7^{\prime \prime}, 2^{\prime \prime \prime}\right.$-quaterfluoren-7-yl)truxene (octyl) (T4 0)

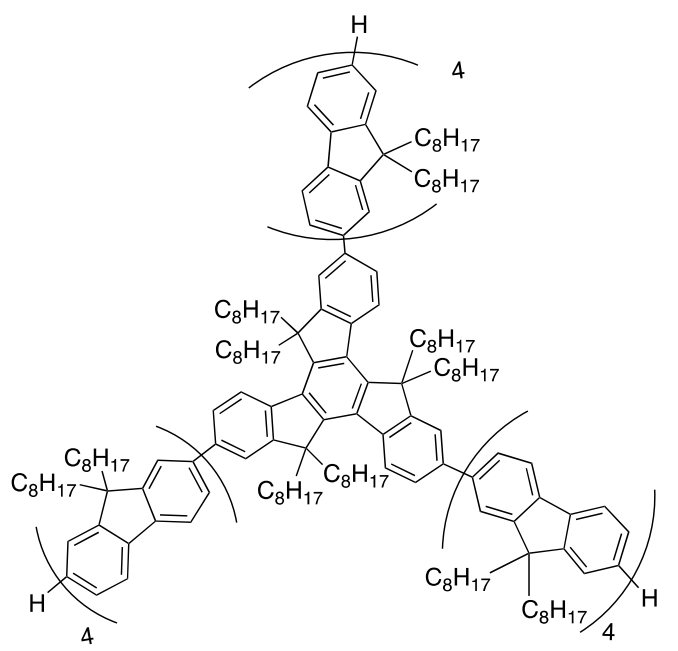

A mixture of tribromohexaoctyltruxene (2) (301 mg, 2.40.10-4 mol), Pd(PPh $)_{4}\left(73 \mathrm{mg}, 6.30 \cdot 10^{-5} \mathrm{~mol}\right)$,

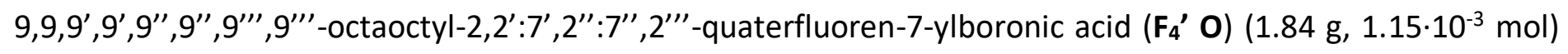
and $\mathrm{Ba}(\mathrm{OH})_{2} \cdot 8 \mathrm{H}_{2} \mathrm{O}\left(571 \mathrm{mg}, 1.76 \cdot 10^{-3} \mathrm{~mol}\right)$ was dissolved in anhydrous thetrahydrofuran $(14 \mathrm{~mL})$. The solution was degassed with $\mathrm{N}_{2}$, followed by the addition of water $(1.35 \mathrm{~mL})$ and the system was stirred under $\mathrm{N}_{2}$ at $70^{\circ} \mathrm{C}$ for $18 \mathrm{~h}$. The reaction was quenched with an aqueous solution of $\mathrm{NH}_{4} \mathrm{Cl}(100 \mathrm{~mL})$ and extracted with $(7 \mathrm{x}$ 
$100 \mathrm{~mL}$ ) of dichloromethane. The combined organic fractions were washed with water (300 $\mathrm{mL})$, dried over anhydrous $\mathrm{MgSO}_{4}$ and the solvent evaporated to yield $2.20 \mathrm{~g}$ of brown oil. The crude product was purified by column chromatography on silica gel eluting with petroleum ether:toluene (10:1) to recover the product as a creamy solid that was dissolved in the minimum amount of dichloromethane and reprecipitated from methanol (780 mg, 1.37·10-4 mol, 57\%). ${ }^{1} \mathrm{H} \mathrm{NMR}\left(\mathrm{CDCl}_{3}\right) \delta(\mathrm{ppm}): 8.53(3 \mathrm{H}, \mathrm{d}, J=6.0 \mathrm{~Hz}), 7.93-7.54(72 \mathrm{H}, \mathrm{m})$, 7.40-7.28 (9 H, m), 3.22-2.96 (6 H, b.s.), 2.39-1.90 (54 H, m), 1.28-0.64 (450 H, m). $\left.{ }^{13} \mathrm{C} \mathrm{NMR} \mathrm{(CDCl} 3\right) \delta(p p m):$ $152.14,151.81,151.34,141.13,140.86,140.82,140.66,140.44,140.36,139.85,127.11,126.48,126.36$, $123.26,121.83,120.28,120.03,55.18,55.72,55.66,55.50,40.70,37.43,32.15,32.11,30.36,30.26,29.62$, 29.58, 29.53, 29.41, 24.25, 24.26, 22.94, 22.91, 22.84, 14.37, 14.33. (MALDI/TOF, $\mathrm{m} / \mathrm{z}$ ): [M+] calcd. for $\mathrm{C}_{423} \mathrm{H}_{594}$ : 5679.2; found, 5679.8. Anal. calcd. for $\mathrm{C}_{423} \mathrm{H}_{594}$ : C, 89.46; $\mathrm{H}, 10.54$. Found: C, 88.21; H, 10.79 .

$\operatorname{Tris}\left(2,2^{\prime}: 7^{\prime}, 2^{\prime \prime}: 7^{\prime \prime}, 2^{\prime \prime \prime}: 7^{\prime \prime \prime}, 2^{\prime \prime \prime \prime}: 7^{\prime \prime \prime \prime}, 2^{\prime \prime \prime \prime \prime \prime}\right.$-sexifluoren-7-yl)truxene (octyl) (T6 O)

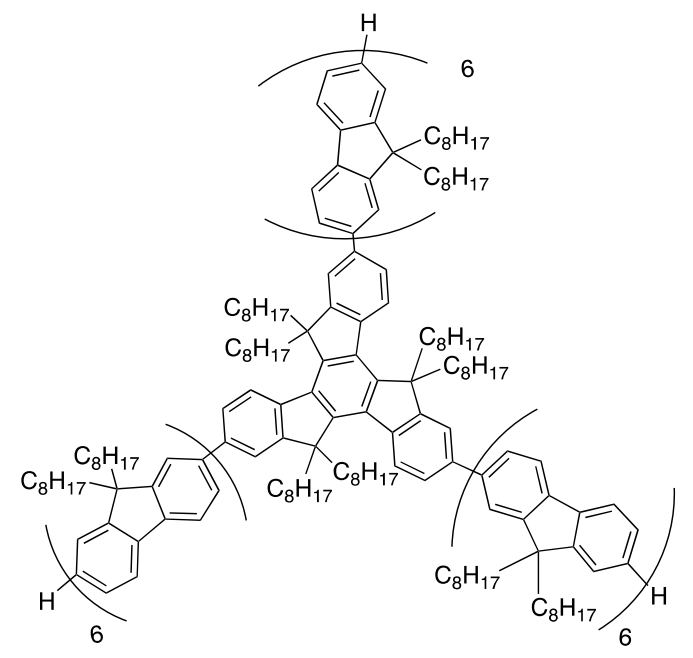

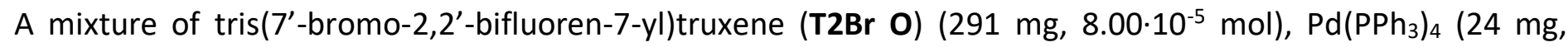

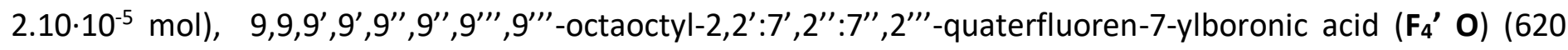
$\left.\mathrm{mg}, 3.90 \cdot 10^{-4} \mathrm{~mol}\right)$ and $\mathrm{Ba}(\mathrm{OH})_{2} \cdot 8 \mathrm{H}_{2} \mathrm{O}\left(193 \mathrm{mg}, 5.90 \cdot 10^{-4} \mathrm{~mol}\right)$ was dissolved in anhydrous thetrahydrofuran (15 $\mathrm{mL}$ ). The solution was degassed with $\mathrm{N}_{2}$, followed by the addition of water $(1.35 \mathrm{~mL})$ and the system was stirred under $\mathrm{N}_{2}$ at $70^{\circ} \mathrm{C}$ for $18 \mathrm{~h}$. The reaction was quenched with an aqueous solution of $\mathrm{NH}_{4} \mathrm{Cl}(100 \mathrm{~mL})$ and extracted with $(7 \times 100 \mathrm{~mL})$ of dichloromethane. The combined organic fractions were washed with water (300 $\mathrm{mL}$ ), dried over anhydrous $\mathrm{MgSO}_{4}$ and the solvent evaporated to yield $0.88 \mathrm{~g}$ of brown oil. The crude product was purified by column chromatography on silica gel eluting initially with petroleum ether:toluene (10:1) and increasing the polarity to petroleum ether:toluene (20:1) to recover the product. It was dissolved in the minimum amount of dichloromethane and reprecipitated from methanol to obtain a creamy solid. (446 mg, 5.62.10-5 mol, 69\%). ${ }^{1} \mathrm{H}$ NMR $\left(\mathrm{CDCl}_{3}\right) \delta(\mathrm{ppm}):$ 8.63-8.43 (3 H, b.s.), 8.00-7.56 (108 H, m), 7.40-7.28 (9 H, m), 3.22-2.96 (6 H, m), 2.33-1.96 (72 H, m), 1.28-0.64 (636 H, m). $\left.{ }^{13} \mathrm{C} \mathrm{NMR}_{(\mathrm{CDCl}}\right) \delta(\mathrm{ppm}): 152.18,151.84,151.37$, $141.17,140.88,140.69,140.39,127.13,126.52,126.39,127.13,126.52,126.39,127.13,126.52,126.39$, 123.30, 121.86, 120.31, 120.06, 74.06, 56.21, 55.76, 55.70, 55.53, 40.74, 32.19, 32.14, 30.40, 30.30, 29.65, 29.62, 29.57, 29.45, 24.28, 24.19, 22.95, 22.88, 14.40, 14.37. (MALDI/TOF, m/z): [M+] calcd. for $\mathrm{C}_{597} \mathrm{H}_{834}$ : 8012.0; found, 8013.8. Anal. calcd. for $\mathrm{C}_{597} \mathrm{H}_{834}$ : C, 89.51; H, 10.49. Found: C, 89.21; H, 10.87 . 


\section{Acknowledgements}

The authors thanks EPSRC for funding under grant EP/R03480X/1.

\section{References}

1. Tsiminis, G.; Wang, Y.; Shaw, P.E.; Kanibolotsky, A.L.; Perepichka, I.F.; Dawson, M.D.; Skabara, P.J.; Turnbull, G.A.; Samuel, I.D.W. Appl. Phys. Lett. 2009, 94, 233304. https://doi.org/10.1063/1.3152782

2. Wang, Y.; Tsiminis, G.; Yang, Y.; Ruseckas, A.; Kanibolotsky, A.L.; Perepichka, I.F.; Skabara, P.J.; Turnbull, G.A.; Samuel, I.D.W. Synth. Met. 2010, 160, 1397-1400.

https://doi.org/10.1016/j.synthmet.2010.04.016

3. Foucher, C.; Guilhabert, B.; Kanibolotsky, A.L.; Skabara, P.J.; Laurand, N.; Dawson, M.D. Opt. Express 2016, 24, 2273-2280.

https://doi.org/10.1364/OE.24.002273

4. Haughey, A.M.; Foucher, C.; Guilhabert, B.; Kanibolotsky, A.L.; Skabara, P.J.; Burley, G.; Dawson, M.D.; Laurand, N. Faraday Discuss. 2014, 174, 369-381.

https://doi.org/10.1039/C4FD00091A

5. Haughey, A.M.; Guilhabert, B.; Kanibolotsky, A.L.; Skabara, P.J.; Burley, G.A.; Dawson, M.D.; Laurand, N. Sens. Actuators, B 2013, 185, 132-139.

https://doi.org/10.1016/j.snb.2013.04.026

6. Haughey, A.-M.; Guilhabert, B.; Kanibolotsky, A.L.; Skabara, P.J.; Dawson, M.D.; Burley, G.A.; Laurand, N. Biosensors \& Bioelectronics 2014, 54, 679-686.

https://doi.org/10.1016/j.bios.2013.11.054

7. Kanibolotsky, A.L.; Laurand, N.; Dawson, M.D.; Turnbull, G.A.; Samuel, I.D.W.; Skabara, P.J. Acc. Chem. Res. 2019, 52, 1665-1674.

https://doi.org/10.1021/acs.accounts.9b00129

8. McConnell, G.; Mabbott, S.; Kanibolotsky, A.L.; Skabara, P.J.; Graham, D.; Burley, G.A.; Laurand, N. Langmuir 2018, 34, 14766-14773.

https://doi.org/10.1021/acs.langmuir.8b01313

9. Wang, Y.; Morawska, P.O.; Kanibolotsky, A.L.; Skabara, P.J.; Turnbull, G.A.; Samuel, I.D.W. Laser Photonics Rev. 2013, 7, L71-L76.

https://doi.org/10.1002/Ipor.201300072

10. Guilhabert, B.; Laurand, N.; Herrnsdorf, J.; Chen, Y.; Kanibolotsky, A.L.; Orofino, C.; Skabara, P.J.; Dawson, M.D. IEEE Photon. J. 2012, 4, 684-690. https://doi.org/10.1109/JPHOT.2012.2195651

11. Kanibolotsky, A.L.; Berridge, R.; Skabara, P.J.; Perepichka, I.F.; Bradley, D.D.C.; Koeberg, M. J. Am. Chem. Soc. 2004, 126, 13695-13702. https://doi.org/10.1021/ja039228n

12. Kanibolotsky, A.L.; Perepichka, I.F.; Skabara, P.J. Chem. Soc. Rev. 2010, 39, 2695-2728. https://doi.org/10.1039/b918154g

13. Roncali, J.; Leriche, P.; Cravino, A. Adv. Mater. 2007, 19, 2045-2060. 
14. Gomez-Lor, B.; de Frutos, O.; Ceballos, P.A.; Granier, T.; Echavarren, A.M. Eur. J. Org. Chem. 2001, 21072114.

https://doi.org/10.1002/1099-0690(200106)2001:11<2107::AID-EJOC2107>3.0.CO;2-F

15. Gomez-Lor, B.; Gonzalez-Cantalapiedra, E.; Ruiz, M.; de Frutos, S.; Cardenas, D.J.; Santos, A.; Echavarren, A.M. Chem. Eur. J. 2004, 10, 2601-2608.

https://doi.org/10.1002/chem.200306023

16. Li, L.-L.; Hu, P.; Wang, B.-Q.; Yu, W.-H.; Shimizu, Y.; Zhao, K.-Q. Liq. Cryst., 2010, 37, 499-506. https://doi.org/10.1080/02678290903215337

17. Tseng, K.-P.; Kao, M.-T.; Tsai, T.W.T.; Hsu, C.-H.; Chan, J.C.C.; Shyue, J.-J.; Sun, S.-S.; Wong, K.-T. Chem. Commun. 2012, 48, 3515-3517. https://doi.org/10.1039/c2cc00099g

18. Tehfe, M.-A.; Dumur, F.; Graff, B.; Clement, J.-L.; Gigmes, D.; Morlet-Savary, F.; Fouassier, J.-P.; Lalevee, J. Macromolecules 2013, 46, 736-746.

https://doi.org/10.1021/ma3024359

19. Pei, J.; Wang, J.L.; Cao, X.Y.; Zhou, X.H.; Zhang, W.B. J. Am. Chem. Soc., 2003, 125, 9944-9945. https://doi.org/10.1021/ja0361650

20. Ye, H.; Kesava, S.V.; Hardigree, J.F.M.; Brown, R.E.; Mazzotta, G.; Warren, R.; Skabara, P.J.; Riede, M. J. Mater. Chem. C 2020, 8, 4909-4918.

https://doi.org/10.1039/C9TC06845G

21. Grimsdale, A.C.; Chan, K.L.; Martin, R.E.; Jokisz, P.G.; Holmes, A.B. Chem. Rev. 2009, 109, 897-1091. https://doi.org/10.1021/cr000013v

22. Beaupre, S.; Boudreault, P.-L.T.; Leclerc, M. Adv. Mater. 2010, 22, E6-E27. https://doi.org/10.1002/adma.200903484

23. Zaumseil, J.; Donley, C.L.; Kim, J.S.; Friend, R.H.; Sirringhaus, H. Adv. Mater. 2006, 18, 2708-2712. https://doi.org/10.1002/adma.200601080

24. Heliotis, G.; Xia, R.; Bradley, D.D.C.; Turnbull, G.A.; Samuel, I.D.W.; Andrew, P.; Barnes, W.L. Appl. Phys. Lett. 2003, 83, 2118-2120.

https://doi.org/10.1063/1.1612903

25. Cho, S.Y.; Grimsdale, A.C.; Jones, D.J.; Watkins, S.E.; Holmes, A.B. J. Am. Chem. Soc. 2007, 129, 1191011911.

https://doi.org/10.1021/ja074634i

26. Sims, M.; Bradley, D.D.C.; Ariu, M.; Koeberg, M.; Asimakis, A.; Grell, M.; Lidzey, D.G. Adv. Funct. Mater. 2004, 14, 765-781.

https://doi.org/10.1002/adfm.200305149

27. Craig, M.R.; de Kok, M.M.; Hofstraat, J.W.; Schenning, A.; Meijer, E.W. J. Mater. Chem. 2003, 13, 28612862.

https://doi.org/10.1039/b308402g

28. Martin, R.E.; Diederich, F. Angew. Chem. Int. Ed. 1999, 38, 1350-1377. https://doi.org/10.1002/(SICI)1521-3773(19990517)38:10<1350::AID-ANIE1350>3.0.CO;2-6

29. Culligan, S.W.; Geng, Y.H.; Chen, S.H.; Klubek, K.; Vaeth, K.M.; Tang, C.W. Adv. Mater. 2003, 15, $1176-1180$. https://doi.org/10.1002/adma.200304972

30. Geng, Y.H.; Culligan, S.W.; Trajkovska, A.; Wallace, J.U.; Chen, S.H. Chem. Mater. 2003, 15, 542-549. https://doi.org/10.1021/cm0208859

31. Yasuda, T.; Fujita, K.; Tsutsui, T.; Geng, Y.H.; Culligan, S.W.; Chen, S.H. Chem. Mater. 2005, 17, $264-268$. 
https://doi.org/10.1021/cm048532s

32. Chinelatto, L.S., Jr.; del Barrio, J.; Pinol, M.; Oriol, L.; Matranga, M.A.; De Santo, M.P.; Barberi, R. J.

Photochem. Photobiol. A: Chem. 2010, 210, 130-139.

https://doi.org/10.1016/i.jphotochem.2010.01.006

33. Omer, K.M.; Kanibolotsky, A.L.; Skabara, P.J.; Perepichka, I.F.; Bard, A.J. J. Phys. Chem. B 2007, 111, 66126619.

https://doi.org/10.1021/jp070765u

34. Moreno Oliva, M.; Casado, J.; Lopez Navarrete, J.T.; Berridge, R.; Skabara, P.J.; Kanibolotsky, A.L.;

Perepichka, I.F. J. Phys. Chem. B 2007, 111, 4026-4035.

https://doi.org/10.1021/jp065271w

35. Kuehne, A.J.C.; Elfstrom, D.; Mackintosh, A.R.; Kanibolotsky, A.L.; Guilhabert, B.; Gu, E.; Perepichka, I.F.; Skabara, P.J.; Dawson, M.D.; Pethrick, R.A. Adv. Mater. 2009, 21, 781-785.

https://doi.org/10.1002/adma.200802656

36. Hernandez-Santana, A.; Mackintosh, A.R.; Guilhabert, B.; Kanibolotsky, A.L.; Dawson, M.D.; Skabara, P.J.; Graham, D. J. Mater. Chem. 2011, 21, 14209-14212.

https://doi.org/10.1039/c1jm11378j

37. Wu, M.; Gong, Z.; Kuehne, A.J.C.; Kanibolotsky, A.L.; Chen, Y.J.; Perepichka, I.F.; Mackintosh, A.R.; Gu, E.; Skabara, P.J.; Pethrick, R.A.; Dawson, M.D. Opt. Express 2009, 17, 16436-16443.

https://doi.org/10.1364/OE.17.016436

38. Wu, M.; Gu, E.; Zarowna, A.; Kanibolotsky, A.L.; Kuehne, A.J.C.; Mackintosh, A.R.; Edwards, P.R.; Rolinski, O.J.; Perepichka, I.F.; Skabara, P.J.; Martin, R.W.; Pethrick, R.A.; Birch, D.J.S.; Dawson, M.D. Appl. Phys. A: Mater. Sci. Process. 2009, 97, 119-123.

https://doi.org/10.1007/s00339-009-5308-x

39. Guilhabert, B.; Laurand, N.; Herrnsdorf, J.; Chen, Y.; Mackintosh, A.R.; Kanibolotsky, A.L.; Gu, E.; Skabara, P.J.; Pethrick, R.A.; Dawson, M.D. J. Opt. 2010, 12.

https://doi.org/10.1088/2040-8978/12/3/035503

40. Herrnsdorf, J.; Guilhabert, B.; Chen, Y.; Kanibolotsky, A.L.; Mackintosh, A.R.; Pethrick, R.A.; Skabara, P.J.; Gu, E.; Laurand, N.; Dawson, M.D. Opt. Express 2010, 18, 25535-25545.

https://doi.org/10.1364/OE.18.025535

41. Belton, C.R.; Kanibolotsky, A.L.; Kirkpatrick, J.; Orofino, C.; Elmasly, S.E.T.; Stavrinou, P.N.; Skabara, P.J.; Bradley, D.D.C. Adv. Funct. Mater. 2013, 23, 2792-2804.

https://doi.org/10.1364/OE.18.025535

42. Sajjad, M.T.; Manousiadis, P.P.; Orofino, C.; Kanibolotsky, A.L.; Findlay, N.J.; Rajbhandari, S.; Vithanage, D.A.; Chun, H.; Faulkner, G.E.; O'Brien, D.C.; Skabara, P.J.; Turnbull, G.A.; Samuel, I.D.W. Appl. Phys. Lett., 2017, 110, 013302.

https://doi.org/10.1063/1.4971823

43. Mohsan, Z.; Kanibolotsky, A.L.; Stewart, A.J.; Inigo, A.R.; Dennany, L.; Skabara, P.J. J. Mater. Chem. C 2015, 3, 1166-1171.

https://doi.org/10.1039/C4TC02638A

44. Guzelturk, B.; Kanibolotsky, A.L.; Orofino-Pena, C.; Laurand, N.; Dawson, M.D.; Skabara, P.J.; Demir, H.V. J. Mater. Chem. C 2015, 3, 12018-12025.

https://doi.org/10.1039/C5TC02247A

45. Zhou, X.H.; Yan, J.C.; Pei, J. Org. Lett. 2003, 5, 3543-3546.

https://doi.org/10.1021/ol035461e 
46. Tsiminis, G.; Montgomery, N.A.; Kanibolotsky, A.L.; Ruseckas, A.; Perepichka, I.F.; Skabara, P.J.; Turnbull, G.A.; Samuel, I.D.W. Semicond. Sci. Technol. 2012, 27.

https://doi.org/10.1039/C5TC02247A

47. Simpson, C.D.; Wu, J.S.; Watson, M.D.; Mullen, K. J. Mater. Chem. 2004, 14, 494-504.

https://doi.org/10.1039/B312789C

48. The Porphyrin Handbook, Volume 1, Synthesis and Organic Chemistry, Kadish, K.M.; Smith, K.M.; Guillard. Vol. 1. 1999, San Diego: Academic Press.

49. The Porphyrin Handbook, Volume 15: Phthalocyanine Synthesis, ed. K.M. Kadish, K.M. Smith, and R. Guillard, R. 2003, Amsterdam: Academic Press.

50. Tavasli, M.; Bettington, S.; Bryce, M.R.; Al Attar, H.A.; Dias, F.B.; King, S.; Monkman, A.P. J. Mater. Chem. 2005, 15, 4963-4970.

https://doi.org/10.1039/b507990j

51. Scanlan, K.; Kanibolotsky, A.L.; Breig, B.; Hedley, G.J.; Skabara, P.J. J. Mater. Chem. C 2019, 7, 6582-6591. https://doi.org/10.1039/C9TC00845D

52. Watanabe, T.; Miyaura, N.; Suzuki, A. Synlett 1992, 207-210.

https://doi.org/10.1055/s-1992-21315

53. Jo, J.H.; Chi, C.Y.; Hoger, S.; Wegner, G.; Yoon, D.Y. Chem. Eur. J. 2004, 10, 2681-2688. https://doi.org/10.1002/chem.200305659

54. Grimme, J.; Kreyenschmidt, M.; Uckert, F.; Mullen, K.; Scherf, U. Adv. Mater. 1995, 7, 292-295. https://doi.org/10.1002/adma.19950070310

55. Montgomery, N.A.; Denis, J.-C.; Schumacher, S.; Ruseckas, A.; Skabara, P.J.; Kanibolotsky, A.; Paterson, M.J.; Galbraith, I.; Turnbull, G.A.; Samuel, I.D.W. J. Phys. Chem. A 2011, 115, 2913-2919. https://doi.org/10.1002/adma.19950070310

56. Gottlieb, H.E.; Kotlyar, V.; Nudelman, A. The Journal of Organic Chemistry 1997, 62, 7512-7515. https://doi.org/10.1021/jo971176v

57. Coulson, D.R.; Satek, L.C.; Grim, S.O. Tetrakis(triphenylphosphine)palladium(0), in Inorg. Synth. 1972, McGraw-Hill, Inc. pp121-124.

https://doi.org/10.1002/9780470132449.ch23

58. Perepichka, II; Perepichka, I.F.; Bryce, M.R.; Palsson, L.O. Chem. Commun. 2005, 3397-3399. https://doi.org/10.1039/b417717g

59. Ranger, M.; Rondeau, D.; Leclerc, M. Macromolecules 1997, 30, 7686-7691. https://doi.org/10.1021/ma970920a

60. Hughes, G.; Wang, C.S.; Batsanov, A.S.; Fern, M.; Frank, S.; Bryce, M.R.; Perepichka, I.F.; Monkman, A.P.; Lyons, B.P. Org. Biomol. Chem. 2003, 1, 3069-3077.

https://doi.org/10.1039/B305870K

61. Lin, N.; Liu, X.Y.; Diao, Y.Y.; Xu, H.; Chen, C.; Ouyang, X.; Yang, H.; Ji, W. Adv. Funct. Mater. 2012, 22, 361368.

https://doi.org/10.1002/adfm.201100649

62. Li, Z.H.; Wong, M.S.; Fukutani, H.; Tao, Y. Org. Lett. 2006, 8, 4271-4274.

https://doi.org/10.1021/ol0615477

63. Jeeva, S.; Moratti, S.C. Synthesis-Stuttgart 2007, 3323-3328. https://doi.org/10.1055/s-2007-990807

64. Wang, Q.; Qu, Y.; Tian, H.; Geng, Y.; Wang, F. Macromolecules 2011, 44, 1256-1260. https://doi.org/10.1021/ma102954h 
65. Zhou, H.; Zhao, X.; Huang, T.; Lu, R.; Zhang, H.; Qi, X.; Xue, P.; Liu, X.; Zhang, X. Org. Biomol. Chem. 2011, 9, 1600-1607.

https://doi.org/10.1039/c0ob00803f

This paper is an open access article distributed under the terms of the Creative Commons Attribution (CC BY) license (http://creativecommons.org/licenses/by/4.0/) 